\title{
Geochemical Factors Affecting Radionuclide Transport Through Near and Far Fields at a Low- Level Waste Disposal Site
}

\section{Available Sorption Constants and Recommendations for Future Studies}

D. I. Kaplan

R. J. Serne

M. G. Piepho(a)

March 1995

Prepared for the U.S. Department of Energy

under Contract DE-AC06-76RLO 1830

Pacific Northwest Laboratory

Richland, Washington 99352

(a) Westinghouse Hanford Company 


\section{DISCLAIMER}

This report was prepared as an account of work sponsored by an agency of the United States Government. Neither the United States Government nor any agency thereof, nor any of their employees, make any warranty, express or implied, or assumes any legal liability or responsibility for the accuracy, completeness, or usefulness of any information, apparatus, product, or process disclosed, or represents that its use would not infringe privately owned rights. Reference herein to any specific commercial product, process, or service by trade name, trademark, manufacturer, or otherwise does not necessarily constitute or imply its endorsement, recommendation, or favoring by the United States Government or any agency thereof. The views and opinions of authors expressed herein do not necessarily state or reflect those of the United States Government or any agency thereof. 


\section{DISCLAIMER}

Portions of this document may be illegible in electronic image products. Images are produced from the best available original document. 


\section{Abstract}

Burial of vitrified low-level waste (LLW) in the vadose zone of the Hanford Site is being considered as a long-term disposal option. Regulations dealing with LLW disposal require that performance assessment (PA) analyses be conducted. Previous PA analyses for proposed disposal actions at the Hanford Site show that groundwater transport presents the greatest potential for long-term dose uptake by humans. The purpose of this report is to provide: 1) a literature review of the key geochemical processes affecting radionuclide migration through the near and far fields for the Hanford LLW PA, 2) a summary of available information and data for geochemical interactions between groundwater, sediments, and radionuclides, 3) a strategy and rationale for generating additional data, and 4) recommendations on data collection methods. Particular attention is directed at understanding the important geochemical factors in unsaturated, alkaline, high-carbonate, low natural organic matter concentration environments affecting the retardation of ${ }^{129} \mathrm{I},{ }^{237} \mathrm{~Np},{ }^{79} \mathrm{Se},{ }^{99} \mathrm{Tc}$, and ${ }^{234,235,238} \mathrm{U}$. These radionuclides have been identified by preliminary scoping studies as presenting the greatest potential health hazard at the Hanford Site. This list may change during the course of the study as more information about the location and design of the burial site, waste form recipe, and engineered barrier(s) become available.

Based on a preliminary literature review of laboratory studies using Hanford sediments and groundwater, conservative estimates of sorption distribution coefficient $\left(K_{d}\right)$ ranges are presented for $\mathrm{Ac}, \mathrm{Am}, \mathrm{C}, \mathrm{Ce}, \mathrm{Cm}, \mathrm{Co}, \mathrm{Cs}, \mathrm{Eu}, \mathrm{I}, \mathrm{Nb}, \mathrm{Ni}, \mathrm{Np}, \mathrm{Pa}, \mathrm{Pb}, \mathrm{Pu}, \mathrm{Ra}, \mathrm{Ru}, \mathrm{Se}, \mathrm{Sn}, \mathrm{Sr}, \mathrm{Tc}, \mathrm{Th}, \mathrm{U}$, and $\mathrm{Zr}$ in four general categories of leachates: 1) alkaline, low salt, low organic, oxidized solutions; 2) alkaline, low salt, low organic, anoxic solutions; 3 ) alkaline, high salt, low organic, oxidized solutions; and 4) alkaline, high salt, low organic, reduced solutions. These broad categories were selected to represent the major types of groundwater likely to exist in the near (Solutions 2, 3 and 4) and far (Solution 1) fields.

A process has been proposed to define and constrain the geochemical data collection program. The initial phase is subdivided into four parts that form the baseline data collection. Radionuclides and contaminants are identified from historical records, existing analyses of waste materials, and computer projections of inventories. Once a database has been established, an iterative process is used to delimit completion of data collection. Additional data needs are identified on the basis of performance assessment modeling (i.e., pathways analysis) or a generally acknowledged lack of information. If the pathways analysis, which is done on a radionuclide-by-radionuclide basis, indicates an unacceptable degree of uncertainty for the reaction values used as input to the models, additional data are required. Additional data may also be required to quantify parameter values that affect geochemical reaction values. For example, the effect of moisture content on $K_{d}$ values can be theoretically calculated, but such calculations are supported by few test data.

A principal recommendation is this report is to use laboratory or bench-scale testing to generate adsorption data, however, other methods are also discussed. The emphasis of the testing approach is empirical; the expected environment is simulated, and geochemical reactions between radionuclides or hazardous chemicals and the simulated environment are observed. This approach is recommended for two reasons. First, in many cases, numerous kinds of reactions are possible such that mechanistic studies could never be completed given the time or resources available. Second, the empirically derived data can be used easily by computer PA codes. 
Technical defensibility is a requirement of all aspects of the Hanford Site LLW PA. To address this requirement, written justification and rationale will be produced for the specific chemical retardation data offered to the transport code users. In addition, various geochemical issues that arise during the PA process will be addressed. Specific issues that already merit discussion include

- the proper method to measure low sorption ("small- $\mathrm{K}_{d}$ issue")

- the gravel dependency of $K_{d}$ ("gravel-corrected- $K_{d}$ issue")

- the moisture content dependency of $\mathrm{K}_{\mathrm{d}}$

- defending the long-term extrapolation of short-term laboratory data

- a proper conceptual model for diffusion of reactive constituents in partially saturated sediments

- the use of natural analogs to verify short-term laboratory-derived for geochemical interaction data

- the influence of colloids on contaminant transport

- the adequacy of $\mathrm{K}_{\mathrm{d}}$ versus more mechanistic adsorption conceptual models.

These geochemical issues and others that emanate from reviews of the PAs will be addressed in letter reports or topical reports that draw from literature and project-specific laboratory studies. For a number of geochemical input parameters for the transport codes, the literature review will be used as the first step in evaluating whether or not there is a need for further laboratory experimentation.

Data of increasing detail and pedigree will be available for each of the three system PA calculations scheduled for completion by September 1997. Ancillary analyses and discussion that justifies the chosen $K_{d}$ values, and addresses the long-term validity of the values, will be prepared for consideration by the various internal and external peer review panels. 


\section{Summary}

The concentration of low-level waste (LLW) contaminants in groundwater is determined by the amount of contaminant present in the solid waste, rate of release from the waste and surrounding barriers, and a number of geochemical processes including adsorption, desorption, diffusion, precipitation, and dissolution. To accurately predict radionuclide transport through the subsurface, it is essential that the important geochemical processes affecting radionuclide transport be identified and, perhaps more importantly, accurately quantified and described in a mathematically defensible manner.

This report provides 1) a literature review of the key geochemical processes affecting radionuclide migration through the near- and far-fields for the Hanford Site LLW Performance Assessment (PA), 2) a summary of available information and data for geochemical interactions between groundwater, sediments, and radionuclides, 3) a strategy and rationale for generating additional data, and 4) recommendations on data collection methods. Particular attention is directed at understanding the important geochemical factors in unsaturated, alkaline, high-carbonate, low natural organic matter concentration environments affecting the retardation of ${ }^{129} \mathrm{I},{ }^{237} \mathrm{~Np},{ }^{79} \mathrm{Se},{ }^{99} \mathrm{Tc}$, and ${ }^{234,235,238} \mathrm{U}$. These radionuclides have been identified by preliminary scoping studies as presenting the greatest potential health hazard at the Hanford Site. This list may change during the course of the study as more information about the location and design of the burial site, waste form recipe, and engineered barrier(s) become available.

The geochemistry of I, Np, Se, Tc, and U relevant to Hanford Site sediments were reviewed. Once I, Se, or Tc is leached from the Hanford Site-vitrified LLW, it is likely to exist as an uncomplexed anion species and travel at approximately the same rate as groundwater through the Hanford Site subsurface environment. Only a minimal amount of geochemical retardation will occur because these radionuclides are not likely to form insoluble precipitates or sorb significantly to the Hanford Site sediments. Consequently, I, Se, and Tc distribution coefficients $\left(\mathrm{K}_{d}\right)$ values traditionally used in transport modeling are low. Neptunium is expected to travel somewhat slower than Tc and I through the Hanford Site vadose zone. Thermodynamic data suggest that Np exists as a monovalent cation $\left(\mathrm{NpO}_{2}^{\ddagger}\right)$ under oxidizing conditions except above a pH of approximately 9, in which it forms neutral or anionic species with bicarbonate $\left(\mathrm{NpO}_{2} \mathrm{HCO}_{3}\right)$. The Hanford Site-vitrified LLW leachate will likely have a high $\mathrm{pH}(\mathrm{pH}>11)$ and therefore the neutral bicarbonate species may exist near the waste form. This neutral species will not be electrostatically attached to the negatively charged sediment surfaces, and therefore only a minimal amount of retardation via adsorption is likely to occur for this species. In the far field, where the plume will be more dilute, the $\mathrm{NpO}_{2}$ species will dominate. This species will participate in cation exchange with the vadose zone sediments; however, $\mathrm{NpO}_{2}$ does not compete strongly with common cations for sorption sites.

Based on a preliminary literature review of laboratory studies using Hanford Site sediments and groundwater, reported $K_{d}$ values are presented: $I$ is 0.04 to $18 \mathrm{~mL} / \mathrm{g}, S e(I V)$ is 0 to $0.78 \mathrm{~mL} / \mathrm{g}$, Tc(VII) is 0 to $1.3 \mathrm{~mL} / \mathrm{g}, \mathrm{U}(\mathrm{VI})$ is 0.08 to $79.3 \mathrm{~mL} / \mathrm{g}$, and $\mathrm{Np}(\mathrm{V})$ is 2.4 to $29.1 \mathrm{~mL} / \mathrm{g}$. These $\mathrm{K}_{\mathrm{d}}$ ranges, as well as those for $\mathrm{Ac}, \mathrm{Am}, \mathrm{C}, \mathrm{Ce}, \mathrm{Cm}, \mathrm{Co}, \mathrm{Cs}, \mathrm{Eu}, \mathrm{Nb}, \mathrm{Ni}, \mathrm{Pa}, \mathrm{Pb}, \mathrm{Pu}, \mathrm{Ra}, \mathrm{Ru}, \mathrm{Sn}, \mathrm{Sr}, \mathrm{Th}$, and $\mathrm{Zr}$ were provided for four general categories of leachates: 1) alkaline, low salt, low organic, oxidized solutions; 2) alkaline, low salt, low organic, anoxic solutions; 3) alkaline, high salt, low organic, oxidized solutions; and 4) alkaline, high salt, low organic, reduced solutions. These broad categories were selected to represent the major types of groundwater likely to exist in the near (Solutions 2, 3, and 4) and far (Solution 1) fields. 
A process has been proposed to define and constrain the geochemical data collection program. The initial phase is subdivided into four parts that form the baseline data collection. Radionuclides and contaminants are identified from historical records, existing analyses of waste materials, and computer projections of inventories. Once a database has been established, an iterative process is used to delimit completion of data collection. Additional data needs are identified on the basis of performance assessment modeling (i.e., pathways analysis) or a generally acknowledged lack of information. If the pathways analysis, which is done on a radionuclide-by-radionuclide basis, indicates an unacceptable degree of uncertainty for the reaction values used as input to the models, additional data are required. Additional data may also be required to quantify parameter values that affect geochemical reaction values. For example, the effect of moisture content on $\mathrm{K}_{d}$ can be calculated using simple conceptual models that require validation, but such calculations are supported by few test data.

Once data have been collected and appropriate analyses have been used to generate model input data, the adequacy of available $K_{d}$ data is evaluated by using a computer code that predicts transport and release of contaminant to the environment. To address uncertainty, a range of input $K_{d}$ values is generally used. The model's sensitivity results are compared to acceptable release values to determine if predicted releases are acceptable. If the range of input values that are used results in a range of predicted release values that is ambiguous (e.g., releases are unacceptable or acceptable, depending on which specific value within the range of values is used), then additional data on the contaminants release from the waste form or engineered system may be required to reduce (or at least better define) the range of uncertainty. Alternatively, more adsorption studies using site sediments may reduce the range in probable $\mathrm{K}_{d}$ values.

The principal emphasis of this report is on laboratory or bench-scale methods of data generation; however, other methods are also discussed. The emphasis of the testing approach will be empirical; the expected environment is simulated, and geochemical reactions between radionuclides or hazardous chemicals and the simulated environment are observed. This approach is recommended for two reasons. First, in many cases, numerous kinds of reactions are possible such that mechanistic studies could never be completed, given the time or resources available. Second, the empirically derived data can be used easily by computer transport codes.

An iterative approach to modeling radionuclide sorption processes and groundwater transport will be conducted using the LLW-PA system codes. The models will build upon each other and become progressively more mechanistic and therefore more robust. The early model will be the constant- $\mathrm{K}_{\mathrm{d}}$ model. This model is the least robust; it describes the sorption of a radionuclide only under one set of aqueous and sediment conditions. Yet, parameters for this model are the easiest and fastest to obtain through laboratory testing. It will be used to provide early guidance for transport modeling. A parametric- $K_{d}$ model will then be built to replace the constant- $K_{d}$ model. The parametric- $K_{d}$ model varies $K_{d}$ values through a set of empirically derived functions of aqueous and sediment parameters. By the time development for this model starts, a much better idea of the burial design and location will be available, providing more information about the aqueous composition of the plume and the types of barriers and sediments that the plume will pass through. The parametric- $\mathrm{K}_{\mathrm{d}}$ model should not be difficult to incorporate into existing transport codes. It can be included by adding a separate subroutine or, more simply, a look-up table to the transport code. The parametric $\mathrm{K}_{\mathrm{d}}$ model will be needed for only those contaminants that appear to significantly impact dose. Finally, the parametric- $K_{d}$ or the constant- $K_{d}$ models will be modified to include some mechanisticbased processes. A mechanistic- based model is more robust, and perhaps more importantly, is more scientifically defensible. However, as stated earlier, an entirely mechanistic model is not possible at this time. This semi-mechanistic model will represent a compromise between increasing robustness 
(and accuracy) and ease of obtaining input parameters for the model. For instance, if the number of radionuclide exchange sites is found to be greatly dependent on the $\mathrm{pH}$ of the system, then data from a laboratory titration may be included in the model, instead of using a fixed exchange capacity value. Again the breadth of contaminants for which a semi-mechanistic adsorption model is needed will be shortened to only those contaminants that contribute significantly to the calculated dose.

Technical defensibility is a requirement of all aspects of the Hanford Site LLW PA. To address this requirement, written justification and rationale will be produced for the specific chemical retardation data offered to the transport code users. In addition, various geochemical issues that arise during the performance assessment process will be addressed. Specific issues that already merit discussion include: a proper method to measure low sorption ("small- $K_{d}$ issue"), the gravel dependency of $\mathbf{K}_{d}$ ("gravel-corrected $K_{d}$ issue"), the moisture content dependency of $K_{d}$, defending the long-term extrapolation of short-term laboratory data, a proper conceptual model for diffusion of reactive constituents in partially saturated sediments, the use of natural analogs for verifying laboratory derived geochemical interaction data, the influence of colloids on contaminant transport, and the adequacy of $\mathbf{K}_{\mathbf{d}}$ versus more mechanistic adsorption conceptual models.

These geochemical issues and others that emanate from reviewers of the PAs will be addressed in letter reports or topical reports that draw from literature and project-specific laboratory studies. For a number of geochemical input parameters for the transport codes, this literature review will be used as the first step in evaluating whether or not there is a need for further laboratory experimentation.

Data of increasing detail and pedigree will be available for each of the three system performance assessment calculations scheduled for completion by September 1997. Ancillary analyses and discussion that justify the $K_{d}$ values chosen and address the long-term validity of the values will be prepared for consideration by the various internal and external peer reviewer panels. 



\section{Acknowledgments}

The authors wish to acknowledge the technical review by Shas Mattigod, editorial review by Rosalind Schrempf, document production coordinated by Teresa Riley, and document preparation and design by the Sigma V communications support team. Calvin Ainsworth assisted in the writing of Section 3.24, Geochemical Behavior of Uranium. 



\section{Contents}

Abstract $\ldots \ldots \ldots \ldots \ldots \ldots \ldots \ldots \ldots \ldots \ldots \ldots \ldots \ldots \ldots \ldots \ldots \ldots \ldots \ldots \ldots \ldots \ldots \ldots \ldots$

Summary $\ldots \ldots \ldots \ldots \ldots \ldots \ldots \ldots \ldots \ldots \ldots \ldots \ldots \ldots \ldots \ldots \ldots \ldots$

Acknowledgments $\ldots \ldots \ldots \ldots \ldots \ldots \ldots \ldots \ldots \ldots \ldots \ldots \ldots \ldots \ldots \ldots \ldots \ldots \ldots$ ix

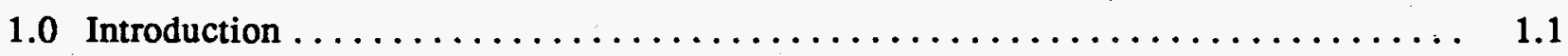

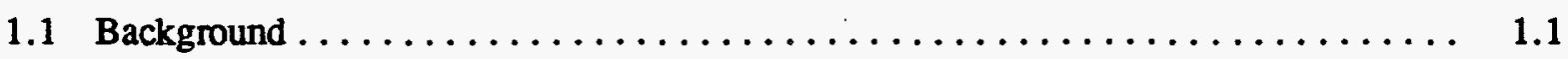

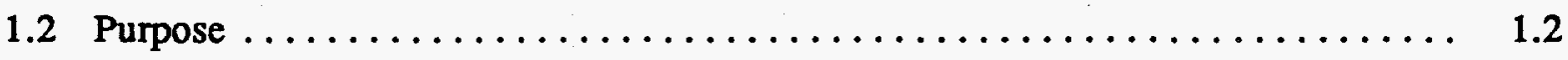

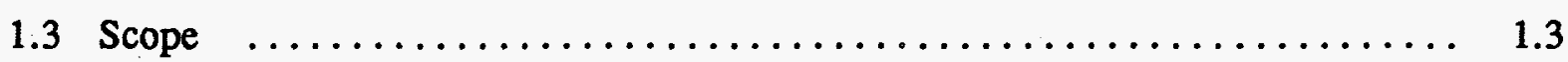

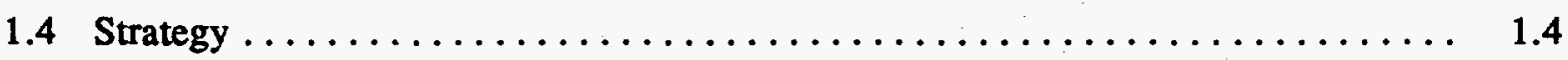

2.0 Geochemical Processes Affecting Contaminant Transport Through
the Near and Far Fields $\ldots \ldots \ldots \ldots \ldots \ldots \ldots \ldots \ldots \ldots \ldots \ldots \ldots \ldots \ldots \ldots \ldots \ldots \ldots \ldots$

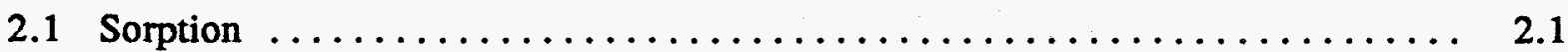

2.1.1 Constant Distribution Coefficient $\left(\mathrm{K}_{\mathrm{d}}\right)$ Model $\ldots \ldots \ldots \ldots \ldots \ldots \ldots \ldots . \ldots \ldots$

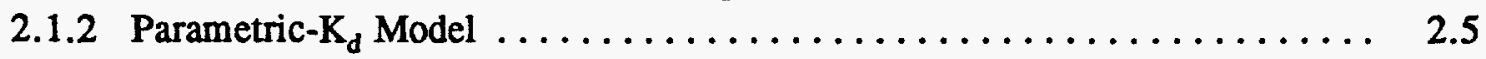

2.1 .3 Overview of Mechanistic Adsorption Models $\ldots \ldots \ldots \ldots \ldots \ldots \ldots \ldots .7$

2.1.4 Effects of Unsaturated Conditions on Transport . . . . . . . . . . . 2.9

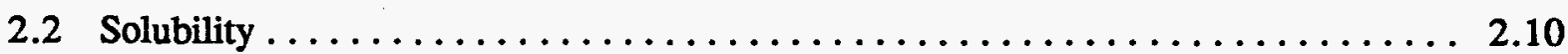

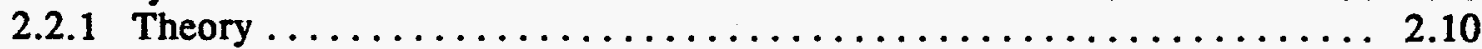

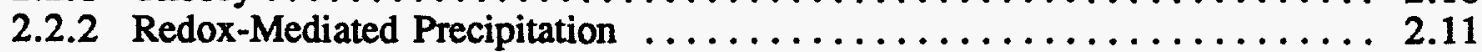

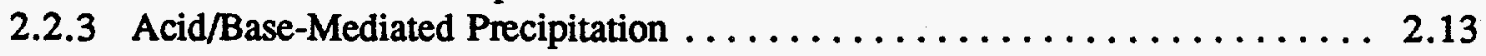

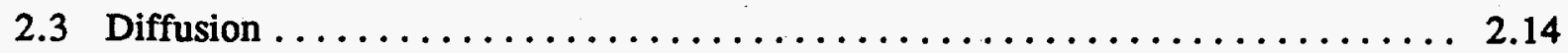

2.4 Subsurface Mobile Colloids $\ldots \ldots \ldots \ldots \ldots \ldots \ldots \ldots \ldots \ldots \ldots \ldots \ldots \ldots \ldots \ldots \ldots$

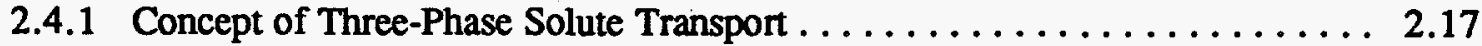

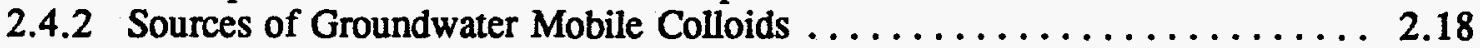

2.4.3 Case Studies of Mobile-Colloid Enhanced Transport of Radionuclides ..... 2.19

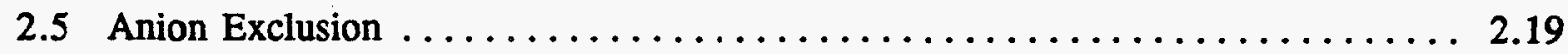

2.5.1 Evidence of Anion Exclusion in Hanford Sediments $\ldots \ldots \ldots \ldots \ldots .20$

3.0 Key Contaminants $\ldots \ldots \ldots \ldots \ldots \ldots \ldots \ldots \ldots \ldots \ldots \ldots \ldots \ldots \ldots \ldots \ldots \ldots$

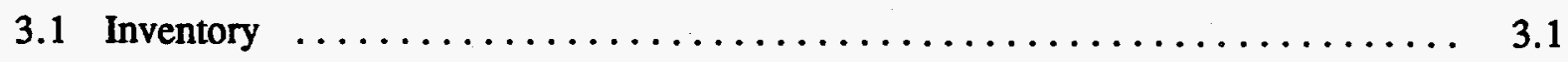


3.2 Geochemical Behavior of Key Radionuclides $\ldots \ldots \ldots \ldots \ldots \ldots \ldots \ldots \ldots \ldots \ldots \ldots \ldots \ldots \ldots \ldots$

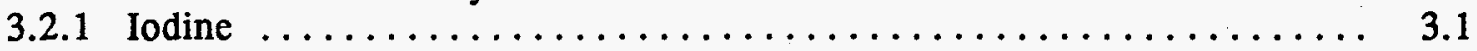

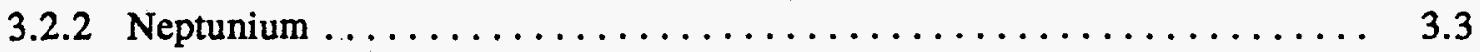

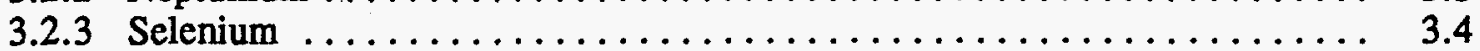

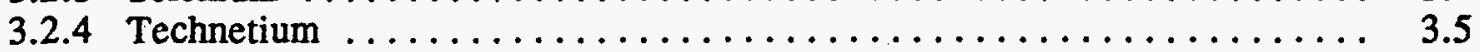

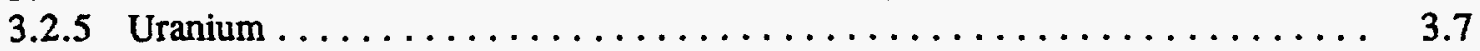

4.0 Near-Field Radionuclide Transport Through Engineered Barriers $\ldots \ldots \ldots \ldots \ldots \ldots$

4.1 Description of Potential Engineered Barriers $\ldots \ldots \ldots \ldots \ldots \ldots \ldots \ldots \ldots \ldots .1$

4.2 Solubility Approach for Describing Chemical Retardation of Sparingly Soluble Contaminants $\ldots \ldots \ldots \ldots \ldots \ldots \ldots \ldots \ldots \ldots \ldots \ldots \ldots .4 .1$

4.3 Sorption Approach for Describing Chemical Retardation of Sparingly Soluble Contaminants $\ldots \ldots \ldots \ldots \ldots \ldots \ldots \ldots \ldots \ldots \ldots \ldots \ldots \ldots \ldots \ldots$

5.0 Far-Field Radionuclide Transport Through the Vadose Zone $\ldots \ldots \ldots \ldots \ldots \ldots \ldots$

5.1 Geochemical Description of the Far Field $\ldots \ldots \ldots \ldots \ldots \ldots \ldots \ldots \ldots \ldots \ldots$

5.2 Sorption Approach to Describing Chemical Retardation $\ldots \ldots \ldots \ldots \ldots \ldots . \ldots$

6.0 Available $K_{d}$ Data Describing Radionuclide Sorption to Hanford Sediments $\ldots \ldots \ldots .6 .1$

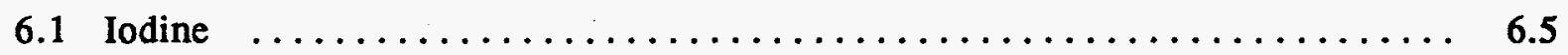

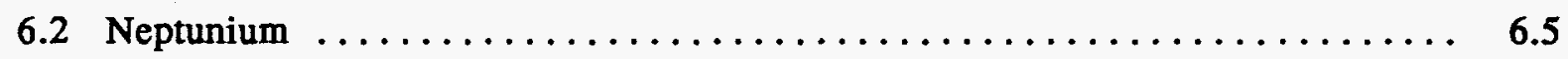

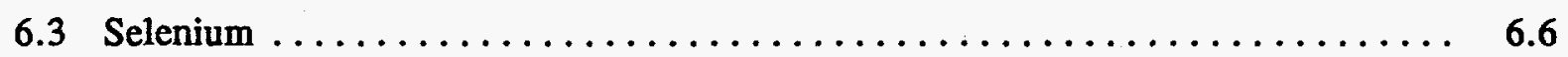

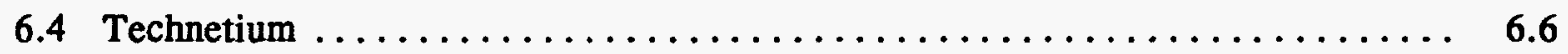

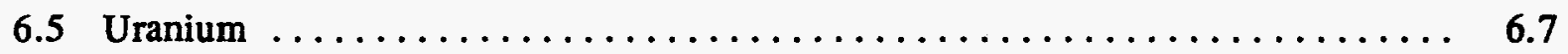

6.6 Other Radionuclides $\ldots \ldots \ldots \ldots \ldots \ldots \ldots \ldots \ldots \ldots \ldots \ldots \ldots \ldots \ldots \ldots$

7.0 Geochemical Data Needs for Improving Transport Modeling of Radionuclides

Through Hanford Sediments and Engineered Barriers $\ldots \ldots \ldots \ldots \ldots \ldots \ldots \ldots \ldots .1$

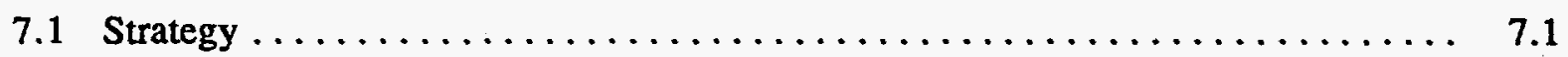

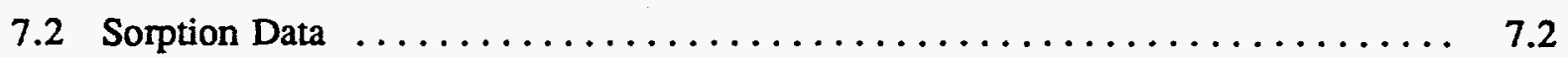

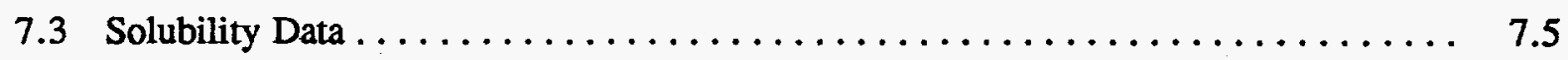

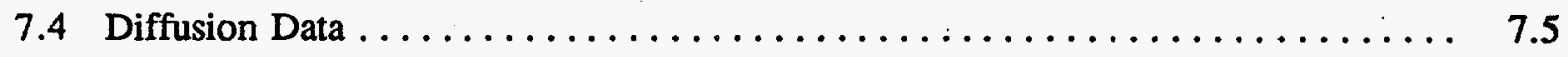

7.5 Mobile Colloids Facilitated Transport Data $\ldots \ldots \ldots \ldots \ldots \ldots \ldots \ldots \ldots$

7.6 Technical Defensibility $\ldots \ldots \ldots \ldots \ldots \ldots \ldots \ldots \ldots \ldots \ldots \ldots \ldots \ldots \ldots \ldots$ 
8.0 Conclusions $\ldots \ldots \ldots \ldots \ldots \ldots \ldots \ldots \ldots \ldots \ldots \ldots \ldots \ldots \ldots \ldots \ldots \ldots \ldots$

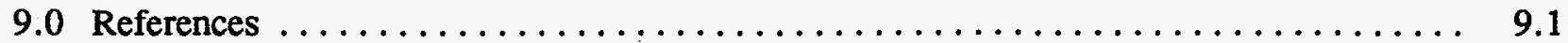




\section{Figures}

1.1 Data Collection Strategy for Low-Level Waste Performance Assessment

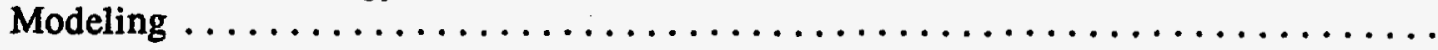

2.1 Diffuse Double Layer and Surface Charge of a Mineral Surface $\ldots \ldots \ldots \ldots \ldots \ldots$

3.1 Eh and $\mathrm{pH}$ Diagram for Iodine/Water System $\ldots \ldots \ldots \ldots \ldots \ldots \ldots \ldots \ldots \ldots$

\section{Tables}

2.1 Sequence of Principal Electron Acceptors in Neutral Aquatic Systems . . . . . . . 2.13

5.1 Selected Physical, Chemical, and Mineralogical Properties of Vadose Zone

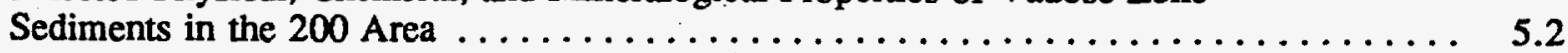

5.2 Range in Composition (mg L ${ }^{-1}$ ) of Hanford Groundwater (Well 6-S3-25 between

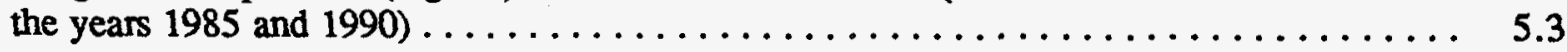

6.1 Reported $\mathrm{K}_{\mathrm{d}}$ Values for Hanford Sediments in Neutral-to-High $\mathrm{pH}$, Low Salt (Ionic Strength $<0.01 \mathrm{M}$ ), Low Organic, Oxic Solutions $\ldots \ldots \ldots \ldots \ldots \ldots \ldots \ldots$

6.2 Reported $\mathrm{K}_{\mathrm{d}}$ Values for Hanford Sediments in Neutral-to-High pH, Low Salt (Ionic Strength $<0.01 \mathrm{M}$ ), Low Organic, Anoxic Solutions $\ldots \ldots \ldots \ldots \ldots \ldots \ldots$

6.3 Reported $K_{d}$ Values for Hanford Sediments in Neutral-to-High pH, High Salt (Ionic Strength $\geq 0.01 \mathrm{M}$ ), Low Organic, Oxic Solutions $\ldots \ldots \ldots \ldots \ldots \ldots \ldots \ldots$

6.4 Reported $\mathrm{K}_{\mathrm{d}}$ Values for Hanford Sediments in Neutral-to-High pH, High Salt (Ionic Strength $\geq 0.01 \mathrm{M}$ ), Low Organic, Anoxic Solutions 


\section{Acronyms}

ANS

CERCLA

DOE

HLW

LLW

NRC

PA

Tri-Party Agreement

TRU
American Nuclear Society

Comprehensive Environmental Response, Compensation, and Liability Act U.S. Department of Energy

high-level waste

low-level waste

Nuclear Regulatory Commission

performance assessment

Hanford Federal Facility Agreement and Consent Order transuranic 


\subsection{Introduction}

\subsection{Background}

The nuclear industry produces wastes, some of which are radioactive. Based on the level of radioactivity and/or place within the nuclear fuel cycle where they are created, these wastes are categorized as low-level waste (LLW), high-level waste (HLW), and transuranic waste (TRU). In general, the hazard represented by the radioactive wastes decreases with isolation and storage, due to radioactive decay as time passes. However, isotopes with long half-lives may persist for more than one million years.

A performance assessment (PA) is underway to evaluate the suitability of the unsaturated zone of the Hanford Site for the long-term disposal of vitrified (glassified) LLW. These assessments [referred to as risk assessments by the Comprehensive Environmental Response, Compensation, and Liability Act (CERCLA)] are analyses that predict the transport of radionuclides and/or contaminants from a source to a receptor via pathways that are considered credible. Previous analyses for proposed disposal actions on the Hanford Site (DOE 1987, Kincaid et al. 1993, Piepho 1994,Wood et al. 1994) show that groundwater transport presents the greatest potential for long-term dose uptake by humans.

In the immediate vicinity of the buried vitrified waste, referred to as the near field, there will be an engineered barrier to provide additional protection in the event the vitrified waste's integrity is breached. To date, the design of the engineered barrier has not been completed. Beyond the near field is the undisturbed region, referred to as the far field. The far field will consist of primarily sediment that has a 4 and 7\% (v/v) moisture content (Gee and Heller 1985), coarse-sand texture, mediumto-high carbonate concentration, alkaline $\mathrm{pH}$, and low natural organic matter content. The concentration of radionuclides in groundwater is determined by the amount present in the solid waste, the rate of release from the waste and surrounding barriers, and a number of geochemical processes including adsorption, desorption, precipitation, and dissolution. To accurately predict radionuclide transport through the subsurface, it is absolutely essential that the important geochemical processes affecting radionuclide transport be identified, and perhaps more importantly, accurately quantified and described in a mathematically defensible manner.

The most conservative estimate of radionuclide migration through the subsurface natural sediment is to assume that the sediment has no ability to slow (retard) radionuclide movement. Consequently, the radionuclides would travel in the direction and at the rate of water. Such an assumption may in fact be appropriate for certain radionuclides such as I and Tc, but may be too conservative for other radionuclides such as Am or Pu. Contaminant retardation describes the rate of contaminant transport relative to that of groundwater or vadose zone water. It includes processes such as surface adsorption, matrix diffusion into internal pores, precipitation, and physical filtration of colloids. Many contaminants react strongly with natural and engineered adsorbents and are found to migrate from $10^{2}$ to $10^{6}$ times more slowly than the water. A simple method used to quantify retardation is to perform laboratory bench tests using simulated waste from leachates or groundwater and representative adsorbents (sediments, rocks, engineered barriers) to measure distribution coefficients $\left(K_{d}\right)$ values. Briefly, $K_{d}$ values are a direct measure of the partitioning of a contaminant between the solid and aqueous phases. Measuring $K_{d}$ values and using them correctly in transport calculations can be challenging. 
Technical issues, complexities, and shortcomings of the $\mathbf{K}_{\mathbf{d}}$ approach are summarized herein with emphasis on issues relevant to the Hanford vitrified LLW PA. Some of the complexities associated with the $K_{d}$ approach are that they are only applicable to trace amounts of contaminants in the aqueous and solid phases, the relationship between the amount of contaminant in the solid and liquid phases must be linear, and equally rapid adsorption and desorption kinetics must exist. Perhaps the greatest limitation of $K_{d}$ values is that they should only be used to predict transport in systems identical to those in which they were measured in the laboratory. Changes in either the sediment or the aqueous phase of a system can result in extremely large differences in $\mathbf{K}_{d}$ values. For example, using one Hanford sediment and varying the aqueous chemistry within limits likely to exist in a HLW plume, Delegard and Barney (1983, Sediment L) measured Am- $K_{d}$ values between 1.1 and $>1080 \mathrm{~mL} / \mathrm{g}$.

A more robust approach to describing the partitioning of radionuclides between the aqueous and solid phases is the parametric- $K_{d}$ model, which varies the $K_{d}$ value according to the chemistry and mineralogy of the system at the node being modeled. Though this approach is more accurate, it has not been used frequently. The added complexity in solving the transport equation with the parametric $\mathrm{K}_{\mathrm{d}}$ adsorption model and its empirical nature may be why this technique has been used sparingly for waste disposal safety assessment exercises. Well-established adsorption conceptual models are available; however, the complexity of installing these models into existing transport codes that are favored for complete disposal system PA, and the diversity of Hanford waste leachate/ sediment/contaminant combinations would require a data collection effort more intense and costly than is likely to be available.

Site-specific studies are necessary because the $\mathbf{K}_{d}$ concept is an empirical metric that attempts to account for various chemical and physical retardation mechanisms that are influenced by a myriad of variables. It is therefore essential to use representative materials (sediment, barrier materials, and aqueous leachates) and to perform laboratory tests under realistic geochemical and hydrological conditions. Sensitivity studies that vary key variables over realistic ranges are important to build technical defensibility. Such tests and supporting analyses (thermodynamic and natural analogues) will be one of the key goals of the geochemical component of the Hanford LLW PA project.

Few direct measurements of contaminant transport have been obtained under unsaturated conditions and none have been obtained under highly unsaturated conditions. This has necessitated the use of very conservative estimates for predictive modeling. The recent development of the unsaturated-flow apparatus (UFA) (Conca and Wright 1992) should fill this void in characterization. The UFAs at Pacific Northwest Laboratory (PNL) and the Washington State University, Tri-Cities can perform chemical transport experiments necessary to predict contaminant transport in the near-field matrix/barriers and far-field vadose zone.

\subsection{Purpose}

The purpose of this report is to provide 1) a literature review of the key geochemical processes affecting radionuclide migration through the near and far fields for the Hanford LLW PA, 2) a summary of available information and data for geochemical interactions between groundwater, sediments, and radionuclides, 3) a strategy and rationale for generating additional data, and 4) recommendations on data collection methods. Particular attention is directed at understanding the important geochemical factors in unsaturated, alkaline, high carbonate, low natural organic matter concentration environments affecting the retardation of I, Np, Se, Tc, and U. These radionuclides have been identified by 
preliminary scoping studies as presenting the greatest potential health hazard at the Hanford Site (Piepho et al. 1994). This list will likely change during the course of the study as more information about the location and design by the burial site, waste form recipe, and engineered barrier become available.

Data of increasing detail and pedigree will be available for each of the three system performance assessment calculations scheduled for completion by September 1997. Ancillary analyses and discussion that justifies the $K_{d}$ values chosen and addresses the long-term validity of the values will be prepared for consideration of the various internal and external peer reviewer panels.

\subsection{Scope}

The scope of this report is to review information pertinent to the transport of contaminants released from the proposed vitrified LLW site at Hanford. At the time of this writing, the specific location on the Hanford Site and the glass and burial design has not been finalized. The Hanford Federal Facility Agreement and Consent Order (Tri-Party Agreement) requires that the waste be buried somewhere in the Hanford Site's 200 Area Plateau, but does not specify the glass form and burial design (Tri-Party Agreement 1994). Therefore, the scope of this review is not defined by a specific wasteform (glass), near-field engineered barrier(s), or far field. To accommodate this uncertainty, the scope has been broadened to encompass a wide range of conditions when describing the geochemistry in the near field and a typical subsurface region of the Hanford Site's 200 Area Plateau when describing the geochemistry in the far field.

A majority of the discussion in the text will describe geochemistry in unsaturated sediments because most of the radionuclide travel time will be in this region before reaching the biosphere. Once the radionuclides reach the saturated zone (the unconfined aquifer) they will move appreciably faster). In the time frame of 10,000 years, transport through the saturated zone will be essentially instantaneous. Furthermore, the scope of the radionuclides considered were limited primarily to ${ }^{129}$ I, ${ }^{237} \mathrm{~Np},{ }^{79} \mathrm{Se},{ }^{99} \mathrm{Tc}$, and $\mathrm{U}$ isotopes. These isotopes were identified as potential problems in a scoping study directed at identifying key technical issues, uncertainties, and disposal facility design options for program guidance (Rawlins et al. 1994; Piepho et al. 1994).

This report covers three main subjects. First, a brief description of the key geochemical processes affecting the transport of these radionuclides through the near and far fields is provided. A summary of the conceptual, and especially the empirical, approaches of describing and quantifying sorption, solubility, diffusion, subsurface mobile colloid transport, and anion exclusion are presented. Also described in this portion of the literature review is how the geochemical interactions are mathematically treated by the PA, and how the geochemical interactions are quantified (i.e., measured). Second, a review is presented of the available Hanford site-specific chemical retardation data $\left(\mathrm{K}_{d}\right.$ values). Exhaustive tables of the available site-specific $\mathrm{K}_{d}$ data are discussed in regard to trends and data needs. Third, a strategy is provided for generating the additional data by means of a rational framework that allows systematic evaluation of data needs for sediments in the far field and all engineered barriers in the near field. Recommendations are made regarding specific data collection methods and tests matrices. 


\subsection{Strategy}

Because the waste disposal is long-term, system failure cannot readily be observed. Predictions of contaminant transport from waste source to receptor by groundwater must consider regulations for evaluating safety and the level of uncertainty inherent in such predictions. To reduce uncertainty, we try to establish an appropriate comprehensive database. For geologic environments, however, naturally occurring heterogeneities and the high costs of data collection constrain the level to which one can remove uncertainty. Consequently, uncertainty about facts affecting contaminant release via the groundwater pathway (i.e., the geochemical database) is inevitable, and the results of assessments require interpretation using professional judgement and sensitivity analyses to determine an adequate geochemical database.

The process used to define and limit the geochemical data collection program has been adopted from that used by Seme and Wood (1990) and is illustrated in Figure 1.1. The initial phase is divided into four parts that are the components of baseline data collections. Radionuclide and hazardous chemicals are identified from tank inventory data and descriptions of the glass melt pretreatment and treatment process. Geochemical data pertinent to performance assessment needs are the chemical and physical properties that influence geochemical reactions between the radionuclide and the hydrogeological environment of the waste site. The reactions of interest are those affecting radionuclide and contaminant mobility including solubility, sorption, desorption, and release rates from waste forms. The most important parameters include pore and recharge water composition, soil composition, and wasteform composition. Other parameters that influence transport by groundwater are soil porosity, permeability, moisture content, and groundwater recharge characteristics.

Hydrologic parameters used in assessing performance are generally derived from properties measured at the site of interest. Geochemical reaction values (e.g., sorption, solubility) for radionuclides or chemical contaminants are generally derived from laboratory studies for the range of values pertinent to the study site. Solubility data are sometimes derived from thermodynamic calculations using site-relevant chemical conditions. In this document, an initial adsorption database has been collected based on available published information and expert opinion.

Having established a baseline database, additional data needs, if any, are identified on the basis of performance assessment modeling (i.e., pathways analysis) or on an acknowledged lack of information (Figure 1.1). If the pathways analysis is done on an element-by-element basis and indicates unacceptable uncertainty (e.g., on contaminant transport to a receptor or in geochemical reaction values used as input to the model), additional data will be required. Additional data may also be required to quantify parameter values that affect geochemical reaction values. For example, the effect of moisture content on $\mathrm{K}_{\mathrm{d}}$ values can be calculated based on simple conceptual models, but such models need to be confirmed by test data.

Once sufficient data have been collected and the results of appropriate analyses have been used to generate model inputs, the transport analyses are performed and the impacts of contaminant release to the environment are calculated. To address uncertainty, a range of input values is generally used. The results of the sensitivity simulations are compared to regulatory criteria to determine if predicted releases are acceptable. If the range of parameter values used results in a predicted range of release values that is equivocal or unacceptable, then the process must be repeated to reduce or better define uncertainty. 
Identify radionuclides and other contaminants in waste

\section{Identify pertinent} geochemical conceptual release and sorption models

Identify available data that quantify parameter values (e.g., pH, Eh, and complexing ligands)

Calculate the range of sorption, solubility, and release-rate values

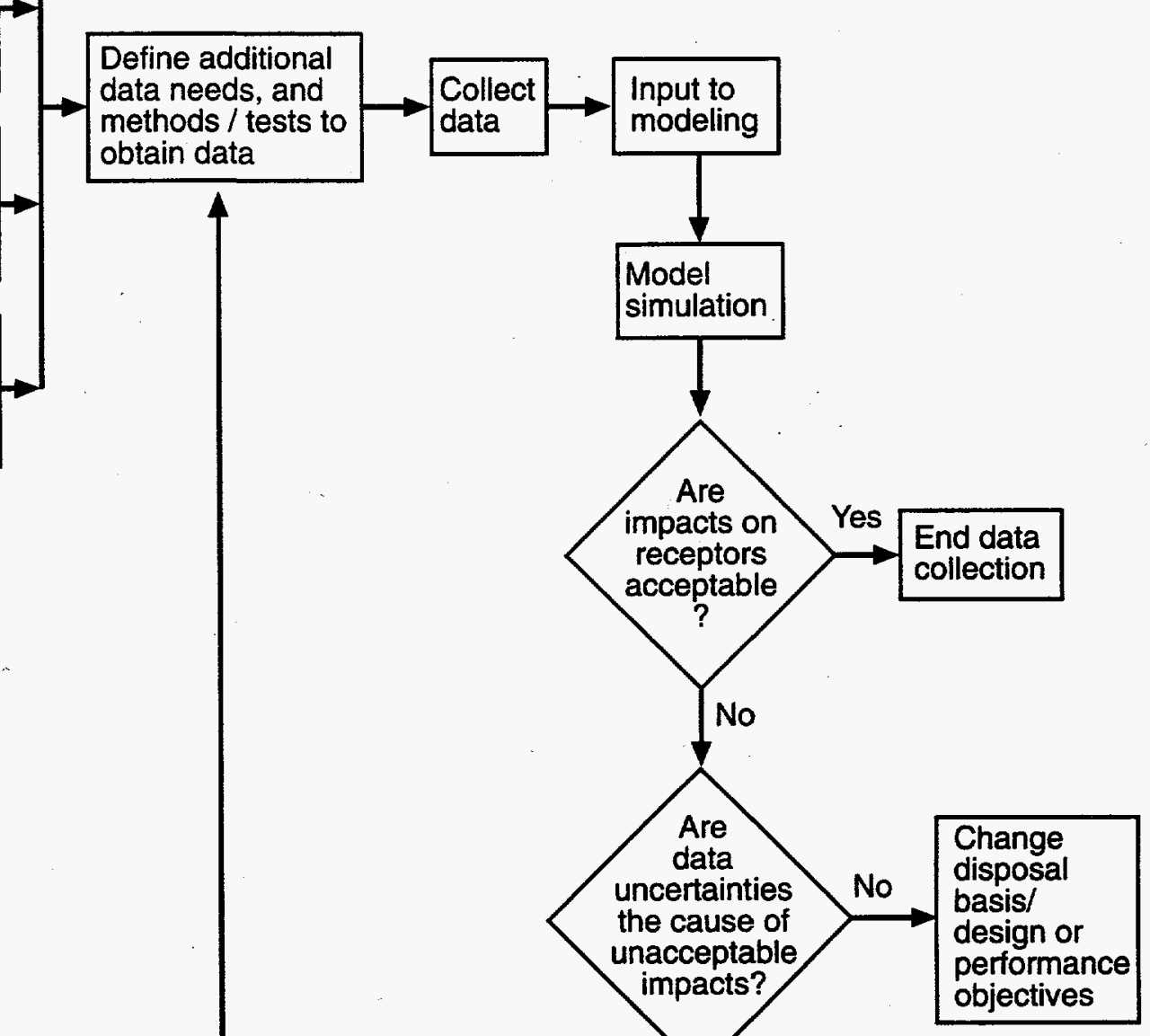

S9409045.1

Figure 1.1. Data Collection Strategy for Low-Level Waste Performance Assessment Modeling 


\subsection{Geochemical Processes Affecting Contaminant Transport Through the Near and Far Fields}

Once contaminants are leached from the buried wastes they will chemically interact with soils and sediments. The major processes affecting transport include dissolution/precipitation, adsorption/ desorption, chemical gradient diffusion, and diffusion into micropores within mineral grains. Recently, attention has been directed at additional geochemical processes that may enhance the transport of certain contaminants: colloid facilitated transport of contaminants and anion exclusion. These latter processes are difficult to quantify, and the extent to which they occur has not been determined. Dissolution/precipitation and adsorption/desorption are considered the most important processes affecting radionuclide interaction with sediments. For the Hanford LLW disposal application, dissolution/precipitation is likely the key process only in the near field, where the system may be in nonequilibrium, or in the far field, where significant $\mathrm{pH}$ and/or redox changes occur. In the far field, adsorption/desorption will likely be the key process controlling contaminant migration. Diffusion flux spreads solute via the concentration gradient (i.e., Fick's law). Diffusion is a dominant transport mechanism when advection is insignificant, and is usually a negligible transport mechanism when water is being advected in response to various forces.

\subsection{Sorption}

When a radionuclide is associated with the solid phase, it is not known if the radionuclide was adsorbed on to the surface of a solid, absorbed into the structure of a solid, precipitated as a threedimensional molecular structure on the surface of the solid, or partitioned into an organic structure. Such detailed information is often unobtainable or very difficult to obtain. A generic term devoid of mechanism and used to describe the partitioning of aqueous phase constituents, including radionuclides, to a solid phase is sorption. Sorption encompasses all of the above processes.

Sorption reactions are usually the most important contaminant retardation processes in far-field transport (Ames and Rai 1978, Delegard and Barney 1983, Serne and Wood 1990). Sorption processes are known to increase the travel times for some contaminants by $10^{3}$ to $10^{6}$ times relative to the groundwater. Such long travel times allow radionuclides to decay to lower concentrations, thereby becoming less hazardous before reaching the accessible environment, the biosphere.

In many natural systems at the Hanford Site, the extent of sorption is controlled by the electrostatic surface change of the mineral phase. Most natural geologic surfaces in the geosphere have net negative charges. These surface charges originate from permanent charge (charge resulting from the substitution of a lower valence cation for a higher valence cation in the mineral structure) and variable charge (charge resulting from the presence of surface functional groups). Permanent charge is the dominate charge of 2:1 clays, such as biotite, and montmorillinite. It constitutes a majority of the charge in the Hanford subsurface and it is not affected by solution $\mathrm{pH}$. Permanent positive charge is essentially nonexistent in natural rock and sediment systems. Variable charge is the dominant charge of $\mathrm{Al}, \mathrm{Fe}$, and $\mathrm{Mn}$ oxides and organic matter. The magnitude and polarity of the charge changes with a number of factors, including $\mathrm{pH}$. As the $\mathrm{pH}$ increases, the surface becomes increasingly more negatively charged. The pH where the surface has a zero net charge is referred to as the zero-point-ofcharge. The zero-point-of-charge of calcite is 10 (Sposito 1984), goethite is 8 to 8.5 (Mott 1981), gibbsite is 9.0 (Mott 1981), kaolinite is 4.7, and organic matter is 2 (Bell et al. 1972). Thus, at the pH of undisturbed Hanford sediments (pH 8.1) calcite, gibbsite, and goethite would be expected to have some, albeit little, positive charge and electrostatically attract anions. 
Adsorption, as discussed in this text, is the net accumulation of matter at the interface between a solid phase and an aqueous-solution phase. It differs from precipitation because it does not include the development of a three-dimensional molecular structure. The matter that accumulates in twodimensional molecular arrangements at the interface is the adsorbate. The solid surface on which it accumulates is the adsorbent. Adsorption on clay particle surfaces can take place via three mechanisms. The inner-sphere surface complex is in direct contact with the surface and lies within the Stern Layer of a charged surface (Figure 2.1). As a rule, the relative affinity of a radionuclide to sorb will increase with the tendency of it to form inner-sphere surface complexes. The higher the valence (more specifically, the higher the ionic potential, which is, the ratio of the valence to the ionic radius) of a cation, the greater the tendency for the cation to form an inner-sphere complex (Sposito 1984). The outer-sphere surface complex has at least one water molecule between the cation and the surface. If a solvated ion (an ion with water molecules surrounding it) does not form a complex with a charged surface functional group but instead neutralizes surface charge only in a delocalized sense, the ion is said to be adsorbed in the diffuse-ion swarm, and these ions lie in a region called the diffuse sublayer (Figure 2.1). The diffuse-ion swarm and the outer-sphere surface complex mechanisms of adsorption involve exclusively ionic bonding, whereas inner-sphere complex mechanisms are likely to involve ionic, as well as covalent, bonding.

Anion sorption is generally limited to variable-charge surfaces with a positive charge. A notable exception is phosphate, which forms surface complexes with hydroxide functional surface groups. Substantial amounts of phosphate may adsorb below the zero-point-of-charge. Anions, such as $\mathrm{I}^{-}$and $\mathrm{TcO}_{4}^{-}$, adsorb via outer-sphere surface complexation and diffuse-ion swarm association to variable charge surfaces (Gu and Schulz 1991). These weaker forms of anion sorption are favored when the $\mathrm{pH}$ is less than the zero-point-of-charge.

\subsubsection{Constant Distribution Coefficient $\left(K_{d}\right)$ Model}

The constant distribution coefficient, $K_{d}$, is a measure of sorption and is defined as the ratio of the quantity of the adsorbate adsorbed per gram of solid to the amount of the adsorbate remaining in solution at equilibrium. The mass action expression for $\mathrm{K}_{\mathrm{d}}(\mathrm{L} / \mathrm{kg})$ is

$$
\mathrm{K}_{\mathrm{d}}=\frac{\mathrm{A}_{1}}{\mathrm{C}_{i}}
$$

in the reaction $A+C_{i}<-->A_{i}$, where $A=$ the free or unoccupied surface adsorption sites, $C_{i}=$ the total dissolved adsorbate remaining in solution at equilibrium $(\mu \mathrm{g} / \mathrm{L})$, and $\mathrm{A}_{i}=$ adsorbate on the solid at equilibrium $(\mu \mathrm{g} / \mathrm{kg})$. Describing the $K_{d}$ in terms of this simple reaction assumes that $A_{i}$ is in great excess with respect to $C_{i}$ and that the activity of $A$ is equal to 1 . Thus, it is valid only for a particular adsorbent and applies only to those aqueous chemical conditions (e.g., adsorbate concentration, solution/electrolyte matrix) and the temperature under which it was measured. Also inherent in the $K_{d}$ term is the assumption that the system is reversible and is independent of the tracer concentration in the aqueous phase.

Essentially, all of these assumptions are violated in the common protocols used to measure $\mathbf{K}_{d}$ values. Typically, the distribution coefficient for a given absorbent is determined in the laboratory using sediment from the study area and actual or simulated groundwater to which an adsorbate is 

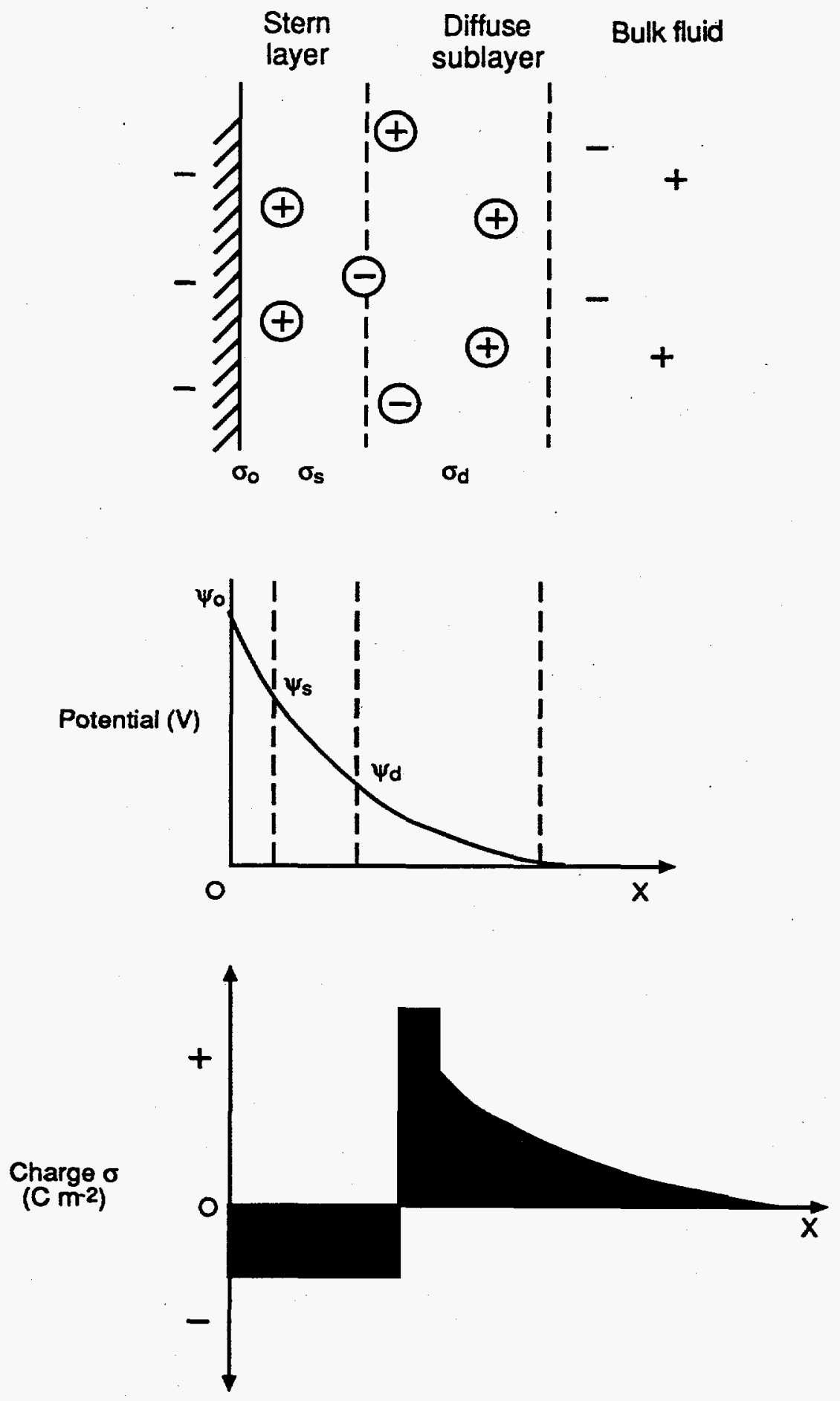

Figure 2.1. Diffuse Double Layer and Surface Charge of a Mineral Surface 
added at some trace concentration. $\mathrm{C}_{i}$ and $\mathrm{A}_{i}$ are operationally defined as the concentrations in the less-than and greater-than fractions, respectively, of some filter pore size, such as $0.45-\mu \mathrm{m}$ diameter. An important practical limitation of the measurement of $K_{d}$ values is that the total concentration or radioactivity of the tracer is measured, thereby treating the adsorbate and the absorbent as a single species. This assumption is not an inherent requirement, but it is generally applied for convenience. A hypothetical example of the species measured in a Np-K $\mathrm{K}_{d}$ experiment are presented in Equation 2:

$$
K_{d}=\frac{\sum_{n=1}^{\infty}\left[\mathrm{NpO}_{2} \mathrm{X}\right]+\left[\mathrm{NpO}_{2} \mathrm{Y}\right]+\left[\mathrm{NaNpO}_{2}\left(\mathrm{CO}_{3}\right)\right]+\left[\mathrm{Na}_{3} \mathrm{NpO}_{2}\left(\mathrm{CO}_{3}\right)_{2}\right] \ldots}{\sum_{n=1}^{\infty}\left[\mathrm{NpO}_{2}^{+}\right]+\left[\left[\mathrm{NpO}_{2}(\mathrm{OH})_{2}^{-}\right]+\left[\mathrm{NpO}_{2}(\mathrm{OH})^{\mathrm{g}}\right]+\left[\mathrm{NpO}_{2}\left(\mathrm{CO}_{3}\right)_{2}^{2}\right] \ldots\right.}
$$

where the square brackets indicate activity, and $\mathrm{X}$ and $\mathrm{Y}$ are two different mineral phases. The solid phase in this example contains four solid Np species including the species adsorbed to minerals $\mathrm{X}$ and $\mathrm{Y}$ and the species precipitated as $\mathrm{NaNpO}_{2}\left(\mathrm{CO}_{3}\right)$ and $\mathrm{Na}_{3} \mathrm{NpO}_{2}\left(\mathrm{CO}_{3}\right)_{2}$. The dissolved phase in this example contains four $\mathrm{Np}$ species including $\mathrm{NpO}_{2}^{+}, \mathrm{NpO}_{2}(\mathrm{OH})_{2}, \mathrm{NpO}_{2}(\mathrm{OH})^{0}$, and $\mathrm{NpO}_{2}\left(\mathrm{CO}_{3}\right)_{2}^{2}$. In this example, there are more than just one dissolved and sorbed species, thereby violating an important assumption underlying the $\mathrm{K}_{\mathrm{d}}$ value. Furthermore, many solutes, including radionuclides, have been observed to sorb more readily than desorb from mineral or organic surfaces, a phenomena referred to as hysteresis. This violates the reversibility assumption. The term "apparent $\mathrm{K}_{\mathrm{d}}$ " is commonly used to identify experimentally derived distribution coefficients that may not necessarily denote an equilibrium value or require some of the other assumptions inherent in the more rigorous use of the term " $K_{d}$." The definition of apparent $K_{d}$ is given in Equation 3;

$$
\text { Apparent } K_{d}=\frac{\sum_{n=1}^{\infty} A_{i}}{\sum_{n=1}^{\infty} C_{i}}
$$

where $A_{i}$ is a sorbed species and $C_{i}$ is a dissolved species. Equation 3 clearly resembles Equation 2 more closely than Equation 1. No attempt will be made in this text to distinguish between true equilibrium, $K_{d}$, and apparent $K_{d}$

An important limitation of the constant- $\mathrm{K}_{\mathrm{d}}$ model is that it does not address sensitivity to changing conditions. If the groundwater properties (such as $\mathrm{pH}$ and solution ionic strength) change, a new experiment must be performed. This limitation will be discussed further in Section 2.1.2.

Chemical retardation, $R_{F}$, is defined as

$$
R_{F}=\frac{V_{W}}{V_{n}}
$$

where $V_{w}$ and $V_{n}$ are the velocity of the water and contaminant through a control volume. The chemical retardation term does not equal unity when the solute interacts with the sediment; almost always the retardation term is $\geq 1$ due to solute sorption to sediments. In rare cases, the retardation factor is actually $<1$, and under such circumstances is referred to as the anion exclusion factor (see 
Section 2.5). To predict the effects of retardation, sorption processes must be described in quantitative terms. The $K_{d}$ provides such a quantitative estimate. Knowledge of the $K_{d}$ and of media bulk density and porosity (for porous flow), or of media fracture surface area, opening width, and matrix diffusion attributes (for fracture flow), allows calculation of the retardation factor. The constant $K_{d}$ model is mathematically very simple and readily incorporated into transport models and codes via the retardation factor term. For porous flow with saturated moisture conditions, the $R_{F}$ is defined as

$$
R_{F}=1+\frac{\rho_{b}}{\phi_{\varepsilon}} K_{d}
$$

where $\mathrm{p}_{b}$ is the porous media bulk density (mass/length ${ }^{3}$ ), and $\phi_{\varepsilon}$ is the effective porosity at saturation of media. For unsaturated moisture content flow, $\phi_{\varepsilon}$ is the moisture content (Bear and Verraijt 1987) (see Section 2.1.4). For one-dimensional advection-dispersion flow with chemical retardation, the transport equation can be written as

$$
\frac{\partial C_{i}}{\partial t}=\frac{\left[D_{x} \frac{\partial^{2} C_{1}}{\partial x^{2}}-v_{x} \frac{\partial C_{i}}{\partial x}\right]}{R_{F}}
$$

where $C_{i}$ is the concentration of a particular radioactive species $i$ in solution (mass/length ${ }^{3}$ ), $D_{X}$ is the dispersion coefficient of species $i$ (length ${ }^{2} /$ time), $v_{x}$ is pore velocity of groundwater (length/time), and $R_{F}(i)$ is the retardation factor for species $i$. For simplicity, radioactive decay has been omitted from Equation 6 . Because the chemical retardation factor is a function of the $K_{d}$ term, it too is devoid of mechanism and implicitly assumes that the reactions go to equilibrium and are reversible and that the chemical environment along the solute flow path does not vary in either space or time (see Section 2.1) (Muller et al. 1983). The limitation associated with these assumptions are wellknown to investigators but the paucity of Hanford Site geochemical data precludes a more rigorous conceptual model (see Section 2.1.3). Geochemical processes may also be irreversible or at least directionally dependent. This phenomena is referred to as hysteresis and typically exist such that the rate of sorption is faster than the rate of desorption. Yet, the assumption of reversibility and singlevalue model parameters are generally employed, with the justification that the approach builds conservatism into the analysis.

\subsubsection{Parametric-K $K_{d}$ Model}

When using the constant- $\mathrm{K}_{\mathrm{d}}$ model, the retardation factor is a constant for each layer of geologic media (each layer is assumed to have a constant bulk density and saturated effective porosity). The transport equation based on a constant- $\mathrm{K}_{d}$ model does not require knowledge of any other geochemical parameters such as $\mathrm{pH}$ or mineralogy, and it is easily solved to determine the solution concentration as a function of time and space. It is the use of the constant- $\mathrm{K}_{\mathbf{d}}$ model in the retardation factor (Equation 5) that has caused most of the criticism; few natural groundwater pathways are spatially or geochemically homogeneous to the extent that the retardation factor for a species remains constant. 
Clearly, the greatest limitation to the constant- $\mathrm{K}_{\mathrm{d}}$ approach is that it describes solute partitioning between the aqueous and solid phases for only one set of environmental conditions. Such homogeneity does not exist in nature and therefore greatly compromises the usefulness of the constant. For instance, when the aqueous phase chemistry was varied, Am- $K_{d}$ values in a Hanford sediment ranged from 0.2 to $53 \mathrm{~mL} / \mathrm{g}$, roughly a 200-fold range (Delegard and Barney 1983). Additional variability in the Am- $K_{d}$ values, albeit less, were observed when slightly different Hanford sediments were used:

4.0 to $28.6 \mathrm{~mL} / \mathrm{g}$ (Delegard and Barney 1983, Solution 1). Using similar aqueous phases but diverse sediments, Sheppard et al. (1976) measured Am-K $K_{d}$ values ranging from 125 to $43,500 \mathrm{~mL} / \mathrm{g}$. (Interestingly, the lowest $\mathrm{K}_{d}$ in this survey of 12 soils/sediments from DOE-national laboratories was in a Hanford sediment.)

The second practical conceptual model for adsorption is called the parametric- $K_{d}$ model. The $K_{d}$ value in this model varies according to empirically derived relationships with aqueous and solid phase independent parameters. Thus, it has the distinct advantage of being more robust and removes the burden of determining new $K_{d}$ values for each environmental condition. Because the $K_{d}$ is a function of a large number of variables, it is common to systematically vary several parameters simultaneously in one experimental study. Factorial design strategies are most often invoked to determine the systematic change resulting from varying the independent variables on the dependent variables, typically the distribution coefficient (Cochran and Cox 1957, Davies 1954, Plackett and Burman 1946, Box and Behnken 1960). Statistical methods commonly used to derive quantitative predictor equations include standard linear or nonlinear regression (Snedecor and Cochran 1967), stepwise regression (Hollander and Wolfe 1973), and adaptive-learning networks (Mucciard et al. 1979, 1980). All these techniques have been used to develop empirical relationships describing $K_{d}$ values in terms of other variables (Routson and Seme 1972, Seme et al. 1973, Routson et al. 1981, Delegard and Barney 1983).

The empirical predictor equations commonly take the form of a nonlinear multinomial expression. For example, after evaluating solutions consisting of several sodium salts, organic chelates, and acids, Delegard and Barney (1983) came up with the following expression for an Am- $\mathrm{K}_{d}$ value on one particular Hanford sediment:

$$
\log \left[K_{d}(A m)\right]=2.0+0.1[\mathrm{NaOH}]-26.8[\mathrm{HEDTA}]+153.4\left[\mathrm{HEDTA}^{2}\right.
$$

The independent parameters and their ranges used to develop Equation 7 were selected to simulate the plume of a HLW emanating from a steel-lined concrete tank into a sediment in the Hanford Site 200 Area Plateau. Numerous salts were found to have no significant effect on americium $K_{d}$ values and therefore were not included in the expression. Delegard and Barney (1983) also evaluated higher exponential and logarithmic terms and determined that these terms did not improve the predictive capabilities of the expression (i.e., the regression coefficients were not significant at $P \leq 0.05$ ).

Although the empirical relationships generated from these types of statistical analyses are more powerful than knowledge of individual $K_{d}$ values, they cannot be used to predict $K_{d}$ values for conditions beyond the range studied. For example, the parametric- $\mathrm{K}_{\mathrm{d}}$ values generated by Delegard and Bamey (1983) for the 200 Area Plateau are likely inappropriate for the vitrified LLW plume because the chemistry of the aqueous phase will be appreciably different. 
These types of statistical relationships are devoid of causality and therefore provide no certain information on the mechanism by which the radionuclide partitioned to the solid phase, whether it be by adsorption, absorption, precipitation, or coprecipitation. That is, the statistical analyses may suggest a very strong relationship between one variable, for instance $\mathrm{pH}$, and the distribution coefficient, when the actual sorption process may be controlled by iron oxide adsorption. Because pH and iron oxide charge are covarients, a statistical relationship could be calculated, suggesting that sorption is solely caused by $\mathrm{pH}$.

The parametric- $\mathrm{K}_{\mathrm{d}}$ model can be used in the retardation factor term (Equation 5) and the transport equation (Equation 6). When used in the transport equation, the code must also keep track of the current value of the independent variables (such as [NaOH] and [HEDTA] for the examples described in Equation 7) at each point in space and time to continually update the concentration of the independent variables affecting the $\mathrm{K}_{\mathrm{d}}$ value. Thus, the code must track many more parameters, and some numerical solving techniques (such as closed-form analytical solutions) can no longer be used to perform the integration necessary to solve for concentration. Generally, computer codes that can accommodate the parametric- $K_{d}$ model use a chemical subroutine to update the $K_{d}$ value used to determine the $R_{F}$, when called by the main transport code. The added complexity in solving the transport equation with the parametric- $K_{d}$ sorption model and its empirical nature may be the reasons this technique has been used sparingly for waste disposal safety assessment exercises.

\subsubsection{Overview of Mechanistic Adsorption Models}

Mechanistic models explicitly accommodate the dependency of $K_{d}$ values on contaminant concentration, competing ion concentration, variable surface charge on the adsorbent, and solute species solution distribution. Incorporating mechanistic, or semi-mechanistic, concepts into models is attempted because the models become more robust and, perhaps more importantly, from the standpoint of the LLW PA, scientifically defensible. There are several mechanistic models describing solute adsorption; some are accurate only under limited environmental conditions (Sposito 1984). For instance, the Stern model is a better model for describing adsorption of inner-sphere complexes, whereas the Gouy-Chapman model is a better model for describing outer-sphere or diffuse swarm adsorption (Sposito 1984, Westall 1986). The description of the models will be presented in a future topical paper for this project entitled "Applicability of Mechanistic Adsorption Models for Key Contaminants in Hanford LLW Glass Disposal." We delay reporting about these models because we judge them of little practical use in near-term performance assessment activities at the Hanford Site. The complexity of installing these models into existing transport codes that are favored for complete disposal system performance assessment and the diversity of Hanford waste leachate/sediment/ contaminant combinations of interest would require a data collection effort more intense and costly than is likely to be available. The September 1998 topical report will familiarize the performance assessment community with available adsorption models so they can gain a complete perspective of adsorption modeling. The topical report will also act as a primer for adsorption models that are considered more sophisticated and mechanistically sound than the constant- or parametric- $K_{d}$ models discussed above. A brief description of the state of the science is presented below. References to excellent review articles have been included in the discussion to provide the interested reader with additional information. 
Several mechanistic models have been proposed; however, their application to complex natural sediments is not resolved (Westall and Hohl 1980, Sposito 1984, Westall 1986, Schindler and Sposito 1991). Any complete mechanistic description of chemical reactions at the mineral-electrolyte interface must include a description of electrical double layer (Figure 2.1). While this fact has been recognized for years, a satisfactory description of the double layer at the mineral-electrolyte interface still does not exist.

Part of the difficulty of characterizing this interface stems from the fact that natural mineral surfaces are very irregular. They consist of many different microcrystalline structures that exhibit quite different chemical properties when exposed to solutions. Thus, examination of the surface by virtually any experimental method yields only averaged characteristics of the surface and the interface. Parsons (1982) discussed the surface chemistry of single crystals of pure metals and showed that the potential of zero charge of different crystal faces of the same pure metal can differ by over $400 \mathrm{mV}$. For an oxide surface, this difference was calculated by Westall (1986) to be energetically equivalent to a variation in the zero-point-of-charge of more than six $\mathrm{pH}$ units. This example indicated that an observable macroscopic property of a polycrystalline surface might be the result of a combination of widely different microscopic properties and that characterizations of these surfaces will remain somewhat operational in nature.

Another fundamental problem encountered in characterizing reactions at the mineral-electrolyte interface is the coupling between electrostatic and chemical interactions, which makes it difficult to distinguish the effects of one from the effects of the other. Westall and Hohl (1980) have shown that many models for reactions at the mineral-electrolyte interface are indeterminate in this regard.

Many of the studies from which our current understanding of reactions at the mineralelectrolyte interface has developed were based on titration of colloidal suspensions of minerals. Resolving questions left open by this work requires in the study of better defined mineral surfaces, the examination of a particular interface by many different spectroscopic and experimental methods, and the development of mathematical methods for interpreting the data.

Experimental data on interactions at the mineral-electrolyte interface can be represented mathematically through two different approaches: 1) empirical models and 2) mechanistic models. An empirical model can be defined as a mathematical description of the experimental data without any particular theoretical basis. For example, the $\mathbf{K}_{d}$, Freundlich isotherm, Langmuir isotherm, Langmuir Two-Surface Isotherm, and Competitive Langmuir are considered empirical models by this definition (Sposito 1984). Mechanistic models refer to models based on thermodynamic concepts such as reactions described by mass action laws and material balance equations. Four of the most commonly used mechanistic models include the Helmholtz, Gouy-Chapman, Stern, and Triple Layer models (Sposito 1984). The specific details of many of these models will be addressed in the September 1998 topic paper. The empirical models are often mathematically simpler than mechanistic models and are suitable for characterizing sets of experimental data with a few adjustable parameters, or for interpolating between data points. On the other hand, mechanistic models contribute to an understanding of the chemistry at the interface and are often useful for describing data from complex multicomponent systems for which the mathematical formulation (i.e., functional relationships) for an empirical model might not be obvious. Mechanistic models can also be used for interpolation and characterization of data sets in terms of a few adjustable parameters. However, mechanistic models are often mathematically more complicated than empirical relationships. Adjustable parameters are required for both mechanistic and empirical models, except the $K_{d}$ model. 


\subsubsection{Effects of Unsaturated Conditions on Transport}

The major pathway for transport of radionuclides from The Hanford Site's arid zone burial grounds is through unsaturated sediments. The average moisture content of Hanford vadose zone sediments ranges from 4 to $7 \%(\mathrm{v} / \mathrm{v})$, which is equivalent to $10 \%$ to $20 \%$ saturation (Gee and Heller 1985, Schalla et al. 1988). Although considerable effort has been expended over the past few years to quantify the mobility of nuclear wastes and determine factors that influence radionuclide mobility (Ames et al. 1976, Serne et al. 1977, Wolfsberg 1978, Relyea and Serne 1979, and Seme et al. 1993), little work has been done to investigate the transport of radionuclides under conditions of partial saturation, which is most commonly found at arid region burial sites.

Because radionuclide migration requires that a liquid move the radionuclides either physically, as dispersed colloids, or as dissolved constituents in solution, hydraulic conductivity is important. Hydraulic conductivity is the ratio of the flux density (the volume of water flowing through a crosssectional area per unit time) to the hydraulic gradient (the head drop per unit distance in the flow direction). If the soil water does not move, then the radionuclides in, or contacted by, the soil water do not move except by diffusion, which is a relatively slow process (Rancon 1973). When the soil is saturated, nearly all pores are filled and conductivity is at a maximum. As the soil becomes unsaturated, some of the pores become air-filled and the conductive cross-sectional areas are decreased. In addition, the first pores to empty under tension are the largest and most conductive, and tortuosity is increased by these empty pores. In unsorted sediments, the large pores that resulted in high conductivity at saturation become barriers to liquid flow between smaller pores during unsaturated flow. Hence, the transition from saturated to unsaturated flow may result in a steep drop in hydraulic conductivity of several orders of magnitude as the tension increase from 0 to 1 bar. At higher tensions, conductivity may be so low that steep negative pressure gradients are required for any appreciable soil water flow to occur. An interesting corollary of the pore size-conductivity relationship is that at, or near, saturation, a sandy soil conducts water more rapidly than a clay soil with many micropores. When the soils are unsaturated, however, many of the micropores in the clay soil remain filled, and consequently, the hydraulic conductivity in the clay soil does not decrease nearly as sharply as it does in sandy soil under the same tension.

In modeling contaminant transport in unsaturated conditions, Equation 5 takes on a new form:

$$
R_{F}=1+\frac{p_{b}}{\theta} K_{d}
$$

where $\theta$, the volumetric water content of the sediment, replaces $\phi$, sediment porosity, in Equation 5 . Equation 8 explicitly assumes that the extent to which contaminants sorb to sediments, the $K_{d}$ value, is constant as a function of the volumetric water content. This relationship is convenient for modeling; however, its validity is not certain. There have been experiments to test this assumption, and the results have been mixed (Knoll 1960, Nielsen and Biggar 1961, Nielsen and Biggar 1962, Baetsle et al. 1966, Routson and Serne 1972, Gee and Campbell 1980).

There are theoretical reasons for believing that $K_{d}$ values vary as a function of volumetric water content. First, as the sediment becomes increasingly unsaturated there will be a smaller percentage of the total exchange sites in contact with the aqueous phase. For example, if only half of the exchange sites of a sediment come into contact with the aqueous phase, then the effective exchange capacity of the sediment is only half of that, had all the available exchange sites come into contact with the aqueous phase. Therefore, as less mineral surface is exposed to the aqueous phase, the lower the effective exchange capacity becomes because less of the surface is exposed to the solute of interest. On the 
other hand, the clay fraction of the soil constitutes the largest exchange capacity and smallest pore sizes. Since the smaller pores are involved in unsaturated flow, there may be little measurable effect on the exchange capacity of the soil in unsaturated conditions. Perhaps by normalizing data by effective pore volume, rather than by effluent volume, the difference in $K_{d}$ values of saturated and unsaturated systems would disappear. Another reason for believing that $\dot{K}_{d}$ values would vary with degree of saturation is because in the unsaturated systems the aqueous phase is in closer contact with the sediment surfaces. Solutes in the middle of large pores have less interaction with sediment surfaces than solutes nearer to the sediment surfaces. In unsaturated conditions, the middle of large pores tend to be empty, resulting in a greater percentage of pore water being in close contact with the sediment surface. Finally, the ionic strength of the aqueous phase tends to increase closer to the clay surfaces. Thus, as a sediment dehydrates, the system tends to have a higher ionic strength. The $\mathbf{K}_{d}$ value for many cations tends to decrease with increases in ionic strength.

Knoll (1960) examined if soil sorption of radionuclides was a function of saturation. Small columns of a fairly uniform, very fine sand at constant temperature, packed bed density, and tension were used with an influent solution containing $1 \mathrm{~g} / \mathrm{L} \mathrm{Ca}^{2+}, 0.1 \mathrm{mg} / \mathrm{L} \mathrm{Sr}^{2+}$, and $2 \times 10^{-2} \mu \mathrm{Ci} / \mathrm{mL}{ }^{90} \mathrm{Sr}$. There was no apparent difference in $\mathrm{Sr}$ retention capacity between saturated and unsaturated soils. However, it is worth noting that column flow rate differences between $100 \%$ saturation and $36 \%$ saturation are less than a factor of 100 . With use of an aggregate of less uniform pore size, flow rate (hydraulic conductivity) differences could have been much greater, the volume of soil contacted by the aqueous phase under unsaturated flow conditions much smaller, and hence the cation exchange capacity of soil might have differed considerably between saturated and unsaturated flow conditions. Routson and Serne (1972), in a study involving experimental verification of their one-dimensional PERCOL model, determined the breakthrough curves and ${ }^{85} \mathrm{Sr}$ capacity for unsaturated Tank Farm sandy loam soil columns at $96 \%, 75 \%, 63 \%$, and $45 \%$ of saturation. They reported no apparent reduction of Sr-retention capacity as a function of saturation. More recently, Gee and Campbell (1980) also reported that changes in saturation percentage of the sediment, from 56 to $31 \%$, had little to no effect on tritium, cobalt-EDTA complex, technetium, and iodine sorption ( $\mathrm{K}_{\mathrm{d}}$ values).

Contrary to the above work, Nielsen and Biggar $(1961,1962)$ showed that the drier the soil, the greater the effluent volume required to reach a tracer effluent/influent $\left(C / C_{0}\right)$ of 1.0 . The desaturation eliminates the larger flow channels and increases the stagnant water volumes, which are difficult to displace. Desaturating the soil progressively shifted the initial breakthrough to the left and increased the skewness of the breakthrough curves. In an eolian sand column of $100 \%, 45 \%$, and $30 \%$ saturation, Baetsle et al. (1966) observed that ${ }^{85} \mathrm{Sr}$ leachate came out in concentration pulses, leading them to conclude that solutions in nonsaturated columns percolated through preferred channels.

\subsection{Solubility}

\subsubsection{Theory}

The precipitation reaction of dissolved species is a special case of the complexation reaction in which the complex formed by two or more aqueous species is a solid. As an example, consider the formation of a sulfide precipitate with a bivalent radionuclide cation:

$$
\mathrm{M}^{2+}(\mathrm{aq})+2 \mathrm{HS}^{-}(\mathrm{aq})=\mathrm{M}(\mathrm{HS})_{2}(\mathrm{~s})
$$


where $M$ can be a radionuclide cation. The dissolution equilibrium constant, $\left(\mathrm{K}_{\mathrm{dis}}\right)$, corresponding to Equation 9 is:

$$
\mathrm{K}_{\mathrm{dis}}=\left[\mathrm{M}(\mathrm{HS})_{2}{ }^{0}(\mathrm{~s})\right] /\left[\mathrm{M}^{2+}(\mathrm{aq})\right]\left[\mathrm{HS}^{-}(\mathrm{aq})\right]^{2}
$$

Precipitation of radionuclides is not likely to be a dominant reaction in the far field because the radionuclide concentrations are not likely to be high enough to push the equilibrium towards the right side of Equation 9. Precipitation or coprecipitation is more likely to occur in the near field as a result of high salt concentrations in the leachate and large $\mathrm{pH}$ or $\mathrm{Eh}$ gradients in the environment. Coprecipitation is the simultaneous precipitation of a chemical element with other elements by any mechanism (Sposito 1984). The three broad types of coprecipitation are inclusion, adsorption, and solid solution formation.

Solubility-controlled models assume that a known solid is present or rapidly forms and controls the solution concentration in the aqueous phase of the constituents being released. Solubility models are thermodynamic equilibrium models and do not consider kinetics (time required to dissolve or completely precipitate). When identification of the likely controlling solid is difficult or when kinetic constraints are suspected, empirical solubility experiments are often performed to gather data that can be used to generate an empirical solubility release model (a model with the mathematical similarity to solubility but no identified thermodynamically acceptable controlling solid). A solubility limit is not a constant value in a chemically dynamic system. That is, the solubility limit is determined by the product of the thermodynamic activities of species that constitute the solid. If the system chemistry changes, then the individual species activities likely change. For example, if the controlling solid for plutonium is the hydrous oxide $\mathrm{Pu}(\mathrm{OH})_{4}$, the solubility product is $[\mathrm{Pu}][\mathrm{OH}]^{4}=$ solubility product $\left(\mathrm{K}_{\mathrm{sp}}\right)$. The solubility product is fixed, but the value of $[\mathrm{Pu}]$ and $[\mathrm{OH}]$ can vary. In fact, if the $\mathrm{pH}$ decreases 1 unit ( $[\mathrm{OH}]$ decreases by 10 ), then for $\mathrm{K}_{\mathrm{sp}}$ to remain constant [Pu] must increase by $10^{4}$, all else held constant. A true solubility model must consider the total system and does not reduce to a fixed value for the concentration of a constituent under all conditions. Numerous constant concentration (i.e., empirical solubility) models are used in performance assessment activities that assume a controlling solid and fix the chemistry of all constituents to derive a fixed value for the concentration of specific contaminants. The value obtained is only valid for the specific conditions assumed.

\subsubsection{Redox-Mediated Precipitation}

An oxidation-reduction (redox) reaction is a chemical reaction in which electrons are transferred completely from one species to another. The chemical specie that loses electrons in this charge transfer process is called oxidized, and the one receiving electrons is called reduced. For example, in the reaction involving $\mathrm{Fe}$ species:

$$
\mathrm{FeOOH}(\mathrm{s})+3 \mathrm{H}^{+}(\mathrm{aq})+\mathrm{e}^{-(a q)}=\mathrm{Fe}^{2+}(\mathrm{aq})+2 \mathrm{H}_{2} \mathrm{O}(\mathrm{aq})
$$

the solid phase, goethite, is the oxidized species, and $\mathrm{Fe}^{2+}(\mathrm{aq})$ is the reduced species. Equation 11 is a reduction half-reaction in which an electron in aqueous solution, denoted $e^{-}(a q)$, serves as one of the reactants. This specie, like the proton in aqueous solution, is understood in a formal sense to participate in charge transfer processes. The overall redox reaction in a system must always be the combination of two half-reactions, an oxidation half-reaction and reduction half-reaction, such that the species 
$\mathrm{e}^{-}$(aq) does not exist explicitly. For example, to represent the oxidation of $\mathrm{Fe}^{2+}$, Equation 11 could be combined (or coupled) with the inverse of a half-reaction involving the reduction of $\mathrm{O}_{2}$ gas:

$$
1 / 4 \mathrm{O}_{2}(\mathrm{~g})+\mathrm{H}^{+}(\mathrm{aq})+\mathrm{e}^{-}(\mathrm{aq})=1 / 2 \mathrm{H}_{2} \mathrm{O}(\mathrm{aq})
$$

Combining Equation 11 with the inverse of Equation 12 results in the cancellation of the aqueous electron and the oxidation of $\mathrm{Fe}^{2+}$ via the reduction of $\mathrm{O}_{2}(\mathrm{~g})$, a possible reaction describing $\mathrm{Fe}^{2+}$ leaching from a reduced environment in the near field to the oxidizing environment of the far field:

$$
\mathrm{Fe}^{2+}(\mathrm{aq})+3 / 2 \mathrm{H}_{2} \mathrm{O}(\mathrm{aq})+1 / 4 \mathrm{O}_{2}(\mathrm{~g})=\mathrm{FeOOH}(\mathrm{s})+2 \mathrm{H}^{+}(\mathrm{aq})
$$

Equation 13 could represent a scenario in which $\mathrm{Fe}^{2+}$ is leached from a reducing environment, where it is mobile, into an oxidized environment, such as the far field, where $\mathrm{Fe}^{3+}$ precipitates as the mineral goethite.

The electron activity is a useful conceptual device for describing the redox status of aqueous systems, just as the aqueous proton activity is so useful for describing the acid-base status of soils. Similar to $\mathrm{pH}$, the propensity of a system to be oxidized can be expressed by the negative common logarithm of the free-electron activity:

$$
\mathrm{pE}=-\log \left(\mathrm{e}^{-}\right)
$$

The range of $\mathrm{pE}$ in the far field may vary between approximately 7 to 1.7 in the vadose zone. If anoxic conditions exist, say in a near-field barrier, than the $\mathrm{pE}$ may get as low as -3 . The most important chemical elements affected by redox reactions in ambient groundwater are $\mathrm{C}, \mathrm{N}, \mathrm{O}, \mathrm{S}, \mathrm{Mn}$, and Fe. In radioactively contaminated groundwater, this list would grow to include $\mathrm{Co}, \mathrm{I}, \mathrm{Np}, \mathrm{Pu}, \mathrm{Tc}$, and $\mathrm{U}$. There is a well defined sequence of reduction of inorganic elements. When an oxidized system is reduced, the order that oxidized species disappear are $\mathrm{O}_{2}, \mathrm{NO}_{3}, \mathrm{Mn}^{2+}, \mathrm{Fe}^{2+}, \mathrm{HS}^{-}$, and $\mathrm{H}_{2}$.

As the $\mathrm{pE}$ of the system drops below +11.0 , enough electrons become available to reduce $\mathrm{O}_{2}(\mathrm{~g})$

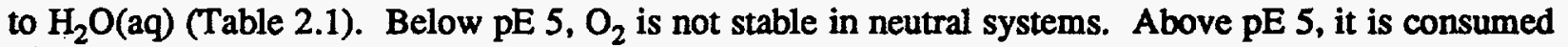
in the respiration processes of aerobic microorganisms. As the $\mathrm{pE}$ decreases below 8, electrons become available to reduce $\mathrm{NO}_{3}$. As the system $\mathrm{pE}$ value drops into the range of 7 to 5 , electrons become plentiful enough to support the reduction of $\mathrm{Fe}$ and $\mathrm{Mn}$ in solid phases. Iron reduction does not occur until $\mathrm{O}_{2}$ and $\mathrm{NO}_{3}$ are depleted, but $\mathrm{Mn}$ reduction can be initiated in the presence of $\mathrm{NO}_{3}$. In the case of $\mathrm{Mn}$ and $\mathrm{Fe}$, decreasing $\mathrm{pE}$ results in solid-phase dissolution because the stable forms of $\mathrm{Mn}$ (IV) and Fe(III) are solid species. Besides the increase in solution concentrations of $\mathrm{Mn}$ and $\mathrm{Fe}$ expected from this effect of lowered $\mathrm{pE}$, a marked increase is usually observed in the aqueous phase concentrations of metals such as $\mathrm{Cd}, \mathrm{Cu}$, or $\mathrm{Zn}$, and of ligands such as $\mathrm{H}_{2} \mathrm{PO}_{4}$ or $\mathrm{HMoO}_{4}$, accompanying $\mathrm{Fe}$ and $\mathrm{Mn}$ reduction. The principal cause of this secondary phenomenon is the desorption of metals and ligands that occurs when the adsorbents to which they are bound become unstable and dissolve. Typically, the metals released in this fashion, including $\mathrm{Mn}$ and $\mathrm{Fe}$, are soon reabsorbed by solids that are stable at low $\mathrm{pE}$ (e.g., clay minerals or organic matter) and become exchangeable surface species. These surface changes have an obvious influence on the availability of the chemical elements involved, particularly phosphorus. If a radionuclide was involved in this dissolution/ exchange set of reactions, it would be expected that the latter radionuclide species would be less strongly associated with the solid phase. 
Table 2.1. Sequence of Principal Electron Acceptors in Neutral Aquatic Systems (Sposito 1984)

\begin{tabular}{|l|c|}
\hline \multicolumn{1}{|c|}{ Reduction half-reactors } & Range of initial $\mathrm{pE}$ \\
\hline $1 / 2 . \mathrm{O}_{2}+2 \mathrm{e}^{-}+2 \mathrm{H}^{+}=\mathrm{H}_{2} \mathrm{O}$ & 5.0 to 11.0 \\
\hline $\mathrm{NO}_{3}^{-}+2 \mathrm{e}^{-}+2 \mathrm{H}^{+}=\mathrm{NO}_{2}^{-}+\mathrm{H}_{2} \mathrm{O}$ & 3.4 to 8.5 \\
\hline $\mathrm{MnO}_{2}+2 \mathrm{e}^{-}+4 \mathrm{H}^{+}=\mathrm{Mn}^{2+}+2 \mathrm{H}_{2} \mathrm{O}$ & 3.4 to 6.8 \\
\hline $\mathrm{FeOOH}^{-} \mathrm{e}^{-}+3 \mathrm{H}^{+}=\mathrm{Fe}^{2+}+2 \mathrm{H}_{2} \mathrm{O}$ & 1.7 to 5.0 \\
\hline $\mathrm{SO}_{4}^{2-}+6 \mathrm{e}^{-}+9 \mathrm{H}^{+}=\mathrm{HS}^{-}+4 \mathrm{H}_{2} \mathrm{O}$ & 0 to -2.5 \\
\hline $\mathrm{H}^{+}+\mathrm{e}^{-}=1 / 2 \mathrm{H}_{2}$ & -2.5 to -3.7 \\
\hline$\left(\mathrm{CH}_{2} \mathrm{O}\right)_{\mathrm{n}}=\mathrm{n} / 2 \mathrm{CO}_{2}+\mathrm{n} / 2 \mathrm{CH}_{4}$ & -2.5 to -3.7 \\
\hline
\end{tabular}

As $\mathrm{pE}$ becomes negative, sulfur reduction can take place. If radioactive metals such as $\mathrm{Se}$ (VI) and $\mathrm{Tc}(\mathrm{VI})$ are present in the aqueous phase at high enough concentrations, they can react with bisulfide (HS-) to form metal sulfides that are quite insoluble. Thus, anoxic barrier conditions can diminish significantly the solubility of radioactive metals, thereby reconcentrating them in a solid phase.

Redox chemistry may also have a direct affect on radionuclide chemistry. It can directly affect the oxidation state (and therefore the potential to precipitate) of $\mathrm{I}, \mathrm{Np}, \mathrm{Pu}, \mathrm{Se}, \mathrm{Tc}$, and $\mathrm{U}$. For example, the reduction of $\mathrm{Pu}$,

$$
{ }^{239} \mathrm{Pu}(\mathrm{IV})+\mathrm{e}^{-}={ }^{239} \mathrm{Pu}(\mathrm{III}) \quad \mathrm{pE}=1.7
$$

makes ${ }^{239} \mathrm{Pu}$ appreciably less reactive in complexation [i.e., ${ }^{239} \mathrm{Pu}(\mathrm{III})$ stability constants are much less than those of ${ }^{239} \mathrm{Pu}(\mathrm{IV})$ ] and sorption/partitioning reactions (Kim 1986). The reduction of U(VI) to U(III) or U(IV), has the opposite effect, i.e., U(III) or U(IV) form stronger complexes and sorb more strongly to surfaces than U(VI). Therefore, changes in redox may increase or decrease the tendency for reconcentration of radionuclides in leachate, depending on the aqueous phase chemical composition and the radionuclide in question. However, if the redox status gets low enough to induce sulfide formation, reconcentration of radionuclides can be expected.

Redox-mediated reactions are incorporated into most geochemical codes and can be modeled conceptually. The resultant speciation distribution calculated by such a code is used to determine potential solubility controls and adsorption potential. Many redox reactions have been found to be kinetically slow in natural groundwater, and several elements may never reach redox equilibrium between their various oxidation states. Thus, it is more difficult to predict with accuracy the migration potential of redox-sensitive species.

\subsubsection{Acid/Base-Mediated Precipitation}

The composition of the vitrified waste is unknown; however, preliminary modeling efforts (Piepho et al. 1994) indicate that the leachate will have a $\mathrm{pH}>11$ and contain appreciably higher concentrations of total $\mathrm{S}, \mathrm{Na}^{+}$, and $\mathrm{H}_{4} \mathrm{SiO}_{4}$ and lower concentration of $\mathrm{Ca}^{2+}$ and inorganic carbon than the 
ambient groundwater. Assuming this is the composition of the plume as it enters the far field, it appears that the plume will initially be far from ambient equilibrium conditions, which may result in the formation of insoluble precipitates (best modeled using the thermodynamic construct, $\mathbf{K}_{\text {sp }}$, the solubility product described in Equation 10). The steep pH gradient is likely to have an especially profound effect on precipitation. Soluble polymeric hydroxo solids of metallic cations tend to form between pH 5 and 10 (Morel and Hering 1993). At pH levels $>10$, many transition metals and transuranic hydroxide species become increasingly more soluble. The increase in solubility results from the formation of anionic hydroxo species such as $\mathrm{Fe}(\mathrm{OH})_{4}$. As the $\mathrm{pH}$ of the plume changes from $>11$ to ambient levels, approximately $\mathrm{pH} 8.1$, some metal hydroxo solids such as $\mathrm{NpO}_{2}(\mathrm{~s})$ and $\mathrm{Fe}(\mathrm{OH})_{3}(\mathrm{~s})$ may precipitate.

Studying the precipitation of hydroxide solids as a function of $\mathrm{pH}$ is a relatively straightforward exercise because the hydroxide concentration is known immediately at any given pH (Morel and Hering 1993). This is not the case with other ligands such as carbonate, sulfide, or phosphate, whose free concentrations depend not only on $\mathrm{pH}$ but also on the total ligand concentration and perhaps on the concentration of the precipitating metals (if it is present in excess of the ligand). For example, calcite precipitation is an explicit function of $\mathrm{pH}$ : as alkaline $\mathrm{pH}$ levels decrease, calcite precipitation decreases. As the chemical composition of the Hanford vitrified waste becomes defined, the extent of precipitation that may occur in the near field and at the plume front will be estimated.

\subsection{Diffusion}

The transport of matter in the absence of bulk flow is referred to as the process of diffusion. The flux of matter due to diffusion is proportional to the concentration gradient and is a molecular process. In general terms, the flux, $\mathrm{J}_{i z}$, of component $i$ in the $z$ direction is

$$
J_{k z}=-D \frac{d n_{i}}{d z}
$$

where $\mathrm{D}$ is the proportionality constant or diffusion coefficient, with the dimensions of length $2 /$ time, $\mathrm{J}_{i z}$ has the dimensions of moles/length ${ }^{2} /$ time, $\mathrm{n}_{i}$ is the concentration of material $i$, and the negative sign indicates that flow of material $i$ in the $z$ direction is also in the direction of lower $i$ concentration. In a binary electrolyte, at infinite dilution, the aqueous diffusion coefficient is:

$$
D_{0}=\frac{2 \mu_{1} \mu_{2} R T}{\left(\mu_{1}+\mu_{2}\right) F}
$$

where $\mu_{1}$ and $\mu_{2}$ are the mobilities of the two ions ( $\mathrm{K}^{+}$and $\mathrm{Cl}^{-}$, for example, as a binary electrolyte former), RT is the gas constant times the degrees Kelvin, and F is a faraday. The dimensions of $D_{0}$ are once again length ${ }^{2} /$ time. The ionic mobilities of many ions are known (Dean 1973) in aqueous solutions. Scott et al. (1974) defines an effective or measured diffusion coefficient $\left(D_{e}\right)$ and its relation to the aqueous diffusion coefficient $\left(D_{0}\right)$ as

$$
D_{e}=\frac{D_{0}}{R_{F}}
$$


Equation 18 has been incorporated into the transport equation:

$$
\frac{\partial C}{\partial t}=\frac{D_{o}}{R_{F}} \frac{\partial^{2} C}{\partial x^{2}}
$$

where $\mathbf{R}_{F}$ is a retardation factor, as defined in Equations 5 or 8. Note that Equation 19 is similar to the Equation 6, used to evaluate the relationship between groundwater velocity and radionuclide migration velocity, only it does not contain the advection term.

Therefore, the effective diffusion coefficients for reactive constituents account for the chemical retardation as well as the physical hindrance to leaching caused by the small pore sizes and tortuosity of the waste form. Leached species may dissolve or desorb from the waste form and surrounding barrier matrix, and the solubilized wastes may then diffuse out to the surrounding sediments. Using the effective diffusion model, most radionuclides and inorganic hazardous chemicals leaching from waste forms exhibit coefficients ranging from $10^{-6}$ to less than $10^{-12} \mathrm{~cm}^{2} / \mathrm{s}$. For comparison, most cations and anions exhibit a diffusion coefficient of approximately $10^{-5} \mathrm{~cm}^{2} / \mathrm{s}$ in water (Dayal et al. 1983). The large range in the effective diffusion coefficients observed for species in solid waste forms is a reflection of the other processes, such as adsorption, precipitation, and mineral substitution, that impede the release of some constituents.

For a semi-infinite porous waste form (large inventory of contaminants), a plot of the cumulative amount of each contaminant leached versus the square root of time should be linear if diffusion is controlling and the fraction leached remains below $20 \%$. For a cylindrical waste form of semi-infinite inventory, the governing equation is

$$
\frac{\sum_{n=1}^{\infty} a_{n}}{A_{0}}=2\left(\frac{S}{V}\right) \sqrt{\frac{D_{\theta} t}{\pi}}
$$

where $a_{n}$ is the amount of contaminant leached during each interval, $A_{0}$ is the total amount of contaminant in the waste form, $V$ is the volume of waste form $\left(\mathrm{cm}^{3}\right), S$ is the geometric surface area of waste form $\left(\mathrm{cm}^{2}\right), t$ is the total elapsed time of leaching $\left[t=\Sigma \Delta t_{n}(s)\right], \Delta t_{n}$ is the time of each leach interval (s), and $\mathrm{D}_{e}$ is the effective diffusion coefficient $\left(\mathrm{cm}^{2} / \mathrm{s}\right)$. It is often found that actual leach data indicate a much faster release in the early time periods of the leach test and later satisfy the linear dependence of square root of the time parameter.

Matsuzuru and Moriyama (1982), Godbee et al. (1980), Matsuzuru and Ito (1978), and Dayal et al (1983) discuss cement waste form leach experiments that show a similar initial rapid release. Data from these studies are analyzed using linear regression of the cumulative fraction leached versus the square root of time to provide a best-fit De value (from the slope) and empirical instantaneous wash-off fraction, " $k_{o}$ ", from the intercept at $t=0$.

The actual mechanism or cause of the "instantaneous wash-off" has not been conclusively identified and perhaps could indicate that the experiments themselves do not satisfy all model assumptions. Some explanations offered include rapid dissolution of evaporated salts left on the waste form surface after curing, dissolution or resuspension of very small particles of waste form clinging to the surface, or release of material in waste form pores that directly intercept the surface (those with no tortuosity or constrictivity restraints). 
The mathematical equation that describes diffusion plus instantaneous wash-off is

$$
\frac{\sum_{n=1}^{\infty} a_{n}}{A_{0}}=2\left(\frac{S}{V}\right) \sqrt{\frac{D_{e} t}{\pi}}+k_{0}
$$

where $\mathbf{k}_{\mathbf{d}}=$ constant.

For constituents that leach a significant portion of the total inventory during laboratory testing, the semi-infinite condition is not appropriate. The American Nuclear Society (ANS 1986) presents a discussion that shows that Equation 20 deviates from actual data when the cumulative fraction leached exceeds $20 \%$. For finite cylindrical waste forms that contain a uniform concentration and a surface boundary concentration of zero at all times, the following mathematical expression is valid:

$$
\frac{\sum a_{n}}{A_{0}}=1-\frac{32}{\pi r^{2}} \sum_{n=1}^{\infty} \sum_{m=1}^{\infty} \frac{e^{\left.-D_{\alpha}\left[\alpha_{m}^{2}+(2 n-1)^{2} \pi^{2} 4\right\}^{2}\right\} t}}{(2 n-1)^{2} \alpha_{m}^{2}}
$$

where $\mathbf{r}=$ radius of the cylinder $(\mathrm{cm})$

$l=$ half-height of the cylinder $(\mathrm{cm})$

$\alpha_{m}=$ positive roots of the zero-order Bessel function

$$
J_{0}\left(r \alpha_{m}\right)=0\left(\mathrm{~cm}^{-1}\right) \text {. }
$$

Côté et al. (1987) derive several leaching models for cement-based waste forms based on bulk diffusion (Equations 20 and 21), bulk diffusion plus chemical reaction in which the chemical reaction is either an instantaneous equilibrium linear adsorption isotherm or first-order surface dissolution (i.e., moving boundary), and interface mass resistance.

From a practical point, Côté et al. (1987) presents a semi-empirical leach model that combines the general mathematical forms of these different conceptual models. The equation is

$$
\frac{\sum a_{n}}{A_{0}}=k_{1}\left(1-e^{-k_{2} t}\right)+k_{3} t^{0.5}+k_{4} t
$$

where $k_{1}, k_{2}, k_{3}, k_{4}$ are empirical constants.

The first term on the right-hand side of Equation 23 describes the kinetics of exchange of species between the surface of the solid waste form and solution (pore water or leachant). When the exchange is fast, $k_{2} \rightarrow \infty$ and the term reduces to a constant $\left(k_{1}\right)$ akin to the instantaneous wash-off. 
term in Equation 21. The second term on the right-hand side of Equation 23 is the bulk diffusion term. When diffusion dominates the semi-empirical constant, $k_{3}$, is related to the $D_{e}$ (Equation 20) by the relationship

$$
k_{3}=2 \frac{S}{\nabla} \sqrt{\frac{D_{\theta}}{\pi}}
$$

The third term in Equation 23 represents leaching from a slow chemical reaction such as corrosion or structural breakdown of the waste form matrix, which releases species. In addition to the diffusioncontrolled release models, there are solubility-controlled release models (see Section 2.2) and desorption-controlled release models (see Section 2.1 ).

In the unsaturated sediments underneath the protective barrier where contaminants are considered to migrate predominately by diffusion, the effective diffusion coefficient is varied as a function of soil moisture content:

$$
\mathrm{D}_{\text {Soil }}=\mathrm{D}_{\mathrm{o}} \mathrm{ae^{ \textrm {b \theta } }}
$$

where $D_{0}$ is the diffusion coefficient of a typical species in dilute water $\left(2.5 \times 10^{-5} \mathrm{~cm}^{2} / \mathrm{s}\right)$, $a$ is an empirical constant $(0.003), \mathrm{b}$ is another empirical constant $(10)$, and $\theta$ is the volumetric water content of soil $\left(\mathrm{cm}^{3} / \mathrm{cm}^{3}\right)$ which should be greater or equal to 0.05 for use in Equation 25 . For additional information about the empirical relationship described in Equation 25 see Kemper and Van Schaik (1966) and Olsen and Kemper (1968). Another soil-diffusion model often used is the Scheidegger model (Scheidegger 1961) which actually includes hydrodynamic dispersion. Without dispersion effects, the molecular diffusion alone is given by

$$
D_{\text {soil }}=D_{0} \theta \tau
$$

where $\tau$ is the tortuosity factor. Equation 25 approximates the tortuosity factor times the moisture content, $\theta \tau$, by $a e^{b \theta}$ for moisture contents greater than $5 \%$. Except for extremely low recharges (less than $0.1 \mathrm{~cm} / \mathrm{yr}$ ), dispersion effects will dominate the diffusion effects in soils. It is believed that by ignoring dispersion in the transport models, the contaminant plumes will not spread out as much and result in higher (more conservative) concentrations in the groundwater. Other vadosezone diffusion models have been proposed and they have been reviewed in Serne and Wood (1990).

\subsection{Subsurface Mobile Colloids}

\subsubsection{Concept of Three-Phase Solute Transport}

Contaminant transport models generally treat the subsurface environment as a two-phase system in which contaminants are distributed between a mobile aqueous phase and an immobile solid phase (sediment). Contaminants with a high affinity for sorbing to rock or vadose zone sediments are assumed to be retarded relative to the rate of groundwater flow. However, an increasing body of evidence indicates that under some subsurface conditions, components of the solid phase may exist as 
colloids and particles suspended in and transported with the flowing water. Association of contaminants with this additional mobile phase may enhance the rate of contaminant transport; conversely, deposition of the colloidal particles may reduce the permeability of a formation and thereby decrease transport. Accurate assessment of current contamination problems and performance assessment of containment and disposal options requires fundamental understanding of the potential role of colloidal particles in enhancing or diminishing contaminant transport in the subsurface.

\subsubsection{Sources of Groundwater Mobile Colloids}

Subsurface mobile colloids originate from 1) the dispersion of surface or subsurface sediments, 2) de-cementation of secondary mineral phase, and 3) homogeneous precipitation of groundwater constituents. First, colloidal particles can be dispersed and become mobile in aquifers as a result of changes in the groundwater chemistry such as a decrease in ionic strength or changes in ionic composition from calcium- to sodium-dominated chemistry. The effect of sodium and ionic strength on colloid suspension stability is interactive such that the dispersive quality of sodium is enhanced at low salt levels (Kaplan et al. 1995b). Although the plume from the vitrified waste will contain very high concentrations of $\mathrm{Na}$ (preliminary estimates indicate that the plume will contain $1.6 \mathrm{M} \mathrm{Na}^{+}$), (McGrail 1994), it will also possess the colloid suspension/destabilizing characteristic of high salt concentrations.

Second, colloidal particles may be immobilized within aquifers by secondary mineral phases that cement the colloids to each other and to the larger mineral grains. Geochemical or microbiological changes that result in dissolution of these cementing phases can result in release of colloids. For example, Gschwend et al. (1990) observed 10 to $100 \mathrm{mg} / \mathrm{L}$ of silica colloids in groundwater receiving recharge from evaporation ponds and a fly ash basin. The infiltrate was enriched in carbon dioxide that dissolved the soil-cementing carbonate mineral, thus releasing the silica colloids. The third source of groundwater mobile colloids is homogeneous precipitation. Changes in groundwater geochemical conditions such as $\mathrm{pH}$, major element composition, redox potential, or partial pressures of $\mathrm{CO}_{2}$ can induce supersaturation and coprecipitation of colloidal particles. The precipitates can include major elements such as oxides of iron and manganese, calcium carbonates, and iron sulfides, as well as minor elements such as carbonates and sulfides of radionuclides. Mobile colloid precipitates may form when soluble contaminants are introduced into a system resulting in their exceeding the solubility product. For example, Gschwend and Reynolds (1987) observed precipitation of ferrous phosphate colloids ( 1 to $10 \mathrm{mg} / \mathrm{L}$ of $100 \mathrm{~nm}$-sized particles) down gradient of a sewage infiltration site. Solubility calculations suggested that the dissolved phosphate ions from the sewage and reduced iron in the aquifer exceeded the solubility product of ferrous phosphate, resulting in the formation of insoluble colloids. Other studies have documented the formation of iron oxide colloids in groundwater as a result of changes in $\mathrm{pH}$ and oxygenation that caused the solubility limit of Fe(III) to be exceeded (Liang et al 1993). Many strongly hydrolyzing radionuclides also form submicronsized particles. Increases in solution $\mathrm{pH}$ have been shown to induce the formation of $\mathrm{Pu}-, \mathrm{U}-$, and Am-oxide colloids in carbonate systems (Kim 1986, Ho and Miller 1986). Robertson (1974) determined the speciation of $\mathrm{Np}$ in the cooling water effluent from the Hanford $\mathrm{N}$ Reactor. Through the use of ultrafiltration and cation and anion exchange resins, the following distribution was observed: $25 \%$ particulate, $70 \%$ cationic, $<3 \%$ anionic and $<1 \%$ non-ionic. The fact that Np may become associated with a particulate phase provides some evidence that $\mathrm{Np}$ has the capability to be transported in association with a mobile colloid. Sheppard et al. (1976) reported Np colloids present in the soil solution environment, while Routson et al. (1976) specifically showed that they were absent from his solutions that had contacted soils. As a first approximation, inorganic colloidal precipitates might be 
the only source for mobile colloids in the Hanford LLW far field because naturally occurring organic substances (the primary detrital mobile solid) exist in very low concentration in the vadose zone of the Hanford Site.

Precipitation may be the primary sources for mobile colloids in the Hanford vadose zone because such colloids tend to be smaller $(<100$-nm diameters) than those originating from detrital matrix materials (>200-nm diameters) (McCarthy and Degueldre 1993, Ho and Miller 1986, Kaplan et al. 1994). The question of whether precipitation/coprecipitation of radionuclides is thermodynamically likely must be resolved once more information becomes available about the composition of the contaminant plume.

\subsubsection{Case Studies of Mobile-Colloid Enhanced Transport of Radionuclides}

The role of colloids in facilitating contaminant transport is poorly understood. Attention has recently been directed at understanding this and the environmental conditions conducive to its occurrence because failure to account for this mode of transport can lead to serious underestimates of the distance that contaminants will migrate (McCarthy and Degueldre 1993). For example, although laboratory studies at Los Alamos National Laboratory predicted that the movement of actinides in subsurface environments would be limited to less than a few meters, both Am and Pu were detectable in monitoring wells as far as $3390 \mathrm{~m}$ down gradient from the point source (Penrose et al. 1990). Almost all of the Am and $\mathrm{Pu}$ in the groundwater at the $3390 \mathrm{~m}$ well were associated with colloids 0.025 to $0.45 \mu \mathrm{m}$ in diameter. Similarly, based on laboratory measurements using site-specific sediments and a two-phase solute transport code $\mathrm{Am}, \mathrm{Cm}, \mathrm{Pu}$, and $\mathrm{U}$ were expected to travel less than $10 \mathrm{~m}$ in the F-Area of the Savannah River Site; the contaminants were found associated with groundwater colloids $1200 \mathrm{~m}$ away from the point source (Kaplan et al.1995a).

There have been four field studies providing circumstantial evidence that mobile colloids may be involved in enhancing radionulcide transport though the subsurface (Buddemeier and Hunt 1988, Degueldre et al. 1989, Penrose et al. 1990, Kaplan et al. 1995). No mobile colloid studies have been reported at the Hanford Site. Few field studies have been conducted, primarily because of the difficulty of obtaining groundwater samples without creating colloidal artifacts. Also, it is difficult to definitively determine if mobile colloids are, in fact, the transport vector or if some other form of enhanced transport may be in place such as preferential flow or complexation with natural or anthropogenic organic compounds.

\subsection{Anion Exclusion}

Chloride, $\mathrm{Br}$, and $\mathrm{NO}_{3}$ are usually reported to travel through natural systems or soil columns at the same rate as, or faster than, water (McMahon and Thomas 1974, James and Rubin 1986). Anion exclusion, the mechanism by which anions move faster than water, occurs when the diffuse double layer, an extension of a particle's negative surface charge into the surrounding solution, repulses anions (Sposito 1984). By excluding anions from the diffuse double layer, where water is relatively immobile, the system restricts anions to the faster moving pore water, resulting in an average rate of anion transport that is greater than the average pore water velocity defined by Darcy's Law (McMahon and Thomas 1974, James and Rubin 1986). The higher the cation exchange capacity (negative charge) of the soil or rock, the more pronounced the anion exclusion. For example; smectites exhibit anion exclusion to a greater degree than do the kaolinite minerals (McMahon and Thomas 1974). 


\subsubsection{Evidence of Anion Exclusion in Hanford Sediments}

There are a number of reason why anion exclusion of ${ }^{99} \mathrm{Tc}$ and ${ }^{129} \mathrm{I}$ may not be expected to occur in the unsaturated zone at the Hanford Site. Unsaturated conditions appear to be less favorable for anion exclusion because there is less faster moving water in the middle of the pore spaces. Also, there is evidence of some anion sorption in subsurface Hanford sediments, more so for iodide/iodate than for $\mathrm{TcO}_{4}^{-}$(Gee and Campbell 1980, Delegard et al. 1981, Gee et al. 1981, Wildung et al. 1986). Anions may sorb to positively charged sites in organic matter (though there is not much organic matter in the Hanford subsurface) and Al- and Fe-oxides. The number of charged sites increase as $\mathrm{pH}$ decreases (see Section 3.1). Iodide has $K_{d}$ values between 0 to $18 \mathrm{~mL} / \mathrm{g}$ in Hanford sediments (Gee and Campbell 1980, Serne et al. 1993). Pertechnetate- $K_{d}$ values measured by the batch technique are between the 0 and $1.3 \mathrm{~mL} / \mathrm{g}$ (Gee and Campbell 1980, Serne et al. 1993). Anion exclusion could not be detected by the common $\mathrm{K}_{\mathrm{d}}$ laboratory method.

The implication of anion exclusion for anionic radionuclides and anionic complexes of radionuclides is that they may be able to travel through the subsurface at a rate greater than water. There is some indirect evidence that anion exclusion may exist for pertechnetate. In the only unsaturated column study conducted in Hanford sediments, pertechnetate breakthrough $\left(C / C_{0}, 0.5\right)$ occurred at 0.95 pore volumes, whereas for tritium, a conservative tracer, breakthrough occurred at 1.02 pore volumes; that is, pertechnetate may have travelled 5\% faster than tritium (Gee and Campbell 1980). As an aside, $\mathrm{Cl}$ breakthrough in these columns occurred at 0.80 , or $22 \%$ faster than tritium, providing evidence that anion exclusion may exist for some anions in this Hanford sediment system. 


\subsection{Key Contaminants}

This section provides a brief description of the geochemistry of radionuclides identified by preliminary subsurface transport simulations as potentially presenting the greatest health risk. Emphasis is placed on describing the chemical processes relevant to the Hanford unsaturated zone, which is a coarse-sand textured, alkaline, carbonate, sediment with low natural organic matter concentrations. Geochemical information relevant to other environments, such as reducing environments, is also provided to address possible near-field systems.

\subsection{Inventory}

The amount of each radionuclide in the vitrified waste is not entirely known because tank-bytank inventories of the radionuclides are not presently available. However, overall reactor production records are accurate enough to establish reasonable total tank waste inventory estimates for most of the fission products and $U$. The loss of fission products, particularly I and Tc, by material processing, or by loss of soluble contaminant inventory via tank leaks have introduced uncertainty into the actual inventory. Although these losses are likely to be significant, are not generally included in inventory calculations, thereby providing the most conservative estimates. Much of the Cs and Sr produced in the reactors was separated in previous chemical processing campaigns at the Hanford Site. Following pretreatment, vitrification of the LLW stream is expected to result in volatilization of some species, notably C, Cs, I, selenium, and potentially Tc (depending upon melter oxidation potential and other operating conditions.) The amount of volatilization is highly uncertain and therefore conservative estimates assume volatilization occurs only for $\mathrm{C}$.

\subsection{Geochemical Behavior of Key Radionuclides}

\subsection{1 lodine}

There are 24 known isotopes of I with 18 of these isotopes having half-lives of less than 1 day. The only stable isotope is ${ }^{127} \mathrm{I}$. Its average natural abundance in geologic materials is $5 \mathrm{mg} / \mathrm{kg}$ (Gu and Schulz 1991), and its concentration in uncontaminated surface waters is typically $<1 \mathrm{mg} / \mathrm{L}$ (Stumm and Morgan 1981). The isotope of concern for long-term disposal at the Hanford Site is ${ }^{129} \mathrm{I}$, which has a half-life of $1.7 \times 10^{7}$ years. Iodine is also a volatile element, subliming at atmospheric pressures without melting.

\subsubsection{Aqueous Speciation}

Iodine usually exists in fresh water in the (-I) oxidation state as iodide (I-) (Whitehead 1984). In alkaline and marine environments, I usually exists in the (VII) oxidation state as iodate $\left(\mathrm{IO}_{3}^{-}\right)$ (Whitehead 1984). The other oxidation states of $I$, (III) and (V), are much less frequently found in nature. Iodide is likely to be the dominant I species in the Hanford subsurface because its domain of predominance extends throughout the $\mathrm{pH}$ scale, completely covering a large part of the stability 
domain of water (Figure 3.1) (Pourbaix 1966, Ticknor and Cho 1990). Oxidation of $I_{2}$ to produce $\mathrm{IO}_{3}$, the second most abundant form of $\mathrm{I}$ in aqueous systems, is easily accomplished in basic solution by the reaction:

$$
3 \mathrm{I}_{2}+6 \mathrm{OH}^{-}=5 \mathrm{I}^{-}+\mathrm{IO}_{3}^{-}+3 \mathrm{H}_{2} \mathrm{O}
$$

(Cotton and Wilkinson 1972). Thus, the $\mathrm{IO}_{3}^{-}$form of iodine is likely dominant in well-oxidized, high-pH systems as may exist in the far field within the plume emanating from the LLW glass. Iodide and $\mathrm{IO}_{3}$ were the most commonly detected species in rainwater collected after the Chernobyl accident (Muramatsu et al. 1990). Iodide and $\mathrm{IO}_{3}^{-}$tend to exist as free ions, but the complexes they do form are generally the most soluble of all halide complexes.

\subsubsection{Precipitation and Coprecipitation}

Precipitation and coprecipitation is not likely to be a dominant reaction path for I in the far field. Iodide, in comparison with the other halides, forms especially weak complexes with metal ions as a result of its large size $\left(0.22-\mathrm{nm}\right.$ ionic radius, Langmuir 1979). The metals which $\mathrm{I}^{-}$and $\mathrm{IO}_{3}^{-}$form sparingly soluble compounds, $\mathrm{Ag}, \mathrm{Ba}, \mathrm{Hg}, \mathrm{Pb}$, and $\mathrm{Pd}$ (Pourbaix 1966), are likely to exist in the contaminant plume at very low concentrations, and therefore, these precipitates are not anticipated to exist in the contaminant plume. The low concentrations of $I$ in the contaminant plume will likely exist as either free species or as highly soluble complex species.

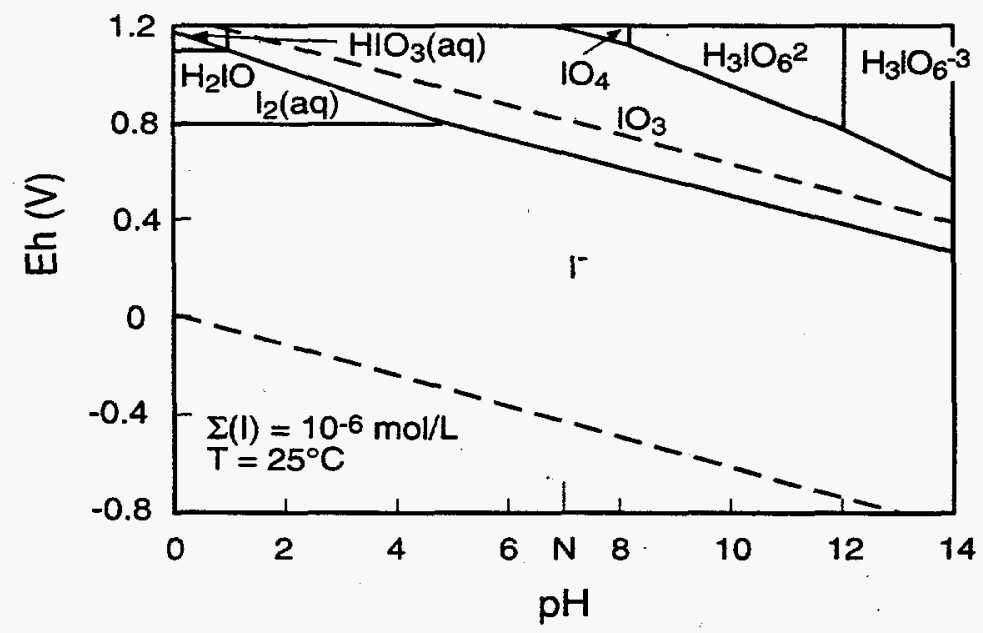

$\$ 9409045.3$

Figure 3.1. Eh and pH Diagram for Iodine/Water System (Ticknor and Cho 1990) 


\subsubsection{Sorption}

Two types of reactions between anions and inorganic solids are recognized: specific adsorption and nonspecific adsorption (see Section 2.1). Specific adsorption refers to incorporation of anions as a ligand in the coordination shell of an adsorbent, while nonspecific adsorption refers to adsorption of anions by simple coloumbic (electrostatic) interactions with positive charges. Iodine anions are believed to sorb primarily through nonspecific, anion-exchange reactions on mineral surfaces $(\mathrm{Gu}$ and Schulz 1991) and through specific adsorption on organic substances (Walters and Winchester 1971). Nonspecific sorption may occur at the localized positive charges that occur on 1) Fe- and Aloxide surfaces, 2) edges of aluminosilicate clay surfaces where the oxygen atoms are not fully coordinated by $\mathrm{Al}$ or $\mathrm{Si}$ atoms, and 3) on amine and amino groups of organic substances. These positive charges, which increase with decreasing $\mathrm{pH}$ (see Sections 2.1 and 2.5), attract anions electrostatically. Whitehead (1973), for example, reported that sorption of I- by soils was associated with both soil organic matter and $\mathrm{Fe}$ and $\mathrm{Al}$ oxides, with the oxides increasingly important under more acidic conditions. The maximum amounts sorbed by two surface soils was at $\mathrm{pH}$ 6.6. At this $\mathrm{pH}$, the amounts of I- sorbed were found to be closely related to the contents of organic matter but not to Fe- or Aloxides or clay. At $\mathrm{pH}<5$, the removal of $\mathrm{Fe}$ - and Al-oxides resulted in a marked reduction in $\mathrm{I}^{-}$ sorption. Whitehead (1974) further observed that freshly precipitated ferric- and Al-oxides sorbed substantial amount of $\mathrm{I}^{-}$from solutions of $\mathrm{pH}<5.5$ but the amount decreased to zero as the $\mathrm{pH}$ approached 7. Presumably, this trend reflects the presence of an increasing amount of positive charge (anion-exchange capacity) on the amphoteric oxide surfaces at lower $\mathrm{pH}$ levels.

Ticknor and Cho (1990) studied the interaction of $\mathrm{I}^{-}$and $\mathrm{IO}_{3}$ over a pH range of 7.5 to 8.0 with a number of minerals including calcite, chlorite, epidote, goethite, gypsum, hematite, kaolinite, bentonite, muscovite, and quartz. No detectable I- sorption was detected from any of the solutions on any of the minerals. Iodate was removed from solution to a somewhat greater extent than $\mathrm{I}$. $\mathrm{No}^{\mathrm{O}} \mathrm{O}_{3}$ was adsorbed by bentonite, calcite, gypsum, and muscovite. Muramatsu et al. (1990) reported that neither $\mathrm{I}^{-}$nor $\mathrm{IO}_{3}$ sorbed to quartz sand. The authors concluded that the low $\mathrm{I}^{-}$and $\mathrm{IO}_{3}$ sorption was the result of the low anion-exchange capacities of the minerals at the high $\mathrm{pH}$ of the systems in the investigation. Hanford subsurface sediments sorb only trace amounts of iodide from solution (Gee and Campbell 1980, Serne and Wood 1990). Additional information about iodide sorption to Hanford sediments is presented in Section 6.1.

\subsubsection{Neptunium}

There are 16 known isotopes of $\mathrm{Np}$ from ${ }^{228} \mathrm{~Np}$ to ${ }^{241} \mathrm{~Np}$ (Keller, 1971). Only ${ }^{237} \mathrm{~Np}$, a neutron reactor product of ${ }^{238} \mathrm{~Np}(\mathrm{n}, 2 \mathrm{n})$, and ${ }^{235} \mathrm{~Np}(\mathrm{n}, \gamma)$, with a half-life of $2.14 \times 10^{6}$ years, are of interest.

\subsubsection{Aqueous Speciation}

Neptunium exists in aqueous solutions in five oxidation states, $\mathrm{Np}$ (III), $\mathrm{Np}(\mathrm{IV}), \mathrm{Np}(\mathrm{V}), \mathrm{Np}(\mathrm{VI})$, and $\mathrm{Np}$ (VII). In the absence of complexing agents, the first four oxidation states exist as hydrated ions $\mathrm{Np}^{+3} \cdot \mathrm{H}_{2} \mathrm{O}, \mathrm{Np}^{+4} \cdot \mathrm{H}_{2} \mathrm{O}, \mathrm{NpO}+\mathrm{H}_{2} \mathrm{O}, \mathrm{NpO}_{2}^{2} \cdot \mathrm{H}_{2} \mathrm{O}$ (Ames and Rai 1978). $\mathrm{Np}$ (VII) is a strong oxidizing agent that is stable in strong alkaline solution as $\mathrm{NpO}_{5}^{-3}$. The most stable oxidation state in solution is the pentavalent one in which $\mathrm{Np}$ exists as a single charged neptunyl ion, $\mathrm{NpO}_{2} \cdot \mathrm{aq}$, with symmetrical linear bonding $(\mathrm{O}-\mathrm{Np}-\mathrm{O})^{+}$. It hydrolyses only at a $\mathrm{pH}$ of greater than 7 , disproportionates only at high-acid concentrations, and forms no polynuclear complexes (Keller 1971). The $\mathrm{NpO}_{2}$ ion is a poor complexing agent with inorganic ligands. 


\subsubsection{Preclpitation and Copreclpltation}

In an oxidizing environment, the solids in an increasing order of stability are $\mathrm{Np}(\mathrm{OH})_{4}, \mathrm{NpO}_{2}$, $\mathrm{NpO}_{2} \mathrm{OH}$, and $\mathrm{NpO}_{2}(\mathrm{OH})_{2}$. Because $\mathrm{NpO}_{2}$ can maintain a very high concentration of $\mathrm{Np}$ in solution, it is unlikely that $\mathrm{NpO}_{2}$ would be found as a discrete solid in terrestrial environments. It may exist in very reducing conditions. $\mathrm{NpO}_{2}^{+}$is the usual $\mathrm{Np}$ species between $\mathrm{pH} 0$ to 9 (Ames and Rai 1978). Above $\mathrm{pH} \mathrm{9,} \mathrm{an} \mathrm{uncharged} \mathrm{bicarbonate} \mathrm{complex} \mathrm{is} \mathrm{formed.} \mathrm{According} \mathrm{to} \mathrm{Keller} \mathrm{(1971),} \mathrm{Np}(\mathrm{V})$ does not hydrolyze below a $\mathrm{pH}$ of 7 .

\subsubsection{Sorption}

A singly charged neptunyl ion, $\mathrm{NpO}_{2}^{ \pm}$, is likely the dominant species of $\mathrm{Np}$ in oxidized groundwater and would be expected to enter into ion exchange reactions (Ames and $\mathrm{Rai} 1978$ ). $\mathrm{NpO}_{2}^{\ddagger}$ does not compete favorably with $\mathrm{Ca}^{2+}$ and other common divalent ions, and the distribution coefficients are usually relatively low in most soils (Routson et al. 1976, Sheppard et al. 1976). Benson (1961) examined the adsorption on minerals of $\mathrm{Np}$ in reactor effluent cooling water. Neptunium was adsorbed on 25 common sulfide, silicate, and carbonate minerals, from 0.05 to $0.25 \mathrm{~mm}$, in equilibrium tests with trace amounts of $\mathrm{Np}$ in Columbia River water at $80^{\circ} \mathrm{C}$. Neptunium was adsorbed poorly or not at all by the minerals tested. Robertson (1974) determined the speciation of $\mathrm{Np}$ in the cooling water effluent from the Hanford N Reactor. Through the use of ultrafiltration and cation and anion exchange resins, the following distribution was observed: $25 \%$ particulate, $70 \%$ cationic, $<3 \%$ anionic, and $<1 \%$ non-ionic. The fact that $\mathrm{Np}$ may become associated with a particulate phase may have significant ramifications regarding the potential role of subsurface mobile colloids in enhancing contaminant transport (see Section 2.4). A few studies have been conducted to evaluate the propensity of Np to sorb to Hanford sediments (Routson et al. 1976, Seme et al. 1993). These studies will be discussed in Section 6.4.

\subsubsection{Selenium}

Selenium-79 is a long-lived fission product with a half-life of $6.5 \times 10^{4}$ years. It is commonly found as a fission product in spent fuel elements. The stable, nonradioactive form of Se is ubiquitous, especially in the westem U.S. After nonradioactive Se was found to be the cause of reduced fecundity of migrating birds in the mid-1980s, much research was directed at understanding the environmental fate of Se.

\subsubsection{Aqueous Speciation}

Selenium exists in natural aqueous environments in $-2,+4$, and +6 valence states. Most of the $\mathrm{Se}$ species in the environmental $\mathrm{Eh}$ and $\mathrm{pH}$ range (4 to 10) exist as anions: selenate [Se(VI)] or senenite [Se(IV)]. Under reducing conditions, $\mathrm{H}_{2} \mathrm{Se}^{0}$ would dominate below $\mathrm{pH} 3.8$ and $\mathrm{HSe}$ - would dominate above pH 3.8 (Rai and Zachara 1984). The selenite species would predominate under intermediate to slightly oxidizing conditions. Highly oxidizing conditions $(\mathrm{pe}+\mathrm{pH}>15)$ are necessary for $\mathrm{SeO}_{4}^{2-}$ to form to a significant extent. Selenate and selenite may form ion-pair species with $\mathrm{Ca}^{2+}$. Although some of the studies indicate precipitation may occur, no definitive information on solubility-controlling solids is available. Solid phases in order of increasing solubility are $\mathrm{FeSe}_{2}$, 
$\mathrm{FeSe}, \mathrm{CuSe}$, and $\mathrm{Se}$ (c) (Rai and Zachara 1984). If an Fe oxide less soluble then $\mathrm{Fe}(\mathrm{OH})_{3}(\mathrm{am})$ were chosen to control $\mathrm{Fe}^{2+}$ activity, then the solubilities of $\mathrm{FeSe}_{2}$ and FeSe would increase. However, the solubility product, $\mathrm{K}_{\mathrm{sp}}$, for $\mathrm{FeSe}_{2}$ is not well-defined.

\subsubsection{Precipitation and Coprecipitation}

Although several solid phases (such as $\mathrm{Se}(\mathrm{c})$ and $\mathrm{FeSe}_{2}$ ) are predicted to be stable under relatively reducing conditions, and some studies indicate precipitation may be occurring, no definitive information on solubility-controlling solids is available. $\mathrm{Fe}(\mathrm{OH})_{4} \mathrm{SeO}_{3}$ was proposed (Geering et al. 1968) to help explain the insolubility of Se in soils as well as the strong association of Se with $\mathrm{Fe}$ in precipitates. Benjamin and Bloom (1981) observed that metal ion adsorption onto amorphous iron oxyhydroxide was enhanced in the presence of adsorbed Se. It was postulated that the enhanced metal absorption was the result of the formation of an Fe-Se solid phase on the oxyhydroxide surface. Benjamin and Bloom (1981) observed that selenite was irreversibly adsorbed on crystalline iron oxide surfaces (goethite, hematite), which is an indication of the possible formation of a solid phase.

\subsubsection{Sorption}

Laboratory studies indicate that, in spite of their anionic nature, selenite and selenate may be adsorbed significantly by some soils. The experimental evidence suggests that cryptocrystalline and amorphous forms of $\mathrm{SiO}_{2}, \mathrm{Al}_{2} \mathrm{O}_{3}$, and $\mathrm{Fe}_{2} \mathrm{O}_{3}$ control Se adsorption (John et al. 1976, Singh et al. 1981). Studies with pure mineral phases demonstrate that hydrous oxides of $\mathrm{Fe}$ an $\mathrm{Al}$ and amorphous aluminosilicates have a high affinity for Se(IV, VI) (Leckie et al. 1980, Hingston et al. 1968), which significantly exceeds that of layer lattice silicates (Frost and Griffin 1977, Hamdy and GisselNelson 1977). Though selenite $\left(\mathrm{pK}_{2}: 7.9\right)$ and selenate $\left(\mathrm{pK}_{2}: 1.7\right)$ differ appreciably in their acidity, little difference is seen in their adsorption by soil (Singh et al. 1981). Selenate may be adsorbed more strongly by clay minerals than selenite (Frost and Griffin 1977), while the inverse applies to hydrous oxides of Fe (Leckie et al. 1980, Benjamin and Bloom 1981).

The adsorption of Se(IV) and Se(VI) on goethite, amorphous iron oxyhydroxide, and gibbsite is strongly pH dependent (Hingston et al. 1968, Leckie et al. 1980, Hingston et al. 1972). These anions are strongly sorbed under acidic conditions, but fractional sorption decreases with increasing $\mathrm{pH}$. Limited experimental evidence suggests that, at a given $\mathrm{pH}, \mathrm{Se}$ adsorbs to neutral and positively charged amphoteric oxide surfaces displacing water, hydroxyls, and other adsorbed ligands (e.g., sulfate, silicate) until the surface is neutral in charge (Rajan 1979).

The presence of competing anions may reduce Se(IV) and Se(VI) adsorption by using limited ligand exchange sites and reducing surface net positive charge. Phosphate reduces Se adsorption on goethite, though some sites are specific to Se (Hingston et al. 1971). Sulfate reduces $\mathrm{SeO}_{4}^{2-}$ adsorption on amorphous iron oxyhydroxides in a manner consistent with the competitive Langmuir equation (Leckie et al. 1980).

\subsubsection{Technetium}

All isotopes of Tc are radioactive. Several Tc isotopes are obtained by the fissioning of nuclear fuels of $U$ in the reactor. The Tc isotopes and their yields resulting from $U$ fission include: ${ }^{99} \mathrm{Tc}$, 
$6.06 \% ;{ }^{101} \mathrm{Tc}, 5.6 \% ;{ }^{102} \mathrm{Tc}, 4.3 \% ;{ }^{103} \mathrm{Tc}, 3.0 \% ;{ }^{104} \mathrm{Tc}, 1.8 \% ;{ }^{105} \mathrm{Tc}, 0.9 \%$, and ${ }^{106} \mathrm{Tc}, 0.19 \%$ (Coughtrey et al. 1983). Of these fission products, only ${ }^{99} \mathrm{Tc}$ is a potential hazard from long-term burial of LLW because this isotope has a long half-life $\left(2.12 \times 10^{5}\right.$ years $)$.

\subsubsection{Aqueous Speciation}

Technetium exists in valence states from (VII) to (-I). The most stable and characteristic oxidation state of $\mathrm{Tc}$ in slightly acid, neutral, or basic aqueous solution in equilibrium with the atmosphere is the pertechnetate ion $\left(\mathrm{TcO}_{4}\right)$ in which $\mathrm{Tc}$ is in its heptavalent state (Coughtrey et al. 1983, Hanke et al. 1986). Various Tc(V), Tc(IV), or Tc(III) species may be formed under reduced conditions (Pilkington 1990). However, the most stable of these reduced oxidation states is generally Tc(IV) (Bondietti and Francis 1979). The nature of the Tc(IV) species is uncertain: the most common species is $\mathrm{TcO}_{2}(\mathrm{~s})$ (Bondietti and Francis 1979, Gu and Schulz 1991). The reduced Tc species are rapidly oxidized to Tc(VII) by atmospheric oxygen (Coughtrey et al. 1983), and therefore, regardless of the oxidation state of the Tc emanating from the near field, it is likely to be in the (VII) oxidation state once it reaches the far field.

The pertechnetate ion is highly soluble (Baes and Mesmer 1976, Pilkington 1990). In alkaline solutions and at low redox potential, the $\mathrm{Tc}$ (IV) species are more prevalent and its complexes are typically much less soluble, in the order of $10^{-7}$ to $10^{-8} \mathrm{~mol} \mathrm{L-1}$ over a range from pH 4 to 10 (Pilkington 1990). In the presence of air, Hanke et al. (1986) found that the solubility of $\mathrm{TcO}_{2}$ depended on the mass of $\mathrm{TcO}_{2}$, and that it increased linearly with time. The solubility of Tc in contact with hydrated $\mathrm{TcO}_{2}$ was investigated by Pilkington (1990). He found that pH had little effect on the measured solubility of Tc over the range of 1 to 12.5. However, the presence of organic materials increased the measured solubility of $\mathrm{Tc}$ by a factor of 10 , indicating that complexation between the dissolved organic materials and the Tc is important. Wildung et al. (1986) suggested that low molecular weight organic ligands may increase the solubility of reduced forms of Tc, whereas complexation with the higher molecular weight organic ligands, particularly insoluble organic ligands, may lead to insolubilization. Schulte and Scoppa (1987) showed that Tc(IV) had a strong tendency to coordinate with ligands containing highly polar groups and positively charged ligands.

\subsubsection{Preclpitation and Copreclpltation}

Precipitation of $\mathrm{TCO}_{4}$-containing solids is not likely to be an important geochemical process affecting ${ }^{99} \mathrm{Tc}$ transport through the Hanford vadose zone. Technetium(VII) forms very soluble oxides and halide complexes (Baes and Mesmer 1976). However, if Tc(VII) is reduced to Tc(IV) in the near field, it may form a number of sparingly insoluble complexes such as $\mathrm{TcO}_{2}$ or $\mathrm{Tc}$-sulfide solids.

\subsubsection{Sorption}

A number of studies have shown that retention of Tc by solid phases is related to the physicochemical properties of the solid phase (reviewed by Ames and Rai 1978, Gu and Schulz 1991). These studies indicate that the retention of Tc is largely determined by the oxidation states of the system, due to the vast difference in the solubility between $\mathrm{Tc}$ (VII) and Tc(IV)-containing compounds. These studies also indicate that systems containing low amounts of clay, organic carbon, and $\mathrm{Al} / \mathrm{Fe}$ oxides show very little adsorption, whereas those containing relatively high amounts of clay, organic carbon, and Al/Fe oxides can sorb substantial higher amounts of Tc. Bowen (1966) reported that in oxic conditions, $90 \%$ of added $\mathrm{TcO}_{4}$ was readily extractable from soils and assumed 
to remain in solution either as the free ion or weakly adsorbed to ion-exchange sites. Similarly, Wildung et al. (1977) reported that under oxic conditions, 78 to $88 \%$ of the $\mathrm{TcO}_{4}$ added to soil could be extracted easily 30 days after application. Under anaerobic conditions, Cataldo et al. (1978) reported that Tc removal from solution by soils could exceed $97 \%$ in 2 to 5 weeks.

In a study of 7 mineral soils and 27 organic soils, Sheppard et al. (1990) reported that in addition to the redox status, the organic matter content of soils play an important role in Tc sorption. Evidence of the complexation between organic materials and Tc has also been presented by Van Loon et al. (1986). They indicated that such complexes can be readily synthesized by chemical reduction in the presence of organic matter.

Reduced Tc species as precipitates or organic matter-Tc complexes are not resolubilized by the chelating agent EDTA and DTPA, which are known to from stable Tc complexes (Stalmans et al. 1986). This would indicate that EDTA and DTPA complexes cannot match the stability of the Tc-organic matter complexes, suggesting that naturally occurring organic matter plays a significant role by forming relatively stable Tc (with reduced valence state) complexes. Whether these complexes are soluble or insoluble, depends on the size of the organic ligand. It is not known whether the organic matter - Tc(IV) complexation reaction can favorably compete with Tc(IV) hydrolysis.

\subsubsection{Uranium}

The natural abundance of $U$ in geologic matter is about $3 \mathrm{mg} / \mathrm{kg}$ (Ames and Rai 1978). Naturally occurring $U$ typically contains $99.283 \%{ }^{238} U, 0.711 \%{ }^{235} \mathrm{U}$, and $0.0054 \%{ }^{234} \mathrm{U}$ by weight. The

half-lives of these $U$ isotopes are $4.51 \times 10^{9} \mathrm{yr}, 7.1 \times 10^{8} \mathrm{yr}$, and $2.47 \times 10^{5} \mathrm{yr}$, respectively. Geologically, $U$ occurs as U(IV) in minerals such as pitchblende, uraninite, carnotite, autunite, and as U(VI) in uranophane. It is also found in phosphate rock, lignite, and monazite sands at levels that can be commercially recovered. In the presence of lignite and other sedimentary carbonaceous substances, $U$ enrichment is believed to be the result of $U$ reduction to form insoluble precipitates, such as uraninite. The $U$ isotopes of interest in waste disposal and their respective half-lives include: ${ }^{233} \mathrm{U}$, 162,000 years; ${ }^{234} \mathrm{U}, 247,000$ years; ${ }^{235} \mathrm{U}, 7.13 \times 10^{8}$ years; ${ }^{236} \mathrm{U}, 2.39 \times 10^{7}$ years; and ${ }^{238} \mathrm{U}$, $4.51 \times 10^{9}$ years.

\subsubsection{Aqueous Speciation}

Uranium can exist in the (III), (IV), (V), and (VI) oxidation states. The aqueous U(VI) uranyl cation $\left(\mathrm{UO}_{2}^{2+}\right.$ ) is the most stable ion in oxidizing solutions. The U(III) species easily oxidizes to U(IV) under most reducing environmental conditions, while the $U(V)$ aqueous species (UO disproportionates to U(IV) and U(VI). In aqueous systems, the U(IV) species will not be present to any great extent as a result of precipitation, probably as uraninite $\left(\mathrm{UO}_{2}\right)$ or some other solids with O/U ratios between 2.3 and 2.7 (Bruno et al. 1988, Bruno et al. 1991). Average U concentrations in natural waters under reducing conditions are between 3 and $30 \mathrm{ppb}$ (Bruno et al. 1991); this is consistent with equilibrium concentrations supported by $\mathrm{UO}_{2}(\mathrm{~s})$ (Bruno et al. 1988). In the absence of any complexing agents, U(IV) is expected to hydrolyze to form mononuclear hydroxo complexes, $\mathrm{U}(\mathrm{OH})_{\mathrm{n}}^{4-\mathrm{n}}$ (Langmuir 1978). Complexation of (IV) actinides with natural organic humic and fulvic acids has been suggested as an important process (log $K=12$ to 16; Birch and Bachofen 1990). Hence, U(IV) could form stable organic complexes, increasing the solubility of the U(IV). In general, (IV) actinides species form stronger organic complexes than do the (VI) actinides species (Birch and Bachofen 1990). 
Aqueous uranyl, $\mathrm{UO}_{2}^{2+}$, tends to form strong complexes with inorganic oxygen-containing ligands such as hydroxide, carbonate, and phosphate. Aqueous $\mathrm{UO}_{2}^{2+}$ hydrolyses to form a number of aqueous hydroxo complexes including $\mathrm{UO}_{2} \mathrm{OH}^{+},\left(\mathrm{UO}_{2}\right)_{2}(\mathrm{OH})_{2}^{2+},\left(\mathrm{UO}_{2}\right)_{3}(\mathrm{OH})_{5}^{+}$, and $\mathrm{UO}_{2}(\mathrm{OH})_{3}$. In aqueous systems equilibrated with air or higher $\mathrm{pCO}_{2}$ waters at near neutral to high $\mathrm{pH}$, the carbonate complexes $\left(\mathrm{UO}_{2} \mathrm{CO}_{3}{ }^{0}, \mathrm{UO}_{2}\left(\mathrm{CO}_{3}\right)_{2}^{-}, \mathrm{UO}_{2}\left(\mathrm{CO}_{3}\right)_{3}^{4}\right)$ will dominate, but at lower $\mathrm{pH}$ the hydrolysis species will dominate as $\mathrm{CO}_{2}$ solubility decreases. Phosphate- $\mathrm{UO}_{2}^{2+}$ complexes $\left(\mathrm{UO}_{2} \mathrm{HPO}_{4}^{0}, \mathrm{UO}_{2} \mathrm{PO}_{4}^{-}\right)$could be important in aqueous systems with a pH between 6 and 9 when the total concentration ratio $\left(\mathrm{PO}_{4}^{3-}\right.$ Total $/\left(\mathrm{CO}_{3}^{2-}\right)_{\text {Total }}$ is greater than $10^{-1}$ (Sandino and Bruno 1992, Langmuir 1978). Complexes with $\mathrm{SO}_{4}^{2-}, \mathrm{F}^{-}$, and possibly $\mathrm{Cl}^{-}$are potentially important $\mathrm{U}(\mathrm{VI})$ species where concentrations of these anions are high. However, their stability is considerably less than the carbonate and phosphate complexes (Grenthe 1992). Because of the high hydroxide, high carbonate, and low organic matter concentrations expected in the far field of the Hanford LLW disposal site, U(VI) is likely to exist as a complexed carbonate and/or to a lesser extent, as hydroxide species.

\subsubsection{Precipltation and Coprecipltation}

Precipitation or coprecipitation of a solid phase will likely not control the mobility of U(VI) in the far field vadose zone. However, reduced conditions may be created in the near field that may maintain the waste $\mathrm{U}$ as a uraninite precipitate, $\mathrm{UO}_{2}$ (s), (Rai et al. 1990).

\subsubsection{Sorption}

Uranium is most mobile in oxidizing, carbonate-rich solutions. Therefore, under these conditions, one would anticipate that $U$ would be most soluble. However, other secondary factors may affect the mobility as well. For example, in the presence of low ionic strength solutions, the uranyl ion concentrations will probably be regulated, in part, by cation-exchange processes. The uranyl ion will adsorb onto clays, organics, and oxides, and this will limit its mobility. As the ionic strength of an oxidized solution increases, other ions, notably $\mathrm{Ca}^{2+}, \mathrm{Mg}^{2+}$, and $\mathrm{K}^{+}$will displace the uranyl ion, forcing it into solution. For this reason, the uranyl ion is particularly mobile in high-ionic-strength solutions such is expected to exist in the plume emanating from the Hanford LLW burial site. Not only will other cations out compete the uranyl ion for exchange sites, but carbonate ions will form strong soluble complexes with the uranyl ion, further lowering its activity while increasing the total amount of $U$ in solution (Yeh and Tripathi 1991).

Some of the sorption processes to which uranyl ion is subjected are not completely reversible. Sorption onto iron and manganese oxides can be a major process for extraction of $\mathrm{U}$ from solution. These oxide phases act as a short-term, irreversible sink for $U$ in soils. Uranium bound in these phases is not generally in isotopic equilibrium with dissolved $U$ in the same system, suggesting that the reaction mediating the transfer of the metal between the two phases is slow.

Organics are another possible sink for uranyl ions in soils, and to a smaller extent, in sediments. The mechanisms for $U$ sequestration have not been worked out in detail, although several different processes may be involved. One possible process may involve sorption of the ion onto exchange sites such as carboxylic acid groups. These groups can coordinate with the uranyl ion, displacing waters of hydration, and form stable complexes. A process such as this probably accounts for a significant fraction of the organically bound $U$ in soils, and perhaps, in sediments. Alternatively, sedimentary organics may act to reduce dissolved $\mathrm{UO}_{2}^{2+}$ species to U(IV) species. These reduced species are notoriously low in solubility and may remain associated with the organic phase after precipitation as a 
reduced oxide. Little seems to be known about the nature of organic-U associations in soils or sediments, although several different types of interaction may be taking place. The amount of naturally occurring organic substances, such as fulvic and humic acids, is quite low in the subsurface of the Hanford Site. However, there is a possibility that the contaminant plume may contain some organic substances (the sulfur polymer cement contains 5\% organic binder), and this waste may possess some of the chemical properties of the naturally occurring organic substances.

Uranium sorption to iron oxides and smectite clay has been shown to be extensive in the absence of $\mathrm{CO}_{3}^{2-}$ (Kent et al. 1988, Hsi and Langmuir 1985, Ames et al. 1982, McKinley et al. in press), but in the presence of $\mathrm{CO}_{3}^{2-}$ and organic complexants sorption was shown to be substantially reduced or severely inhibited (Hsi and Langmuir 1985, Kent et al. 1988, Ames et al. 1982). The importance of U(VI) sorption to inorganic solid phases, such as clays and iron oxides, may be minor in many natural environments because of the limited quantity of these materials and because of the presence of particulate organic matter and dissolved carbonate.

Rancon (1973) studied the adsorption of $U$ using four soils and three pure phase minerals. Quartz was characterized as inert $\left(K_{d}=0 \mathrm{~mL} / \mathrm{g}\right)$, calcite was a poor $U$ adsorber $\left(K_{d}=7 \mathrm{~mL} / \mathrm{g}\right)$, and illite and other $2: 1$ clays $\left(K_{d}=139\right.$ to $\left.270 \mathrm{~mL} / \mathrm{g}\right)$ were the best adsorbers of $U$ from solution. Acid, organic-rich soils showed much higher $U$ sorption $\left(K_{d}=33 \mathrm{~mL} / \mathrm{g}\right)$ than soils containing carbonate minerals $\left(K_{d}=16 \mathrm{~mL} / \mathrm{g}\right)$.

Formation of complexes between U(VI) and organic ligands such as humic and fulvic particulates has been studied most frequently because of interest in ore-forming environments. At ambient temperatures $\left(-25^{\circ} \mathrm{C}\right), \mathrm{U}$ is adsorbed to humic substances through rapid ion-exchange and complexation processes with carboxylic and other acidic functional groups (Idiz et al. 1986, Boggs et al. 1985, Shanbhag and Choppin 1981, Nash et al. 1981, Borovec et al. 1979, Szalay 1964) without reduction to the U(IV) species. It has been suggested that U(VI) adsorbed (or fixed) to organic matter may undergo reduction to U(IV) followed by precipitation of $\mathrm{UO}_{2}$ (Andreyev and Chumachenko 1964). In studies with lignite, however, the uranyl species formed a stable complex with the lignite without subsequent reduction; reduction only occurred at elevated temperatures (Nakashima et al. 1984). However, organic matter does have the capacity to act as a reductant, most notably because of the presence of quinone, sulfone, and reduced metal porrphryn (tetrapyroles) moeities (Macalady et al. 1986). 


\subsection{Near-Field Radionuclide Transport Through Engineered Barriers}

\subsection{Description of Potential Engineered Barriers}

The near field of the Hanford vitrified LLW burial site has not been designed yet. It will likely include a surface barrier, the waste form, a concrete vault surrounding the waste form, one or more subsurface engineered barriers, and all nearby sediment disturbed as a result of burying the waste. The purpose of the surface barrier is to provide a physical barrier to infiltration by precipitation. It typically consists of a series of layers of geologic materials (Kincaid et al. 1993) including a sloping bottom layer consisting of clay to provide a physical barrier to infiltrating water. Above this layer is one or more layers of larger-size particles to break capillarity and to promote the flow of water along the top of the clay layer. The top layer typically consist of soil that is a growing media for plants, which will reduce, via transpiration, the amount of water reaching the waste. The vault surrounding the waste form provides a physical and chemical barrier to infiltration water. Three possible materials for the vault are a pozzolanic cement (compatible with the waste glass), bitumen asphalt, and a sulfur polymer cement (a mixture of $95 \%$ sulfur and $5 \%$ organic binders). Guidance from the Nuclear Regulatory Commission (NRC) indicates that concrete vaults used in waste disposal should not be postulated to last more than 500 years. There are several possible engineered structures that may be placed around the concrete vault to provide either additional physical or both chemical and physical barriers to infiltration water. A retardation pad below the disposal vault may also be installed. This would be a layer of material that either lowers the solubility of the leachate constituents (typically by creating a low redox environment) or has a high adsorption capacity for the leachate constituents (such as a 1:3 bentonite and Warden silt loam). The waste will be vitrified, most probably as a silicate glass. The amount of contaminant release from vitrified waste is generally quite low as a function of time. Hanford-specific tests to accurately quantify radionuclide release from Hanford LLW glass are planned (Bates et al. 1994, McGrail 1994).

\subsection{Solubility Approach for Describing Chemical Retardation of Sparingly Soluble Contaminants}

Beneath the surface barrier, concrete vault, and retardation pad, advective water movement will be at a minimum. Therefore, diffusion will be controlling the movement of radionuclides once they are dissolved in the infiltrating water. The driving force of diffusional movement of solutes is the concentration gradient, where the gradient ranges from its maximum at the waste form surface, $C_{0}$, to its minimum at the boundary of the diffusion-controlled and advection-controlled zones. The concentration gradient between these two points is typically assumed to be linear. Values for $C_{0}$ vary greatly as a function of time and may be among some of the hardest data to predict for the PA. A simplifying assumption used in past PAs is that $C_{0}$ is constant, that is, the rate of release is constant.

Solubility or adsorption will control retardation of released solutes from the vitrified waste. If thermodynamic calculations indicate that the saturation index is exceeded, then solubility will be used to set the rate of chemical retardation. Solubility is likely to play an important role in the near field for two reasons. First, the released contaminants will be introduced into an environment, thereby disrupting local equilibrium. For example, $\mathrm{Np}$ and $\mathrm{U}$ released from the glass may form sparingly soluble compounds (solubilities of between $10^{-7}$ to $10^{-8} \mathrm{~mol}$ per gram) in the presence of a sulfide 
engineered barrier. Second, the near field, by definition, will be a geochemically disturbed area and may also be in nonequilibium due to recent perturbation. For example, the introduction of air to the subsurface during the installation of the concrete vaults and engineered barriers will perturb the gas and solid phase equilibrium.

\subsection{Sorption Approach for Describing Chemical Retardation of Sparingly Soluble Contaminants}

The chemical retardation of soluble contaminants through the near field barriers surrounding the vitrified waste will likely be controlled primarily by adsorption. The extent of chemical retardation will vary by radionuclide (see Section 3.2) and barrier material. For example, if the retardation pad is composed of a high adsorbing media, such as zeolite or a 1 part bentonite and 3 parts silt loam, then the $U K_{d}$ of the barrier could be from two to four orders of magnitude greater than might exist in the undisturbed far field. Furthermore, as the radionuclides move through various engineered barriers, the solubility of the radionuclides may change. For instance, the retardation of ${ }^{99} \mathrm{Tc}$ would be controlled by precipitation in a barrier containing sulfides and by adsorption in a retardation pad containing zeolite clays. Thus, each engineered barrier should be evaluated as to whether it may influence radionuclide retardation via precipitation or adsorption. A unique set of solubility constants and $\mathrm{K}_{\mathrm{d}}$ values need to be provided for each barrier. 


\subsection{Far-Field Radionuclide Transport Through the Vadose Zone}

\subsection{Geochemical Description of the Far Field}

The far field, the region beyond the disturbed area containing the concrete vaults and engineered barriers, will be contained in the 200 Area plateau of the Hanford Site. Based on well logs and sediment sample analyses conducted for the Grout-LLW PA (Rockhold et al. 1993), this region lies in the Hanford and Ringold Formations. At the proposed grout-LLW disposal site, the altitude above mean sea level of the ground surface was $204 \mathrm{~m}$, the top of the Hanford Lower Gravel was $152 \mathrm{~m}$, the top of the Ringold Formation was $125 \mathrm{~m}$, and the top of the water table was $120 \mathrm{~m}$. Beneath the Ringold Formation is a basalt member of much lower permeability than that for the overlying sediments, and the member is considered impermeable. The upper $60 \mathrm{~m}$ of the Hanford Formation contains coarse to fine grained sand. The lower $10 \mathrm{~m}$ of this formation consist of a pebbly, very coarse sand to sandy gravel. Immediately below this coarser textured zone is the Ringold Formation, which averages $30 \mathrm{~m}$ thick and consists of well-rounded pebble- to cobble-size gravel with a matrix of sand; silt, and some clay. Selected physical properties of the upper Hanford Formation of the 200 Area are presented in Table 5.1. The composition of an uncontaminated groundwater on the Hanford Site is presented in Table 5.2. The water described in this table was taken from well 6-\$3-25, which is located on the Hanford Site approximately $17 \mathrm{~km}$ from the 200 East Area, where the unconfined aquifer is relatively contaminated from facility operations.

\subsection{Sorption Approach to Describing Chemical Retardation}

The chemical composition of the plume emanating from the vitrified LLW is not known. Preliminary scoping (equilibrium) calculations designed to provide program guidance determined, with great uncertainty, that the leachate with or without the surrounding sulfur polymer barrier will contain high concentrations of salts including $0.1 \mathrm{M}$ sodium, $0.1 \mathrm{M}$ silicate, $0.001 \mathrm{M}$ total sulfur, $1 \times 10^{-5} \mathrm{M}$ total inorganic carton, and $1.6 \times 10^{-5} \mathrm{M}$ calcium (McGrail 1994). When the contaminant plume front first comes into contact with the undisturbed sediment/aqueous system of the far field (Tables 5.1), a number of possible reactions may occur including redox-induced changes in the oxidation state, precipitation, coprecipitation, and adsorption. The portion of the plume following the front will be much less likely to form precipitates or coprecipitates. Instead, the tailing portion of the plume will likely be controlled primarily by sorption processes. Initial attempts at modeling the geochemical interaction with the far field will focus on the sorption, $K_{d}$, process. Once estimates of the plume's chemistry are better known, the adsorption approach will be refined to include equilibrium calculations and empirical laboratory studies to determine the extent of precipitation/coprecipitation occurring at the plume's front. 
Table 5.1. Selected Physical, Chemical, and Mineralogical Properties of Vadose Zone Sediments in the 200 Area

\begin{tabular}{|c|c|c|c|c|}
\hline Parameter & Unit & Method & Conc. & Ref.(a) \\
\hline Gravel (>2mm) & $\%(w / w)$ & In Situ Composition & 32.7 & 1 \\
\hline Sand $(<2 \mathrm{~mm}$ to $>63 \mu \mathrm{m})$ & $\%(w / w)$ & In Situ Composition & 67.0 & 1 \\
\hline Silt $(<63 \mu \mathrm{m}$ to $>2 \mu \mathrm{m})$ & $\%(w / w)$ & In Situ Composition & 0.26 & 1 \\
\hline Clay $(<2 \mu \mathrm{m})$ & $\%(w / w)$ & In Situ Composition & 0.04 & 1 \\
\hline Total Organic Matter & $\%(w / w)$ & $\%$ of $<2 \mathrm{~mm}$ fraction & $\leq 0.01$ & 1 \\
\hline $\mathrm{PO}_{4}^{3-}$ & $\mu \mathrm{g} / \mathrm{g}$ soil & Saturated Paste & $\leq 0.07$ & 2 \\
\hline $\mathrm{Cl}^{-}$ & $\mu \mathrm{g} / \mathrm{g}$ soil & Saturated Paste & 6.3 & 2 \\
\hline $\mathrm{NO}_{3}^{-}$ & $\mu \mathrm{g} / \mathrm{g}$ soil & Saturated Paste & 0.9 & 2 \\
\hline $\mathrm{SO}_{4}^{2-}$ & $\mu \mathrm{g} / \mathrm{g}$ soil & Saturated Paste & 16.4 & 2 \\
\hline Total Alkalinity as $\mathrm{CO}_{3}^{2-}$ & $\mu \mathrm{g} / \mathrm{g}$ soil & Saturated Paste & 14.52 & 2 \\
\hline $\mathrm{Na}^{+}$ & $\mu \mathrm{g} / \mathrm{g}$ soil & Saturated Paste & 5.26 & 2 \\
\hline $\mathrm{Mg}^{2+}$ & $\mu \mathrm{g} / \mathrm{g}$ soil & Saturated Paste & 1.97 & 2 \\
\hline $\mathrm{Ca}^{2+}$ & $\mu \mathrm{g} / \mathrm{g}$ soil & Saturated Paste & 8.10 & 2 \\
\hline $\mathrm{Sr}^{2+}$ & $\mu \mathrm{g} / \mathrm{g}$ soil & Saturated Paste & 0.04 & 2 \\
\hline $\mathrm{Si}$ & $\mu \mathrm{g} / \mathrm{g}$ soil & Saturated Paste & 3.98 & 2 \\
\hline Dissolved Organic C & $\mu \mathrm{g} / \mathrm{g}$ soil & Saturated Paste & 1.66 & 2 \\
\hline Cation Exch. Capacity & meq/100 g & $\mathrm{Na}$ acetate exchangeable & $5.27 \pm 1.2$ & 1 \\
\hline Illite & $\%(w / w)$ & $<2-\mu \mathrm{m}$ fraction & 13 & 1 \\
\hline Plagioclase & $\%(w / w)$ & $<2-\mu \mathrm{m}$ fraction & 26 & 1 \\
\hline Kaolinite & $\%(w / w)$ & $<2-\mu \mathrm{m}$ fraction & 3 & 1 \\
\hline Chlorlite & $\%(w / w)$ & $<2-\mu \mathrm{m}$ fraction & 2 & 1 \\
\hline Vermiculite & $\%(w / w)$ & $<2-\mu \mathrm{m}$ fraction & 8 & 1 \\
\hline Smectite & $\%(w / w)$ & $<2-\mu \mathrm{m}$ fraction & 38 & 1 \\
\hline Quartz & $\%(w / w)$ & $<2-\mu \mathrm{m}$ fraction & 9 & 1 \\
\hline
\end{tabular}

(a) References: 1 = Rhoads et al. 1994, 2 = Serne et al. 1993 
Table 5.2. Range in Composition (mg $\mathrm{L}^{-1}$ ) of Hanford Groundwater (Well 6-S3-25 between the years 1985 and 1990)(a)

\begin{tabular}{|c|c|}
\hline Analyses & Composition \\
\hline$\overline{\mathrm{pH}}$ & $7.82-8.47$ \\
\hline$\overline{E h(m v)}$ & $283-385$ \\
\hline Cations (meq/L) ${ }^{(b)}$ & $4.9-5.4$ \\
\hline Anions (meq/L) & $4.6-6.1$ \\
\hline$\overline{\mathrm{Al}}$ & $<0.03-0.064$ \\
\hline$\overline{\mathbf{B}}$ & $0.02-0.10$ \\
\hline$\overline{\mathrm{Ba}}$ & $0.04-0.08$ \\
\hline $\mathbf{C a}$ & $48.8-58.8$ \\
\hline$\overline{\mathrm{Cd}}$ & $<0.004$ \\
\hline$\overline{\mathrm{Cr}}$ & $<0.02-0.034$ \\
\hline $\mathrm{Cu}$ & $<0.004$ \\
\hline$\overline{F e}$ & $<0.005-0.008$ \\
\hline $\bar{K}$ & $4.9-9.9$ \\
\hline$\overline{L i}$ & $<0.004$ \\
\hline $\mathbf{M g}$ & $13.2-14.6$ \\
\hline Mn & $<0.002-0.13$ \\
\hline$\overline{\mathrm{Na}}$ & $23.8-32.1$ \\
\hline $\bar{P}$ & $<0.1$ \\
\hline$\overline{\mathrm{Pb}}$ & $<0.06$ \\
\hline$\overline{\mathrm{Si}}$ & $14.6-16.4$ \\
\hline $\mathbf{S r}$ & $0.23-0.25$ \\
\hline$\overline{\mathrm{Zn}}$ & $<0.02-0.08$ \\
\hline Fluoride & $<0.5-0.7$ \\
\hline Chloride & 21. -27 \\
\hline Nitrite & $<0.3$ \\
\hline Nitrate & $<0.5$ \\
\hline Phosphate & $<3$. \\
\hline Sulfate & $63 .-92$. \\
\hline Total Alkalinity (as $\mathrm{CO}_{3}^{2-}$ ) & $67.5-92.4$ \\
\hline Total Organic Carbon & $0.03-1.7$ \\
\hline
\end{tabular}

(a) Serne et al. (1993).

(b) One equivalent (eq) equals the gram-atomic mass of a given cation divided by its ionic charge. 


\subsection{Available $K_{d}$ Data Describing Radionuclide Sorption To Hanford Sediments}

The purpose of this section is to document any available Hanford Site-specific data that could be used to develop adsorption conceptual models or actual input values for available transport models. Additionally, this section will provide ranges of reported $\mathrm{K}_{d}$.values that can be used in stochastic transport models or to provide some measure of sensitivity to the performance assessment exercise. The distribution of $K_{d}$ values in Hanford sediments has not been determined; they are commonly assumed to be log-normally distributed (Van Genuchten and Wierenga 1986, Hillel 1980). Radionuclide sorption was tabulated as $\mathrm{K}_{\mathrm{d}}$ values because essentially all the available Hanford Site data on adsorption is in the form of $K_{d}$ values, and most of the transport codes being considered for the Hanford LLW PA require $K_{d}$ values. Four general categories of leachates were considered: 1) alkaline, low salt, low organic, oxidized solutions (Table 6.1 ), 2) alkaline, low salt, low organic, anoxic solutions (Table 6.2), 3) alkaline, high salt, low organic, oxidized solutions (Table 6.3), and 4) alkaline, high salt, low organic, reduced solutions (Table 6.4). Solution 1 was selected to approximate the plume in the far field. Solution 2 was selected to approximate the plume in a near-field barrier that created a reduced environment, (such as a sulphur-polymer cement barrier, a mixture of $95 \%$ sulfur and $5 \%$ organic binders). Solution 3 was selected to approximate the plume in a near-field barrier that created a high electrolyte/oxidized environment (such as vitrified glass or concrete vault leachate). Solution 4 was selected to approximate the plume in a near-field barrier that created a high electrolyte and reduced environment. Broad definitions were chosen for these categories because the precise burial site and burial facility is currently being designed. Refinement of these categories will likely be required as more information about the burial design is available. Attempts were made while compiling these tables to include $K_{d}$ values generated from 1) Hanford sediments of sandy texture, 2) trace concentrations of sorbate, 3) $\mathrm{pH}$ levels in suspension between 7 and 11,4) natural Hanford groundwater or $\mathrm{Na}$ and/or $\mathrm{Ca}$ background electrolyte solution, and 5) solution ionic strengths of 0.00001 to $0.01 \mathrm{M}$ (low ionic strength, Tables 6.1 and 6.3 ) or 0.01 to $1.0 \mathrm{M}$ (high ionic strength, Tables 6.2 and 6.4). Where no data was available, estimates of the $\mathrm{K}_{\mathrm{d}}$ range were provided. These were based on previous conservative estimates and are clearly identified (Seme and Wood 1990, Strenge and Peterson 1989).

At present, the available database for radionuclide adsorption onto Hanford soils includes laboratory-derived $\mathrm{K}_{d}$ values for $\mathrm{Am}, \mathrm{Co}, \mathrm{Cs}, \mathrm{Np}, \mathrm{Pu}, \mathrm{Ru}, \mathrm{Sb}, \mathrm{Sr}$ and for high-level tank leak solutions (Knoll 1966, Knoll 1969, Delegard and Bamey 1983, DOE 1987); Am, Ce, Cm, Co, Cs, Eu, I, Np, Pu, $\mathrm{Ru}, \mathrm{Sr}, \mathrm{Tc}$, and $\mathrm{Zr}$ for selected sediments and solutions similar to diluted Hanford wastes and groundwater (Ames and Rai 1978, Rhodes 1957, Benson 1960, Serne and Rai 1976, Sheppard et al. 1976, Hajek 1966, Routson and Serne 1972, Serne et al. 1973, Routson et al. 1977, 1978, 1980, 1981, Gee et al. 1981, Gee and Campbell 1980, DOE 1987); and for Co, Cs, I, Mn, Sr, Tc, and for grout leachate contacting a typical 200 East Area sediment (Seme et al. 1987). For many other elements, $K_{d}$ values can be estimated by analogy to other elements. (Chemical analogs were used to estimate $K_{d}$ values in HDWEIS: see page 0.39 in volume 3 of DOE (1987) for references to specific unpublished citations.) The available $\mathrm{K}_{d}$ values for $\mathrm{Np}, \mathrm{I}, \mathrm{Se}, \mathrm{Tc}$, and $\mathrm{U}$ are discussed in the following subsections; the data of other radionuclides is tabulated. 
Table 6.1. Reported $K_{d}$ Values for Hanford Sediments in Neutral-to-High pH, Low Salt (Ionic Strength $<0.01 \mathrm{M}$ ), Low Organic, Oxic Solutions (Version 7.0)

\begin{tabular}{|c|c|c|c|}
\hline Radionuclide & Low $\mathrm{K}_{\mathrm{d}}$ & High $\mathbf{K}_{d}$ & Reference $^{(a)} /$ Rationale \\
\hline$A \mathbf{C}$ & 67 & 1330 & Am and $\mathrm{Cm}$ analog, estimate \\
\hline Am & 67 & $>1200$ & $\begin{array}{l}\text { ref. } 8: 67 \text { to }>1200 \mathrm{~mL} / \mathrm{g} \\
\text { ref. 14: } 125 \text { to } 833 \mathrm{~mL} / \mathrm{g}\end{array}$ \\
\hline $\mathbf{C}$ & 0 & 4 & $\begin{array}{l}\text { ref. } 1 \text { and } 7: \text { wide range of } K_{d} \text { depending on type of organic or } \\
\text { inorganic } C \text { compound, estimate }\end{array}$ \\
\hline Ce & 100 & $>2000$ & $\begin{array}{l}\text { ref. 3: pH } 6 \text { to } 12,100 \text { to }>2000 \mathrm{~mL} / \mathrm{g} \\
\text { good adsorber, insoluble }\end{array}$ \\
\hline $\mathrm{Cm}$ & 106 & 1330 & Tef. 14: 106 to $1330 \mathrm{~mL} / \mathrm{g}$ \\
\hline Co & 1200 & 12,500 & $\begin{array}{l}\text { ref. 2: Na sys., } 1290 \text { to } 2120 \mathrm{~mL} / \mathrm{g} \\
\text { ref. 2: Ca sys., } 2000 \text { to } 3870 \mathrm{~mL} / \mathrm{g} \\
\text { ref. 9: } 11,600 \text { to } 12,500 \\
\text { much lower } \mathrm{K}_{d} \text { values exist when } \mathrm{Co} \text { is organically complexed }\end{array}$ \\
\hline Cs & 540 & 3180 & $\begin{array}{l}\text { ref. 2: Na sys., } 1410 \text { to } 1590 \mathrm{~mL} / \mathrm{g} \\
\text { ref. 9: } 540 \text { to } 3180 \mathrm{~mL} / \mathrm{g}\end{array}$ \\
\hline Eu & 100 & 228 & ref. 1 and 7: good adsorber, insoluble, estimate \\
\hline I & 0.04 & 18 & $\begin{array}{l}\text { ref. 9: } 0.7 \text { to } 1.4 \mathrm{~mL} / \mathrm{g} \\
\text { ref. 10: } 0.04 \text { to } 18 \mathrm{~mL} / \mathrm{g}\end{array}$ \\
\hline $\mathrm{Nb}$ & 50 & 100 & ref. 12: 50 to $100 \mathrm{~mL} / \mathrm{g}$, anionic species at $\mathrm{pH}>8$ \\
\hline $\mathrm{Ni}$ & 50 & 2350 & $\begin{array}{l}\text { ref. 9: } 440 \text { to } 2350 \mathrm{~mL} / \mathrm{g} \\
\text { ref. 12: } 50 \text { to } 340 \mathrm{~mL} / \mathrm{g} \\
\text { neutral and (-) charged species at high } \mathrm{pH}\end{array}$ \\
\hline $\mathrm{Np}(\mathrm{V})$ & 2.4 & 29.1 & $\begin{array}{l}\text { ref. 8: Ca sys., } 2.4 \mathrm{~mL} / \mathrm{g} \\
\text { ref. 8: Na sys., } 3.1 \mathrm{~mL} / \mathrm{g} \\
\text { ref. 9: } 13.5 \text { to } 29.1 \mathrm{~mL} / \mathrm{g}\end{array}$ \\
\hline $\mathbf{P a}$ & 10 & 1000 & ref. $1,7,11$ : insoluble precipitates, estimate \\
\hline $\mathbf{P b}$ & 13,000 & 79,000 & ref. 4: pH 6 \& no competing ions, 13,000 to $79,000 \mathrm{~mL} / \mathrm{g}$ \\
\hline $\operatorname{Pu}(\mathrm{V}, \mathrm{VI})$ & 80 & $>1980$ & ref. 3: $\mathrm{pH} 4$ to 12,80 to $>1980 \mathrm{~mL} / \mathrm{g}$ \\
\hline $\mathbf{R a}$ & 24 & 100 & ref. 1 and 7 : estimate \\
\hline $\mathbf{R u}$ & 27 & 274 & ref. 7: estimate \\
\hline $\mathrm{Se}$ & $\mathbf{0}$ & 0.78 & $\begin{array}{l}\text { ref. 9: }-3.44 \text { to } 0.78 \mathrm{~mL} / \mathrm{g} \\
\text { anion }\end{array}$ \\
\hline $\mathbf{S n}$ & 100 & 230 & ref. 6: estimate \\
\hline
\end{tabular}


Table 6.1. (cont'd)

\begin{tabular}{|c|c|c|c|}
\hline Radionuclide & Low $K_{d}$ & High $K_{d}$ & Reference $e^{(\mathrm{x})} /$ Rationale \\
\hline Sr & 5 & 173 & $\begin{array}{l}\text { ref. 2: Na sys., } 173 \mathrm{~mL} / \mathrm{g}, 49 \text { to } 50 \mathrm{~mL} / \mathrm{g} \\
\text { ref. 2: Ca sys., } 8 \text { to } 13 \mathrm{~mL} / \mathrm{g}, 5 \text { to } 19 \mathrm{~mL} / \mathrm{g} \\
\text { ref. 3: } 5 \text { to } 120 \mathrm{~mL} / \mathrm{g} \\
\text { ref. 5: } 40 \text { ppm Ca sys., } 10 \mathrm{~mL} / \mathrm{g} \\
\text { ref. 9: } 19.1 \text { to } 21.5 \mathrm{~mL} / \mathrm{g} \\
\text { ref. 13: Na sys., pH } 7 \text { to } 11,14.9 \text { to } 25.1 \mathrm{~mL} / \mathrm{g}\end{array}$ \\
\hline $\operatorname{Tc}($ VII $)$ & 0 & 1.3 & $\begin{array}{l}\text { ref. 8: } 0 \text { to }<1 \mathrm{~mL} / \mathrm{g} \\
\text { ref. 9: }-0.1 \text { to } 0.4 \mathrm{~mL} / \mathrm{g} \\
\text { ref. 10: }-0.9 \text { to } 1.3 \mathrm{~mL} / \mathrm{g}\end{array}$ \\
\hline Th & 40 & 100 & ref. 1 and 7: estimate ${ }^{(b)}$ \\
\hline $\mathrm{U}(\mathrm{VI})$ & 0.08 & 79.3 & $\begin{array}{l}\text { ref. 9: } 1.7 \text { to } 79.3 \mathrm{~mL} / \mathrm{g} \\
\text { Unsaturated sys., } 0.49 \text { to } 2.81 \mathrm{~mL} / \mathrm{g}^{(c)} \text {; } \\
\text { Saturated sys., } 0.08 \text { to } 0.62 \mathrm{~mL} / \mathrm{g}^{(c)} \text {; } \\
\text { high pH sys. may form anionic complexes }\end{array}$ \\
\hline $\mathbf{Z}$ & 90 & $>2000$ & ref. 3: $\mathrm{pH} 6$ to 12,90 to $>2000 \mathrm{~mL} / \mathrm{g}$ \\
\hline
\end{tabular}

(a) References: 1 = Serne and Wood 1990; 2 = Routson et al. 1978; 3 = Rhodes 1957; 4 = Rhodes et al. 1992; $5=$ Rhodes 1956; 6 = Lindenmeier et al. 1994; 7 = Strenge and Peterson 1989; 8 = Routson et al. 1976;

9 = Serne et al. 1993; 10 = Gee and Campbell 1980; 11 = Seaborg 1994; 12 = Serne and Relyea 1983;

13 = Nelson 1959; 14 = Sheppard et al. 1976.

(b) All estimated $K_{d}$ values are conservative, i.e., low $K_{d}$ values.

(c) Lindenmeier, C. W., R. J. Serne, J. L. Conca, and A. T. Owen. Draft. Solid-Waste Leach Characteristics and Contaminant-Sediment Interactions. Volume II. Contaminant Transport Under Partially Saturated Systems. Pacific Northwest Laboratory, Richland, Washington.

Table 6.2. Reported $\mathrm{K}_{\mathrm{d}}$ Values for Hanford Sediments in Neutral-to-High pH, Low Salt (Ionic Strength $<0.01 \mathrm{M}$ ), Low Organic, Anoxic Solutions. If Radionuclide is not Listed, its $\mathbf{K}_{\mathbf{d}}$ is same as Listed in Table 6.1 (Version 7.0)

\begin{tabular}{||l|c|c|l|}
\hline Radionuclide & Low $\mathrm{K}_{\mathbf{d}}$ & High $\mathrm{K}_{\mathbf{d}}$ & \multicolumn{1}{|c|}{ Reference $^{(\mathbf{a}) / \text { Rational }}$} \\
\hline $\mathrm{Np}$ (IV) & 200 & 1000 & ref. 1, estimate \\
\hline $\mathrm{Pa}$ (IV) & 200 & 1000 & ref. 2, estimate \\
\hline $\mathrm{Pu}$ (III,IV) & 200 & 1000 & ref. 1, estimate \\
\hline Tc (IV) & 200 & 1000 & ref. 1, estimate \\
\hline $\mathrm{U}$ (IV) & 100 & 1000 & ref. 1, estimate \\
\hline
\end{tabular}

(a) References: 1 = Strenge and Peterson 1989; 2 = Seaborg 1994.

(b) All estimated $K_{d}$ values are conservative, i.e., low $K_{d}$ values. 
Table 6.3. Reported $\mathrm{K}_{d}$ Values for Hanford Sediments in Neutral-to-High pH, High Salt (Ionic Strength $\geq 0.01 \mathrm{M}$ ), Low Organic, Oxic Solutions (Version 7.0)

\begin{tabular}{|c|c|c|c|}
\hline Radionuclide & Low $K_{d}$ & High $\mathrm{K}_{\mathbf{d}}$ & Reference (a)/Rational \\
\hline Ac & 280 & $>1200$ & ref. 1: analog to $\mathrm{Am}$ \\
\hline $\mathrm{Am}$ & 280 & $>1200$ & ref. 4: Ca sys., >1200 mL/g; Na sys., $280 \mathrm{~mL} / \mathrm{g}$ \\
\hline$\overline{\mathbf{C}}$ & 0 & $\overline{4}$ & ref. 1: $\mathrm{HCO}_{3}^{-}$or $\mathrm{CO}_{3}^{2-}$, estimate \\
\hline $\mathrm{Ce}$ & 10 & 100 & ref. 1: strong adsorber, insoluble, estimate \\
\hline $\mathrm{Cm}$ & 280 & $>1200$ & ref. 1: analog to $\mathrm{Am}$ \\
\hline $\mathrm{Co}$ & 222 & 4760 & $\begin{array}{l}\text { ref. 2: } \mathrm{Na} \text { sys., } 1060 \text { to } 4760 \mathrm{~mL} / \mathrm{g} \\
\text { ref. 2: Ca sys., } 222 \text { to } 640 \mathrm{~mL} / \mathrm{g} \\
\text { forms complexes especially with organics }\end{array}$ \\
\hline$\overline{C s}$ & 64 & 1360 & $\begin{array}{l}\text { ref. 2: Na sys., } 64 \text { to } 1170 \mathrm{~mL} / \mathrm{g} \\
\text { ref. 2: Ca sys., } 790 \text { to } 1360 \mathrm{~mL} / \mathrm{g} \\
\text { no complexes good adsorber }\end{array}$ \\
\hline $\mathrm{Eu}$ & 10 & 500 & ref. 1: strong adsorber, insoluble, estimate \\
\hline $\mathbf{I}$ & 0 & 0.5 & ref. 1: anion, estimate (b) \\
\hline $\mathrm{Nb}$ & 5 & 25 & ref. 6: estimate \\
\hline$\overline{\mathrm{Ni}}$ & 3 & 40 & ref. 1: moderate complex former, estimate \\
\hline Np (V) & 0.4 & 4 & ref. 4: 0.4 to $4 \mathrm{~mL} / \mathrm{g}$ \\
\hline $\mathbf{P a}$ & 5 & 500 & ref. 5: forms insoluble precipitates, estimate \\
\hline$\overline{\mathrm{Pb}}$ & 20 & 1000 & ref. 1: good adsorber, insoluble, estimate \\
\hline $\mathrm{Pu}(\mathrm{V}, \mathrm{VI})$ & 10 & $>98$ & $\begin{array}{l}\text { ref. 3: }>98 \mathrm{~mL} / \mathrm{g} \\
\text { ref. 1: lower } \mathrm{K}_{\mathrm{d}} \text { value is a conservative (low) estimate }\end{array}$ \\
\hline $\mathbf{R a}$ & 10 & 50 & ref. 1: divalent cation, estimate \\
\hline$\overline{R u}$ & $\mathbf{0}$ & 10 & $\begin{array}{l}\text { may form } \mathrm{RuO}_{4}^{2-} \text { and anionic complexes with } \mathrm{Ru} \text { - } \\
\mathrm{NO}_{2}-\mathrm{NO}_{3} \text {, estimate }\end{array}$ \\
\hline $\mathrm{Se}$ & 0 & 4 & ref. 1: anion, estimate \\
\hline$\overline{\mathrm{Sn}}$ & 10 & 1000 & insoluble, estimate \\
\hline Sr & 0.3 & $\overline{42}$ & $\begin{array}{l}\text { ref. 2: Na sys., } 1.7 \text { to } 42 \mathrm{~mL} / \mathrm{g} \\
\text { ref. 2: Ca sys., } 0.3 \text { to } 1.6 \mathrm{~mL} / \mathrm{g}\end{array}$ \\
\hline Tc (VII) & 0 & 0.01 & ref. 4: 0 to $0.01 \mathrm{~mL} / \mathrm{g}$; anion \\
\hline Th & 40 & 470 & ref. 7: sandy soil data, 40 to $470 \mathrm{~mL} / \mathrm{g}$, estimate \\
\hline $\mathrm{U}(\mathrm{VI})$ & 0 & 4 & $\begin{array}{l}\text { ref. 1: estimate, anionic and neutral carbonate ref. } \\
\text { complexes, estimate }\end{array}$ \\
\hline$\overline{\mathrm{Zr}}$ & 20 & 200 & ref. 1: strong adsorber, estimate \\
\hline
\end{tabular}

(a) References: 1 = Serne and Wood 1990; 2 = Routson et al. 1978; 3 = Rhodes 1957; 4 = Routson et al. 1976; 5 = Seaborg 1994; 6 = Serne and Relyea 1983; 7 = Sheppard et al. 1976.

(b) All estimated $K_{d}$ values are conservative, i.e., low $K_{d}$ values. 
Table 6.4. Reported $\mathrm{K}_{\mathrm{d}}$ Values for Hanford Sediments in Neutral-to-High pH, High Salt (Ionic Strength $\geq 0.01 \mathrm{M}$ ), Low Organic, Anoxic Solutions. Radionuclide not Listed, has Same $K_{d}$ as Listed in Table 6.2 (Version 7.0)

\begin{tabular}{|c|c|c|c|}
\hline Radionuclide & Low $\mathbf{K}_{\mathrm{d}}$ & High $\mathbf{K}_{\mathbf{d}}$ & Reference $^{(\mathrm{a})} /$ Rational \\
\hline Np (IV) & 100 & 1000 & ref. 1: estimate ${ }^{(b)}$ \\
\hline $\mathrm{Pa}$ (IV) & 100 & 1000 & ref. 2: estimate \\
\hline $\mathrm{Pu}(\mathrm{III}, \mathrm{IV})$ & 100 & 1000 & ref. 1: estimate \\
\hline Tc (IV) & 100 & 1000 & ref. 1: estimate \\
\hline U (IV) & 100 & 1000 & ref. 1: estimate \\
\hline
\end{tabular}

(a) References: 1 = Strenge and Peterson 1989; 2 = Seaborg 1994.

(b) All estimated $K_{d}$ values are conservative, i.e., low $K_{d}$ values.

\section{1 lodine}

Iodine will likely exist as an anion, $\mathrm{I}^{-}$or $\mathrm{IO}_{\mathbf{3}}$ (see Section 3.2.1). Sorption of these species has been reported in soils containing organic matter or oxide minerals, especially at low pH levels. However, these sediment constituents exist in very low concentrations in the far field of the 200 Area Plateau region (Table 5.1). Spiking trace concentrations of ${ }^{125} \mathrm{I}$ into Hanford groundwater, Serne et al. (1993) reported that a coarse gravel/sand recovered from the 200 East Area (sample CGS-1) at the Hanford Site had an average $K_{d}$ values of $0.7 \pm 0.5 \mathrm{~mL} / \mathrm{g}$. In the same experiment, a Touchet sand (sample TBS-1) had an average $K_{d}$ values of $1.4 \pm 1.1 \mathrm{~mL} / \mathrm{g}$, and a Hanford sediment from Trench 8 had average $K_{d}$ values of $1.3 \pm 1.4 \mathrm{~mL} / \mathrm{g}$. Gee and Campbell (1980) obtained appreciably higher $\mathrm{K}_{\mathrm{d}}$ values compared to Serne et al. (1993) using batch techniques, but obtained similar values using column techniques. For a subsurface sediment collected from the 200 Area (Soil B), Gee and Campbell (1980) varied the chemical composition of the aqueous phase and determined, by batch technique, a range of $I-K_{d}$ values of $4 \pm 2$ to $18 \pm 22 \mathrm{~mL} / \mathrm{g}$. Two column studies yielded $K_{d}$ values of 0.04 and $0.06 \mathrm{~mL} / \mathrm{g}$. A conservative range of $\mathrm{I}-\mathrm{K}_{\mathrm{d}}$ values in ambient Hanford groundwater conditions is 0.04 to $18 \mathrm{~mL} / \mathrm{g}$ (Table 6.1 ).

\subsection{Neptunium}

Thermodynamic data suggest that $\mathrm{Np}$ exists as a monovalent cation, $\mathrm{NpO}_{2}^{\ddagger}$, under oxidizing conditions, except above a pH of approximately 9 where it forms a neutral species with bicarbonate $\left(\mathrm{NpO}_{2} \mathrm{HCO}_{3}\right)$ (see Section 3.2.2). The data also indicate that $\mathrm{Np}$ is also capable of complexing with other common anions (chloride, sulfate, fluoride, and nitrate). However, complexed species should not occur at significant concentrations under ambient low ionic strength Hanford groundwater conditions (Table 5.1). Assuming that $\mathrm{NpO}_{2}^{\ddagger}$ is the dominant aqueous species, $\mathrm{Np}$ should sorb via cation exchange. Routson et al. (1976) and Benson (1961) indicated that Np does not compete successfully with common cations for sorption sites. Routson et al. (1976) observed $\mathrm{Np}-\mathrm{K}_{\mathrm{d}}$ values of 2.37 and $0.36 \mathrm{~mL} / \mathrm{g}$ for a Burbank sand at calcium concentrations of $2 \times 10^{-3}$ and $2 \times 10^{-1} \mathrm{M}$, respectively. Np 
sorption in the presence of sodium was also very low: $K_{d}$ values of 3.9 to $3.1 \mathrm{~mL} / \mathrm{g}$ at sodium concentration of $1.5 \times 10^{-2}$ to $3.0 \mathrm{M}$. Serne et al. (1993) determined $\mathrm{Np}-\mathrm{K}_{\mathrm{d}}$ values ranging from $13.5 \pm 3$ to $29.5 \pm 3.6 \mathrm{~mL} / \mathrm{g}$ (an average of $21.7 \pm 8.6 \mathrm{~mL} / \mathrm{g}$ ) for Hanford sediment, Trench 8 , in Np-spiked Hanford groundwater. Based on these data, the range of $\mathrm{Np}-\mathrm{K}_{\mathrm{d}}$ values in ambient Hanford groundwater conditions is 2.4 to $29.1 \mathrm{~mL} / \mathrm{g}$ (Table 6.1 ).

\subsection{Selenium}

Selenium is expected to sorb to Hanford sediments very weakly for a number of reasons. It is likely to exist as an anion (see Section 3.2.3). Specific adsorption onto geologic materials is not likely to play an important role in controlling Se mobility because the plume $(\mathrm{pH} \approx 11)$ and natural groundwater $(\mathrm{pH} \approx 8$ ) will have a sufficiently high $\mathrm{pH}$ to greatly reduce the number of anion exchange sites. Additionally, the plume is expected to have high concentrations of sulfate (total $S$ levels in the plume may be $1 \mathrm{mM}$ [Rawlins et al. 1994]), which are known to compete with Se for mineral adsorption sites (Hingston et al. 1971).

Selenate $\left(\mathrm{SeO}_{4}^{2-}\right)$ sorption experiments onto Hanford sediment CGS-1 had similar results when the background solution was a natural Hanford groundwater ( $\mathrm{pH} 8.3$ ) or a process waste stream ( $\mathrm{pH}$ 4.5). $\mathrm{K}_{d}$ values were $0.78 \pm 2.17$ and $-1.32 \pm 1.96 \mathrm{~mL} / \mathrm{g}$, respectively (Serne et al. 1993). Nearly identical $K_{d}$ values were obtained with Hanford sediments TBS-1 and Trench 8. For the TBS-1 sediment, the Se- $\mathrm{K}_{d}$ value in groundwater was $-3.44 \pm 1.37 \mathrm{~mL} / \mathrm{g}$ and in process waste stream $4.6 \pm 0.7 \mathrm{~mL} / \mathrm{g}$. For the Trench-8 sediment, the Se- $\mathrm{K}_{d}$ value in groundwater was $2.1 \pm 1.2 \mathrm{~mL} / \mathrm{g}$. These are exceptionally low $\mathrm{K}_{\mathrm{d}}$ values compared to those reported in the literature (see Section 3.2.3). The presence of small concentrations of $\mathrm{Al}$ or Fe oxides in the solid phase may result in substantially higher Se sorption (Leckie et al. 1980). The range of Se- $K_{d}$ values in ambient vadose zone sediments is 0 to $0.78 \mathrm{~mL} / \mathrm{g}$ (Table 6.1 ). The quality of the Se data is considered to be good. Additional work must be conducted to determine if the extremely low $K_{d}$ values reported by Serne et al. (1993) are typical of other Hanford sediments.

\subsection{Technetium}

Experimental work on Hanford sediments and soils in oxidized environments indicate that Tc exists as an anion, $\mathrm{TcO}_{4}^{-}$, and does not readily complex with other chemical species (see Section 3.2.4). Consequently, $\mathrm{Tc}$ is considered to be relatively nonadsorbing in most environments, especially in low organic matter, low oxide mineral, and high pH systems, as exist in the Hanford far field. Routson et al. (1976) measured Tc sorption on Hanford soil and measured $K_{d}$ values, which ranged form 0 to $<1 \mathrm{~mL} / \mathrm{g}$. Serne et al. (1993) determined the $\mathrm{Tc}-\mathrm{K}_{\mathrm{d}}$ values of three Hanford sediments: sediment TBS-1 had a $\mathrm{K}_{d}$ of $0.1 \pm 0.5 \mathrm{~mL} / \mathrm{g}$; sediment CGS-1 had a $\mathrm{K}_{d}$ of $0.1 \pm 0.7 \mathrm{~mL} / \mathrm{g}$; sediment from Trench 8 had a $K_{d}$ of $0.1 \pm 0.5 \mathrm{~mL} / \mathrm{g}$. Using two different sediments from the Hanford Site, Gee and Campbell (1980) determined $K_{d}$ values by batch technique ranging from -0.9 to $1.3 \mathrm{~mL} / \mathrm{g}$ and by column technique ranging from 0.017 to $0.04 \mathrm{~mL} / \mathrm{g}$. $\mathrm{K}_{\mathrm{d}}$ values determined with Hanford sediment (Trench 8 ) and leachates derived from solid waste (wood, cardboard, and paper), which contained considerable concentrations of total organic carbon ( 407 to $440 \mathrm{mg} \mathrm{C/L}$ ), showed no significant difference from those determined without organics present. Significant sorption may occur in soils that contain considerable amounts of natural organic matter, which tends to sorb 
anionic species and may reduce $\mathrm{Tc}$ to its +4 oxidation state, causing precipitation or sorption. The quality of the $T c K_{d}$ data is considered to be very good as a result of the good agreement between the several Hanford-specific studies and studies published in the general literature. The range of $\mathrm{Tc}-\mathrm{K}_{d}$ values in ambient conditions in Hanford vadose zone sediments is 0 to $1.3 \mathrm{~mL} / \mathrm{g}$ (Table 6.1).

\subsection{Uranium}

Under oxidizing conditions typical for Hanford vadose zone sediments and the upper unconfined aquifer, dissolved $\mathrm{U}$ is predicted to exist as a cation, $\mathrm{UO}_{2}^{2+}$, up to a $\mathrm{pH}$ of approximately 6; as a neutral hydroxide species, $\mathrm{UO}_{2}(\mathrm{OH}) 2$, from a $\mathrm{pH}$ of 6 to 8; and as an anionic carbonate, $\mathrm{UO}_{2}\left(\mathrm{CO}_{3}\right)_{3}^{4}$, above a $\mathrm{pH}$ of 8 (see Section 3.2.5). Uranium may also complex with other anions (e.g., fluoride, chloride, and phosphate) to form neutral or anionic species, but such complexes should not exist in significant concentrations under ambient Hanford groundwater conditions. These estimated species distributions suggest that $U$ would sorb, via cation exchange, under acid conditions and sorb very poorly under neutral and basic conditions.

Recent laboratory studies indicate that $U$ sorption onto Hanford sediments is weak under ambient Hanford groundwater conditions (Serne et al. 1993). U-K $\mathrm{K}_{d}$ values for a Trench 8 sediment and Hanford groundwater were $1.9 \pm 1.4 \mathrm{~mL} / \mathrm{g}$ at 5 days and $2.1 \pm 0.6 \mathrm{~mL} / \mathrm{g}$ at 44 days of contact (Serne et al. 1993). Adsorption of U onto Hanford Trench 8 sediment from solid waste (wood and paper) leachates containing significant concentration of organic matter was significantly decreased over that of ambient groundwater. The average $K_{d}$ under these conditions values was essentially zero. $K_{d}$ values determined between Trench 8 sediment and leachate from solid waste containing a variety of organic materials and cement (high $\mathrm{pH}$ and relatively high ionic strength) were determined to be $2850 \pm 960 \mathrm{~mL} / \mathrm{g}$ after 5 days and $320 \pm 140$ after 44 days of contact. In another study (Seme et al. 1993), the average U-K $K_{d}$ value for Hanford groundwater and CGS-1 sediment was $1.7 \pm 4.2 \mathrm{~mL} / \mathrm{g}$ and TBS-1 sediment was $79 \pm 26 \mathrm{~mL} / \mathrm{g}$.

Lindenmeier et al. (Draft) ${ }^{(\mathrm{a})}$ conducted a number of $\mathrm{UO}_{2}^{2+}$ column studies under saturated and unsaturated conditions for Trench 8 sediment. In total, they reported 12 column studies and determined the $\mathrm{K}_{\mathrm{d}}$ values to range from 0.08 to $2.81 \mathrm{~mL} / \mathrm{g}$. Using batch techniques, Serne et al. (1993) reported slightly larger $\mathrm{K}_{d}$ values for the Trench 8 sediment, $2.4 \pm 0.6 \mathrm{~mL} / \mathrm{g}$. The higher values obtained by the batch than the column technique is expected because of greater residence time and greater mixing of sediment and aqueous phase. The differences should not be overstated because the values are remarkably similar. There were three primary variables in the $U$ column studies conducted by Lindenmeier et al. (Draft): retention time (residence time of the solute in the sediment column),

pore-water velocity, and volumetric water content. The factor having the greatest effects on the $U-K_{d}$ values was the volumetric water content; its correlation coefficient with $U-K_{d}$ was 0.691 (degrees of freedom $=8, P \leq 0.01$ ). Retention time and pore-water velocity was not significantly correlated $(P \geq 0.05)$ to $U-K_{d}$ values. It is important to note that all three of these parameters are concomitant, and therefore a true statistical measure of their significance on the dependent variable, $U-K_{d}$ value, requires covariant analysis. This analysis is not possible with the nonreplicated data set. However,

(a) Lindenmeier, C. W., R. J. Seme, J. L. Conca, and A. T. Owen. Draft. Solid-Waste Leach Characteristics and Contaminant-Sediment Interactions. Volume II. Contaminant Transport Under Partially Saturated Systems. Pacific Northwest Laboratory, Richland, Washington. 
this study represents the first in-depth study of $U$ transport in unsaturated conditions and in addition to providing $\mathrm{K}_{d}$ values under unsaturated conditions identifies a number experimental variables related to unsaturated column studies that have an effect on measured $K_{d}$ values. ${ }^{(a)}$

General indications are that $U$ sorption values will be low under most ambient Hanford circumstances because $U$ tends to form neutral or anionic carbonate species at neutral or basic $\mathrm{pH}$ values. The range of $K_{d}$ values of $U$ in ambient vadose zone sediments is 0.08 to $79.3 \mathrm{~mL} / \mathrm{g}$ (Table 6.1 ). A vast majority of the $U-K_{d}$ values reported are on the lower end of this range. Although the quality of the $U-K_{d}$ data is considered to be fairly good, the PA calculations show that dose is very sensitive to the $K_{d}$ of $U$. When $U-K_{d}$ values below $0.5 \mathrm{~mL} / \mathrm{g}$ were inputed into the transport code, $U$ was the key dose contributor (Piepho et al. 1994).

\subsection{Other Radionuclides}

A number of radionuclides in addition to $\mathrm{Tc}, \mathrm{I}, \mathrm{Np}, \mathrm{Se}$, and $\mathrm{U}$ are known to exist in the LLW tanks. They include ${ }^{241} \mathrm{Am},{ }^{14} \mathrm{C},{ }^{137} \mathrm{Cs},{ }^{239} \mathrm{Pu},{ }^{240} \mathrm{Pu}$, and ${ }^{90} \mathrm{Sr}$. Based on scoping studies that are presently being reexamined, these and other radioisotopes are believed to pose less of a dose threat because they exist in sufficiently low concentrations in the waste, have short half-lives, or are retarded by Hanford vadose sediments sufficiently that they will not reach the biosphere in the next 10,000 to 100,000 years. Estimates of $\mathrm{K}_{\mathrm{d}}$ values for these radionuclides are presented in Tables $6.1,6.2,6.3$, and 6.4 .

(a) Lindenmeier, C. W., R. J. Serne, J. L. Conca, and A. T. Owen. Draft. Solid-Waste Leach Characteristics and Contaminant-Sediment Interactions. Volume II. Contaminant Transport Under Partially Saturated Systems. Pacific Northwest Laboratory, Richland, Washington. 


\subsection{Geochemical Data Needs for Improving Transport Modeling of Radionuclides Through Hanford Sediments and Engineered Barriers}

\subsection{Strategy}

The process proposed to define and constrain the geochemical data collection program is illustrated in Figure 1.1. The initial phase is subdivided into four parts that compose the baseline data collection. Radionuclides and contaminants are identified from historical records, existing analyses of waste materials, and computer projections of inventories.

Geochemical parameters are chemical and physical properties of the waste disposal environment that influence geochemical reactions between the radionuclides and hazardous wastes and the pore water and sediments. The reactions of interest are those affecting radionuclide and contaminant mobility including solubility, sorption, desorption, and release rates from solid-waste forms. The important parameters include pore water and recharge water composition, sediment composition, and waste-form composition and its leachate composition. Other important parameters influencing contaminant transport by groundwater are sediment porosity, permeability, moisture content, and groundwater recharge characteristics.

Hydrologic parameters used in performance assessment analyses are generally derived from properties measured at the specific site of interest. Geochemical reaction values for radionuclides or hazardous chemicals (e.g., sorption, solubility) are generally derived from laboratory studies that evaluate the effects of chemical parameters for the ranges of values that are pertinent to the site. Solubility data are sometimes derived from thermodynamic calculations that use site-relevant chemical conditions. As part of this report, a baseline adsorption database that is specific to Hanford Site defense waste has been assembled from available information.

Having established a database, an iterative process is needed to delimit completion of data collection. Additional data needs are identified on the basis of performance assessment modeling (i.e., pathways analysis) or generally acknowledged lack of information. If the pathways analysis, which is done on an contaminant-by-contaminant basis, indicates an unacceptable degree of uncertainty for the reaction values used as input to the models, additional data are required. Additional data may also be required to quantify parameter values that affect geochemical reaction values. For example, the effect of moisture content on sorption distribution coefficients $\left(\mathrm{K}_{d}\right)$ can be calculated using simple conceptual models, but such conceptual models have not been validated and the calculations are supported by few test data.

Once data have been collected and appropriate analyses have been used to generate model input data, the adequacy of available data is evaluated by using the input data in a computer code that predicts transport and release of contaminants to the environment. To address uncertainty, a range of input values is generally used. The model's sensitivity results are compared to acceptable release values to determine if predicted releases are acceptable. If the range of input values used results in a range of predicted release values that is ambiguous (e.g., releases are unacceptable or acceptable, depending on which specific value within the range of values is used), then additional data on the waste form or engineered system may be required (see Figure 1.1) to reduce (or at least better define) the range of uncertainty. 
The principal emphasis of this report is on laboratory or bench-scale methods of data generation; however, other methods are also discussed. The emphasis of the testing approach will be empirical; the expected environment will be simulated, and geochemical reactions between radionuclides or hazardous chemicals and the simulated environment will be observed. This approach is recommended for two reasons. First, in many cases, numerous kinds of reactions are possible such that mechanistic studies could never be completed, given the time or resources available. Second, the empirically derived data can be used easily by computer PA codes.

A mechanistic approach could be used where feasible (e.g., solubility calculations). For each test method, the data to be collected are identified and their use in a PA is described. The advantages and disadvantages of the proposed test method and the proposed scope of the test matrix are also described. To the extent possible, the decision points to be used to judge when testing is complete will also be identified.

In addition to empirical data collection, associated tasks are identified that provide either information on the environment the tests are to simulate or provide corroborative mechanistic data to compare with empirically derived data. The following subsections describe the general approach proposed for acquiring the needed geochemical data. Greater detail of each experiment is presented in the Statement of Work for the LLW-PA program (Hanford Tank Low-Level Waste Performance Assessment Group Draft).(a)

\subsection{Sorption Data}

An interactive approach to modeling radionuclide sorption processes and groundwater transport will be conducted using LLW PA System codes. The models and the resultant PA calculations will build upon each other and become progressively more mechanistic and therefore more robust. The early model will be the constant $K_{d}$-model (see Section 2.1 .1 ). The current model is the least robust. It describes the sorption of a radionuclide only under one set of aqueous and sediment conditions. Yet, parameters for this model are the easiest and fastest to obtain through laboratory testing. It will be used to provide early guidance for transport modeling. A parametric- $K_{d}$ model (Section 2.1.2) will then be built upon the constant- $K_{d}$ model. The parametric- $K_{d}$ model varies $K_{d}$ values through a set of empirically-derived functions of aqueous and sediment parameters. By the time development for this model begins, a much better idea of the burial design and location will be available, providing more information about the aqueous composition of the plume and the types of barriers and sedi-

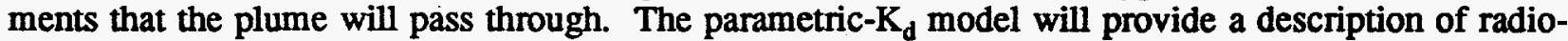
nuclide sorption for key contaminants using regression analysis over the range of conditions likely to exist in the plume's path. The parametric- $K_{d}$ model will not be very difficult to incorporate into existing transport codes. It can be included by adding a separate subroutine or a reference table to the transport code. Finally, the parametric- $K_{d}$ or the constant- $K_{d}$ models will be modified to include some mechanistic-based processes. A mechanistic-based model provides more robustness, and perhaps more importantly, is more scientifically defendable. However, as stated earlier, an entirely mechanistic model is not possible at this time. Our semi-mechanistic model will represent a compromise between increasing robustness, accuracy, and ease of obtaining input parameters for the model.

(a) Hanford Tank Low-Level Waste Performance Assessment Group. Draft. Statements of Work for FY 94. Westinghouse Hanford Company, Richland, Washington. 
For instance, if the number of radionuclide exchange sites is found to be greatly dependent on the $\mathrm{pH}$ of the system, then data from a laboratory titration may be included in the model instead of using a fixed exchange capacity value. Again, we will limit our semi-mechanistic model to address only those nuclides that are shown to be the greatest dose contributors.

At several points during the development of the sorption database an iterative loop process between PA-modeling and laboratory experimentation will be used to determine additional data needs. It is already acknowledged that there is a need to determine the range and distribution (e.g., normal Gaussian, log-normal) of site-specific sorption values for key radionuclides. Such information is necessary for stochastic modeling and uncertainty analyses. This can be accomplished rather easily by collecting a sufficiently large number of sediment water combinations for the site and determining $\mathbf{K}_{d}$ values. The effect of moisture content on sorption is not clearly understood (see Section 2.1.4). Although moisture content effects can be theoretically calculated, such calculations are supported by few test data. This information is not as easily determined, but our laboratory has had experience in this area. An analytical problem also exists concerning the measurement of low $\mathbf{K}_{d}$ values. Large errors (often with coefficients of variation exceeding $200 \%$ ) are associated with these values because two large numbers (influent and effluent solution concentrations) with significant counting uncertainties are subtracted from each other to yield the low $K_{d}$ values with concomitant large uncertainties. Another important issue concerning $K_{d}$ measurements is how to account for particles larger than sand (2-mm diameter). No standard methods exist. The "gravel-corrected $\mathbf{K}_{\mathbf{d}}$ issue" exists at two levels. First, the presence of gravel and larger particles (e.g., cobbles) in the subsurface and a laboratory sample is very heterogeneous. Furthermore, a typical $K_{d}$ test requires between 0.5 and $10 \mathrm{~g}$ of sediment less than the weight of one gravel grain. Second, the specific surface area $\left(\mathrm{m}^{2} / \mathrm{g}\right)$ of gravel and other large particles is orders of magnitude less than that of sandy sediments. Therefore, the inclusion of gravel into the sample greatly reduces measured $\mathrm{K}_{d}$ values.

Batch tests are commonly used to measure $\mathrm{K}_{\mathrm{d}}$ values, the ratio of the concentration of an element associated with the solid (e.g., soil) to that of the liquid (e.g., groundwater) phase (see Section 2.1.1). The test is conducted by spiking a solution with the element of interest, mixing the solution with the solid for a specified period of time, separating the solution from the solid, and measuring for calculating the concentration of the spiked element in the solution and solid. A primary advantage of such data is that they are easily inserted into hydrologic transport codes to quantify reduction in the rate of transport of the contaminant relative to groundwater, either by advection or diffusion. A second advantage is that such experiments can be completed quickly for a wide variety of elements and chemical environments.

The primary disadvantage is that the batch experiment does not necessarily reproduce the chemical reactions that take place in the real environment, where solution is passing through the soil column at a finite rate because both reaction time and the degree of mixing between solid and solution can be much less in the flow-through situation. Consequently, distribution coefficients from batch experiments can be high relative to reality, resulting in nonconservative estimates of release using transport codes with these data as input. A second disadvantage relative to the Hanford Site vadose zone environment is that batch experiments are done under saturated conditions so that the effects of partial saturation on sorption processes cannot be investigated. A third disadvantage is that the batch adsorption experiment does not simulate release of radionuclides or contaminants from a contaminated soil or solid waste source (i.e., such reactions are basically desorption reactions). However, sorption values are frequently used based on the assumption that sorption and desorption reactions are reversible, despite the observation that elements tend to desorb at a slower rate or be 
irreversibly sorbed to some extent. Thus, use of adsorption values from batch tests in release and transport models is generally considered to provide conservative or high release estimates.

Flow-through column experiments are intended to provide a more realistic simulation of the soil column environment and to quantify the movement of contaminants relative to groundwater flow. The basic experiment is completed by passing a liquid spiked with the contaminant of interest through the sediment column. Sorption and desorption processes can be studied in this manner. The column experiment combines the chemical effects of sorption and the hydrologic effects of groundwater flow through a porous medium to provide an estimate of retarded movement of the contaminant of interest. The retardation factor is measured directly from the experimental data, rather than a sorption distribution coefficient $\left(\mathrm{K}_{d}\right)$, as in the case of the batch sorption experiments. A sorption distribution coefficient can be back calculated from the retardation factor. It is frequently useful to compare the back-calculated sorption distribution coefficient $\left(\mathrm{K}_{d}\right)$ from these experiments with those derived directly from the batch experiments to evaluate the influence of limited interaction between solid and solution imposed by the flow-through system.

As with batch sorption data, the retardation factor can be inserted easily into a hydrologic transport code, quantifying the reduction in the rate of transport of the element relative to groundwater by either advection or diffusion. A second advantage is that the column experiment provides a much closer approximation of the real environment than a batch sorption experiment and affords greater confidence in the application of the data to transport models. Not only the influence of limited interaction (by either time or physical contact) between water and solid on sorption reactions, but also the influence of partial saturation and partially saturated flow, can be investigated. A third advantage is that sorption or desorption reactions can occur by numerous mechanisms. The predominance of one mechanism over another cannot be predicted a priori and thus generalizing the results from one set of laboratory experimental conditions to field conditions is never without some uncertainty. A potential disadvantage is that some soil properties cannot be accommodated by laboratory-size equipment because of the large particle size of some typical soils (e.g., cobbles and boulders). Care must be taken to justify the assumption that environmental changes between laboratory and field situations have no significant effect on contaminant distributions between soil and water.

The types of parameters to be considered as a matrix for column tests are similar to those for batch sorption tests. These include soil types, contaminants and their concentration, and liquid/ groundwater waste compositions. However, both physical and chemical soil characteristics are needed for column experiments, particularly ranges of porosity, permeability, and grain-size distribution. Physical properties dictate the flow of contaminants through a column while chemical properties influence chemical reactions that retard or reduce contaminant transport relative to groundwater. The list of contaminants (radionuclides and chemicals) and liquid waste compositions to be tested with column experiments will be reduced relative to the combinations tested in the batch sorption experiments because of time and laboratory constraints. Additional potentially influential parameters include the degree of saturation and flow characteristics. The most important zone of transport that needs quantification is the Hanford vadose zone, which is variably saturated depending on the depth below surface, the intermittent and seasonal variability of recharge from precipitation, and particle size distribution. At present, these variations have not been rigorously examined. Similarly, current mathematical representations of transport through the vadose zone are extremely simplified. 


\subsection{Solubility Data}

Examination of solubility data needs will be delayed until FY1996 to provide additional time for site selection and completion of the burial design. Solubility data will be used primarily in the near field where the system may not be in equilibrium (see Section 4.0) and will be collected in a threestep process. The first step is to review the literature and determine what constants are available. The second step is to conduct thermodynamic calculations to determine if the concentration of a particular radionuclide is in fact likely to be controlled by solubility. These first two steps will progress in an iterative fashion until laboratory-derived data needs are identified. The third step is to conduct laboratory empirical solubility studies.

Only a few solubility-type experiments need to be done because solubility values from literature sources likely can be used for most radionuclides of interest. A solubility experiment may be completed in a fashion similar to the batch sorption tests: a known solid containing the radionuclide would be contacted with various pore water compositions. The steady-state solution concentration is assumed to be the solubility controlled value. As a check, the solubility could be approached from oversaturation by adding dissolved contaminants to the system until the solution concentration stopped increasing when placed in contact with the soil or backfill material of interest. The empirical solubility value can be determined by observing the relationship between the initial and final solution compositions. When the final solution concentration cannot be increased as the initial concentration continues to be increased, that concentration value will be taken as the solubility value. A similar experiment can also be completed without the soil or backfill. Alternatively, excess suspected precipitate can be placed in simulated groundwater and the final steady-state solution concentration measured. When these tests yield similar results, it will be fairly certain that an accurate solubility value has been determined for the given conditions.

As with sorption values, empirical solubility concentrations can be placed easily in transport codes as the source-term and provide conservative estimates of release unless environmental conditions change such that solubility is increased. It is important to justify the likely range of chemical conditions over time that the near-field and perhaps the far-field sediment will experience. A disadvantage of the empirical solubility experiment is that other factors such as colloid formation may artificially increase the observed concentration, thereby increasing release estimates and possibly leading to unnecessary and costly remedial action proposals.

The parameter types to be considered in solubility experiments are essentially identical to those for batch adsorption tests: soil and/or backfill types, choice of radionuclide, and types of effluent solutions. Establishment of the test matrix will depend on the final design and location of the burial site.

\subsection{Diffusion Data}

One of the parameters to be used in the aqueous transport modeling of radionuclides through sediment is diffusion (Equation 6; Section 2.3). Diffusion is the transport of solutes in the absence of bulk flow. It is a much slower solute transport process than advection and is likely to dominate immediately below the impermeable surface barrier and through any engi-neered barriers that may exist in the near field. Advective flow will predominate in the unsaturated zone sediments outside the protective barriers. 
The determination of effective diffusion coefficients (Equation 25) will be delayed until 1) a full literature review of available Hanford Site data is completed, and 2) the design of the near field barriers are better known. The effective diffusion coefficient is a semi-empirical parameter that is unique for a given porous material and aqueous phase. The determination of the effective diffusion coefficients of nonsite-specific materials and leachates may provide little additional guidance that is not already available from the literature. Thus, once the burial design (engineered barriers and type of vitrified glass) and the chemical composition of the vitrified waste have been determined, a more detailed description will be provided of the experiments to be performed. Because of the empirical nature of this parameter, it is presently known that a separate test will have to be conducted for each radionuclide, leachate, and porous media.

The barrier materials to be used at the burial site will have very low effective diffusion coefficients. Diffusion of water solutes through such barrier materials as asphalt/aggregate are likely to be $<10^{-10} \mathrm{~cm}^{2} / \mathrm{s}$ and therefore would require several years to determine by classical methods. For example, Daiev and Vassilev (1985) found ${ }^{90} \mathrm{Sr}$ diffusion coefficients through pure bitumen to be $1.5 \times 10^{-12}$ to $3.3 \times 10^{-12} \mathrm{~cm}^{2} / \mathrm{s}$ in tests that took 6 to 12 years to yield data. The penetration depth of ${ }^{90} \mathrm{Sr}$ was only $0.06 \mathrm{~cm}$ and $0.09 \mathrm{~cm}$ after 6 and 12 years, respectively. The experimental methods to be used to determine effective diffusion coefficients may include the ANS 16.1 leach method, an immersion method, and/or a half-cell method. These methods are used on a routine basis at PNL and are described in Kincaid et al. (1993).

\subsection{Mobile Colloids Facilitated Transport Data}

To determine if mobile colloids are important in the transport of radionuclides in the burial site, three "go/no-go" decision steps will be conducted. The first such decision step will be determined after conducting a comprehensive literature review and calculating the extent of chemical precipitation that may result in the in situ formation of mobile colloids. The literature review is the subject of a topical paper that will be submitted June 1997 entitled "Importance of Colloid-facilitated Transport of Contaminants for Hanford LLW PA" (Section 7.6). This will be an important step because if colloids are found to be important to the PA, this finding will provide essential focus to the ensuing laboratory experiments. For example, poorly sorbing or highly soluble radionuclides are known not to be influenced by colloid-facilitated contaminant transport. Thus, there is little need to evaluate the extent that ${ }^{129} \mathrm{I}^{-}$and ${ }^{99} \mathrm{TcO}_{4}^{-}$are transported on colloids. This step will be defined as a "go" if the literature review and modeling provides reason to believe that colloids may be important to the PA. The second step involves determining whether colloids can move through Hanford site-specific sediments under unsaturated conditions. A set of column experiments will be conducted in the laboratory using fluorescent microspheres ranging between 20 to $200 \mathrm{~nm}$ in diameter. Several different size colloids, each with a unique fluorescence, will be introduced into unsaturated columns, recovered as a function of time, and determined by epifluorescent-microscopy techniques (Hobbie et al. 1977). This step will be defined as a "go" if colloids can be transported through unsaturated sediments. If colloids cannot be transported through the Hanford unsaturated sediments, the step will be defined as a "no-go" and colloid experimentation will cease. The third step in this experimentation involves sorbing radionuclides to colloids (precipitating or adsorbing radionuclides to the $<200$-nm fraction of site-specific sediment or radionuclide homogeneous precipitates), introducing them to unsaturated Hanford sediment packed in columns, and then determining the activity of the radionuclides in ultrafiltered effluent. The results of these experiments can be modelled by a number of already existing codes (Bengtsson et al. 1987, Mills et al. 1991, Smith and Degueldre 1993). As is the case in many fields of science, empirical modeling of three-phase solute transport is more advanced than the understanding of the phenomena. The simplest way that these 
phenomena can be included in existing transport codes is through the use of four, instead of two, inputs: the concentration of radionuclide in dissolved phase $\left(\mathrm{C}_{i}\right)$, the concentration of radionuclide in the colloid phase $\left(C_{c i}\right)$, the $K_{d}$ value of $C_{i}\left(C_{i}-K_{d}\right)$, and the the $K_{d}$ value of $C_{c i}\left(C_{c i}-K_{d}\right)$. More sophisticated approaches to modeling three phase transport are available; however, such models require a fairly large number of input parameters (reviewed by Mills et al. 1991, McCarthy and Degueldre 1993, Smith and Degueldre 1993).

\subsection{Technical Defensibility}

Technical defensibility is a requirement for all aspects of the Hanford LLW PA. To address this requirement, written justification/rationale will be produced for the specific chemical retardation data offered to the transport code users. In addition, various geochemical issues that arise during the performance assessment process will be addressed. Specific issues that already merit discussion include: the proper method to measure low sorption ("small- $K_{d}$ issue"), the gravel dependency of $K_{d}$ ("gravel-corrected- $K_{d}$ issue"), the moisture content dependency of $K_{d}$ (see Section 2.1.4), defending the long-term extrapolation of short-term laboratory data, the proper conceptual model for diffusion of reactive constituents in partially saturated sediments (see Section 2.3), the use of natural analogs to validate lab-generated geochemical interaction data, the influence of colloids on contaminant transport (see Section 2.4), and the adequacy of $K_{d}$ versus more mechanistic adsorption conceptual models (see Section 2.1.3).

These geochemical issues and others that emanate from the reviewers of the performance assessments will be addressed using letter reports or topical reports that draw from literature and projectspecific laboratory studies. For a number of geochemical input parameters for the transport codes, the literature review will be used as the first go/no-go decision step in evaluating the need for further laboratory experimentation (see previous sections in this chapter). The following topical reports are forecast (others will be identified as issues surface):

- "Proper Treatment of Reactive Contaminant Diffusion in Partially Saturated Sediments" (due September 1996)

- "Influences of Moisture Content on Measured Kd Values" (due June 1996)

- "Technical Rationale for Chemical Retardation Values Used in Preliminary Performance Assessment" (due March 1997)

- "Importance of Colloid-facilitated Transport of Contaminants for Hanford LLW Performance Assessment" (due June 1997)

- "Technical Rationale for Chemical Retardation Values Used in Final Performance Assessment" (due January 1999)

- "Use of Natural Analogues and Thermodynamics to Defend Long-term Extrapolation of Laboratory Chemical Retardation Data" (due November 1997)

- "Applicability of Mechanistic Adsorption Models for Key Contaminants in Hanford LLW Glass Disposal" (due September 1998). 
Additionally, WHC and PNL will organize a workshop in the next years specifically to obtain expert consensus on a number of geochemical issues relevant to the Hanford vitrified LLW PA including: 1) appropriate lab methods to obtain accurate $K_{d}$ results for low adsorbing contaminants, i.e., the "small- $K_{d}$ issue," 2) dependency of $K_{d}$ on moisture content, 3) appropriate treatment of sorption on coarse material, i.e., the "gravel-corrected- $K_{d}$ issue," 4) long-term extrapolation of short-term laboratory data using thermodynamic and natural analogues, 5) adequacy of the $\mathrm{K}_{\mathrm{d}}$ approach versus more mechanistic adsorption conceptual models, and 6) influence of colloids on facilitating contaminant transport. 


\subsection{Conclusions}

Burial of vitrified LLW in the vadose zone of the Hanford Site is being considered as a long-term disposal option. Regulations dealing with LLW disposal require that PA analyses be conducted before licensing. Previous PA analyses for proposed disposal actions at the Hanford Site (DOE 1987, Kincaid et al. 1993, Piepho 1994, Wood et al. 1994) show that groundwater transport presents the greatest potential for long-term dose uptake by humans. The concentration of LLW contaminants in groundwater is determined by the amount of contaminant present in the solid waste, rate of release from the waste and surrounding barriers, and a number of geochemical processes including adsorption, desorption, diffusion, precipitation, and dissolution. To accurately predict radionuclide transport through the subsurface, it is essential that the important geochemical processes affecting radionuclide transport be identified, and perhaps more importantly, accurately quantified and described in a mathematically defensible manner.

Particular attention was directed at understanding the important geochemical factors in unsaturated, alkaline, high carbonate, low natural organic matter concentration environments affecting the retardation of ${ }^{129} \mathrm{I},{ }^{237} \mathrm{~Np},{ }^{79} \mathrm{Se},{ }^{99} \mathrm{Tc}$, and ${ }^{234,235,238} \mathrm{U}$. These radionuclides have been identified by preliminary scoping studies as presenting the greatest potential health hazard at Hanford (Piepho et al. 1994). This list will likely change during the course of the study as more information about the location and design of the burial site, waste form recipe, and engineered barrier become available. Based on a preliminary literature review of laboratory studies conducted with Hanford sediments and groundwater, reported $K_{d}$ values were presented: $I$ is 0.04 to $18 \mathrm{~mL} / \mathrm{g}, \mathrm{Np}(\mathrm{V})$ is 2.4 to $29.1 \mathrm{~mL} / \mathrm{g}$, $\mathrm{Se}(\mathrm{IV})$ is 0 to $0.78 \mathrm{~mL} / \mathrm{g}, \mathrm{Tc}$ (VII) is 0 to $1.3 \mathrm{~mL} / \mathrm{g}$, and $\mathrm{U}(\mathrm{VI})$ is 0.08 to $79.3 \mathrm{~mL} / \mathrm{g}$. A conservative estimate of the $K_{d}$ range for I is 0 to $0.8 \mathrm{~mL} / g, N p(V)$ is 2 to $5 \mathrm{~mL} / \mathrm{g}, \mathrm{Se}(I V$ or VI) is 0 to $4 \mathrm{~mL} / \mathrm{g}$ Tc(VII) is 0 to $0.8 \mathrm{~mL} / \mathrm{g}$, and $\mathrm{U}(\mathrm{VI})$ is 0 to $10 \mathrm{~mL} / \mathrm{g}$ (Table 6.1). These $\mathrm{K}_{\mathrm{d}}$ ranges, as well as those for $\mathrm{Ac}, \mathrm{Am}, \mathrm{C}, \mathrm{Ce}, \mathrm{Cm}, \mathrm{Co}, \mathrm{Cs}, \mathrm{Eu}, \mathrm{Nb}, \mathrm{Ni}, \mathrm{Pa}, \mathrm{Pb}, \mathrm{Pu}, \mathrm{Ra}, \mathrm{Ru}, \mathrm{Sn}, \mathrm{Sr}$, Th, and $\mathrm{Zr}$ were provided for four general categories of leachates: 1) alkaline, low salt, low organic, oxidized solutions (Table 6.1); 2) alkaline, low salt, low organic, anoxic solutions (Table 6.2); 3) alkaline, high salt, low organic, oxidized solutions; and 4) alkaline, high salt, low organic, reduced solutions. Refinement of these categories will likely be required as more information about the burial design becomes available.

A process has been proposed to define and constrain the geochemical data collection program (Figure 1.1). The initial phase is subdivided into four parts that compose the baseline data collection. Radionuclides and contaminants are identified from historical records, existing analyses of waste site materials, and computer projections of inventories. A detailed outline of the laboratory work proposed in this document has been previously reported (Hanford Tank Low-Level Waste Performance Assessment Group Draft).(a) This work is expected to take five years to finish.

Once a database has been established, an iterative process is used to delimit completion of data collection. Additional data needs are identified on the basis of PA modeling (i.e., pathways analysis) or generally acknowledged lack of information. If the pathways analysis, which is done on a contaminant-by-contaminant basis, indicates an unacceptable degree of uncertainty for the reaction values used as input to the models, additional data are required. Additional data may also be required to quantify parameter values that affect geochemical reaction values. For example, the effect of moisture content on chemical retardation $\left(R_{f}\right)$ can be theoretically calculated from simple conceptual models, but such calculations are supported by few test data.

(a) Hanford Tank Low-Level Waste Performance Assessment Group. Draft. Statements of Work for FY 94. Westinghouse Hanford Company, Richland, Washington. 
release of contaminant to the environment. To address uncertainty, a range of input values is generally used. The model's sensitivity results are compared to acceptable release values to determine if predicted releases are acceptable. If the range of input values used results in a range of predicted release values that is ambiguous (e.g., releases are unacceptable or acceptable, depending on which specific value within the range of values is used), then additional data on the waste form or engineered system may be required (see Figure 1.1) to reduce (or at least better define) the range of uncertainty.

The principal emphasis of this report is on laboratory or bench-scale methods of data generation; however, other methods are also discussed. The emphasis of the testing approach will be empirical; the expected environment is simulated, and geochemical reactions between radionuclides or hazardous chemicals and the simulated environment are observed. This approach is recommended for two reasons. First, in many cases, numerous kinds of reactions are possible such that mechanistic studies could never be completed, given the time or resources available. Second, the empirically derived data can easily be used by computer PA codes.

Technical defensibility is a requirement of all aspects of the Hanford LLW PA. To address this requirement, written justification and rationale will be produced for the specific chemical retardation data offered to the transport code users. In addition, various geochemical issues that arise during the PA process will be addressed.

These geochemical issues and others that emanate from reviewers of the PAs will be addressed using letter or topical reports that draw from literature and project-specific laboratory studies. For a number of geochemical input parameters for the transport codes, the literature review will be used as the first go/no-go decision step in evaluating the need for further laboratory experimentation (Sections 7.2, 7.3, 7.4, and 7.5). Data of increasing detail and pedigree will be available for each of the three system performance assessment calculations scheduled for completion by September 1997. Ancillary analyses and discussion that justifies the $K_{d}$ values chosen and addresses the long-term validity of the values will be prepared for consideration of the various internal and external peer review panels. 


\subsection{References}

Ames, L. L., J. E. McGarrah, B. A. Walker, and P. F. Salter. 1982. "Sorption of Uranium and Cesium by Hanford Basalts and Associated Secondary Smectites." Chem. Geol. 35:205-225.

Ames, L. L., and S. J. Phillips. 1979. Characterization of the Hanford 300 Area Burial Grounds. PNL-2658, Pacific Northwest Laboratory, Richland, Washington.

Ames, L. L., D. Rai, and R. J. Seme. 1976. A Review of Actinide-Sediment Reactions with an Annotated Bibliography. BNWL-1983, Pacific Northwest Laboratory, Richland, Washington.

Ames, L. L., and D. Rai. 1978. Radionuclide Interactions with Soil and Rock Media.

EPA 520/6-78-007, U.S. Environmental Protection Agency.

Andreyev, P. F., and A. P. Chumachenko. 1964. "Reduction of Uranium by Natural Organic Substances." Geochem. Int. 1:3-7.

American Nuclear Society (ANS). 1986. Measurement of the Leachability of Solidified Low-Level Radioactive Wastes by a Short-Term Test Procedure. ANSI/ANS 16.1, American Nuclear Society, La Grange Park, Illinois.

Baes, C. J., Jr., and R. E. Mesmer. 1976. The Hydrolysis of Cations. John Wiley, New York.

Baetsle, L. W., F. Maes, J. Souffriau, and P. I. Staner. 1966. Migration de Radi-Elements Dans le Sol. EUR 2481.f.

Bates, J. K., W. L. Ebert, B. P. McGrail, and D. Rai. 1994. "Investigation Plan: Long-Term Performance Evaluation of Waste Forms for Hanford Low-Level Waste." PVTD-C94-21.01G. Letter report submitted to Westinghouse Hanford Company.

Bear, J., and A. Verraijt. 1987. "Modeling Groundwater Flow and Pollution." P. Reidel Publishing Co., Boston, Massachusetts.

Bell, L. C., A. M. Posner, and J. P. Quirk. 1972. "Surface Charge Characteristics of Hydroxyapatite and Fluorapatite." Nature. 239:515-517.

Bengtsson, G., C. F. Enfield, and R. Lingquist. 1987. "Macromolecultes Facilitate the Transport of Trace Organics." Sci. Total Environ. 67:159-164.

Benjamin, M. M., and N. S. Bloom. 1981. "Effects of Strong Binding of Anionic Adsorbates on Adsorption of Trace Metals on Amorphous Iron Oxhydroxide." Adsorption from Aqueous Solutions. ed., P. H. Tenari, pp. 41-60. New York: Plenum Press.

Benson, D. W. 1961. Mineral Adsorption of Radionuclides in Reactor Effluent. HW-69225, General Electric Company, Hanford Atomic Products Operation, Richland, Washington.

Benson, D. W. 1960. Review of Soil Chemistry Research at Hanford. HW-67201. Hanford Atomic Products Operation, Richland, Washington. 
Birch, L. D., and R. Bachofen. 1990. "Effects of Microorganisms on the Environmental Mobility of Radionuclides." In Soil Biochemistry: Volume 6. eds. J. M. Bollag and G. Stotzky, pp. 101-124, Marcel Dekker, Inc., New York.

Boggs, S., Jr., D. Livermore, and M. G. Seitz. 1985. Humic Substances in Natural Waters and their Complexation with Trace Metals and Radionuclides: A Review. ANL-84-78, Argonne National Laboratory, Argonne, Illinois.

Bondietti, E. A., and C. W. Francis. 1979. "Geologic Migration Potentials of Technetium-99 and Np-237." Sci. 203:1337.

Borovec, Z., B. Kribek, and V. Tolar. 1979. "Sorption of Uranyl by Humic Acids." Chem. Geol. 27:39-46.

Bowen, H. J. N. 1966. Trace Elements in Biochemistry. Academic Press, London.

Box, G. E. P., and D. W. Behnken. 1960. "Some New Three Level Designs for the Study of Quantitative Variables." Technometrics. 2:455-475.

Bruno, J., I. Casas, and I. Puigdomenech. 1988. "The Kinetics of Dissolution of $\mathrm{UO}_{2}(\mathrm{~s})$ Under Reducing Conditions." Radiochim. Acta 11:44-45.

Bruno, J., I. Casas, and I. Puigdomenech. 1991. "The Kinetics of Dissolution of $\mathrm{UO}_{2}$ Under Reducing Conditions and the Influence of an Oxidized Surface Layer $\left(\mathrm{UO}_{2+\mathrm{x}}\right)$ : Application of a Continuous Flow-through Reactor," Geochim. Cosmochim. Acta 55:647-658.

Buddemeir, R. W., and J. R. Hunt. 1988. "Transport of Collodial Contaminants in Groundwater: Radionuclide Migration at the Nevada Test Site." Applied Geochem. 3:535-548.

Cataldo, D. A., R. E. Wildung, and T. R. Garland. 1978. "Technetium Accumulation, Fate, and Behavior in Plants." pp. 207-220. In Environmental Cycling Processes, D. C. Adriano and I. L. Brisbin, eds. University of Georgia, Athens, Georgia.

Cochran, G. W., and G. M. Cox. 1957. Experimental Design. 2nd ed. Wiley, New York.

Conca, J. L., and J. Wright. 1992. Direct Determinations of Unsaturated Flow and Transport. Proceedings of the 12th Annual AGU Hydrology Days Conference. American Geophysical Union. Washington, DC.

Côté, P. L., T. W. Constable, and A. Moreira. 1987. "An Evaluation of Cement-Based Waste Forms Using the Results of Approximately Two Years of Dynamic Leaching." Nucl. Chem. Waste Manage 7:129-139.

Cotton, F. A., and G. Wilkinson. 1972. Advanced Inorganic Chemistry, A Comprehensive Test, 3rd Edition. John Wiley and Sons, Inc., New York.

Coughtrey, P. J., D. Jackson, and M. C. Thome. 1983. "Radionuclide Distribution and Transport in Terrestrial and Aquatic Ecosystems. A Critical Review of Data." ECSC, EEC, EAEC, Brussels and Luxembourg. 
Daiev, Ch. R., and G. P. Vassilev. 1985. "On the Diffusion of ${ }^{90} \mathrm{Sr}$ From Radioactive Wastes Bitumenized by the Mould Method." J. of Nucl. Mat. 127:132-136.

Davies, O. L. 1954. Design and Analysis of Industrial Experiments. Hafner, New York.

Dayal, R., H. Arora, and N. Morcos. 1983. Estimation of Cesium-137 Release from Waste/Cement Composites Using Data from Small-Scale Specimen. NUREG/CR-3382, Nuclear Regulatory Commission, Washington, D.C.

Dean, J. A., Editor. 1973. Lange's Handbook of Chemistry. McGraw-Hill, New York, pp. 6-30.

Degueldre, C., G. Longworth, V. Mowlin, and P. Vilks. 1989. "Grimsel Colloid Exercise. An International Intercomparison Exercise on the Sampling and Characterization of Groundwater Colloids." No. 39. Paul Scherrer Institut-Bericht, Wurenlingen und Villigen, Switzerland.

Delegard, C. H., and G. S. Barney. 1983. Effects of Hanford High-Level Waste Components on Sorption of Cobalt, Strontium, Neptunium, Plutonium, and Americium of Hanford Sediments. RHO-RE-ST-1 P, Rockwell Hanford Operations, Richland, Washington.

Delegard, C. H., S. A. Gallagher, and R. B. Kasper. 1981. Saturated Column Leach Studies: Hanford 216Z-Z-1A Sediment. RHO-SA-210, Rockwell Hanford Operations, Richland, Washington.

DOE. 1987. Final Environmental Impact Statement, Disposal of Hanford Defense High Level, Transuranic and Tank Wastes. DOE/EIS-0113-Final, U.S. Department of Energy, Washington, D.C.

Frost, R. R., and R. A. Griffin. 1977. "Effect of pH on Adsorption of Copper, Zinc, and Cadmium from Landfill Leachate by Clay Minerals." J. Environ. Sci. Health Vol. A. 12, pp. 139-156.

Gee, G. W., and A. C. Campbell. 1980. Monitoring and Physical Characterization of Unsaturated Zone Transport - Laboratory Analysis. PNL-3304, Pacific Northwest Laboratory, Richland, Washington.

Gee, G. W., A. C. Campbell, P. J. Wierenga, and T. L. Jones. 1981. Unsaturated Moisture and Radionuclide Transport: Laboratory Analysis and Modeling. PNL-3616, Pacific Northwest Laboratory, Richland, Washington.

Gee, G. W., and P. R. Heller. 1985. Unsaturated Water Flow at the Hanford Site: A Review of Literature and Annotated Bibliography. PNL-5428, Pacific Northwest Laboratory, Richland, Washington.

Geering, H. R., E. E. Cary, L. H. P. Jones, and W. H. Allaway. 1968. "Solubility and Redox Criteria for the Possible Forms of Selenium in Soils." Soil Sci. Soc. Am. Proc. 32:35-40.

Godbee, H. W., E. L. Compere, D. S. Joy, A. H. Kibbey, J. G. Moore, C. W. Nestor, Jr., O. U. Anders, and R. M. Neilson, Jr. 1980. "Application of Mass Transport Theory to the Leaching of Radionuclides From Waste Solids." Nucl. Chem. Waste Manage 1:29-35.

Grenthe, I. 1992. Chemical Thermodynamics of Uranium. North-Holland, New York.

Gschwend, P. M., and M. C. Reynolds. 1987. "Monodispersed Ferrous Phosphate Colloids in an Anoxic Groundwater Plume." J. Contam. Hydro. 1:309-327. 
Gschwend, P. M., D. Backhus, J. K. MacFarlane, and A. L. Page. 1990. "Mobilization of Colloids in Groundwater Due to Infiltration of Water at Coal Ash Disposal Site." J. Contam. Hydrol. 6:307-320.

Gu, B., and R. K. Schulz. 1991. Anion Retention in Soil: Possible Application to Reduce Migration of Buried Technetium and Iodine. NUREG/CR-5464. U.S. Nuclear Regulatory Commission, Washington, D.C.

Hajek, B. F. 1966. Soil Survey, Hanford Project in Benton County, Washington. BNWL-243, Pacific Northwest Laboratory, Richland, Washington.

Hamby, A. A., and G. Gissel-Nelson. 1977. "Fixation of Selenium by Clay Minerals and Iron Oxides." Z. Pflanzenernaehr. Bodenkd. Vol. 140, 1 pp. 63-70.

Hanke, K., B. Jahrling, and K. J. Lieser. 1986. "Properties and Solubility of Technetium Dioxide." pp. 179-187. In Technetium in the Environment. eds. G. Desmet and C. Myttenaere. Elsevier Applied Science Publishers, Amsterdam.

Hillel, D. 1980. Fundamentals of Soil Physics. Academic Press, University of Massachusetts; Amherst, Massachusetts.

Hingston, F. J., A. M. Posner, and J. P. Quirk. 1968. "Adsoprtion of Selenite by Goethite." Adv. Chem. Series, No. Vol. 79, pp. 82-90.

Hingston, F. J., A. M. Posner, and J. P. Quirk. 1971. "Competitive Adsorption of Negatively Charged Ligands on Oxide Surfaces." Disc. Farada Soc. Vol. 52, pp. 234-342.

Hingston, F. J., A. M. Posner, and J. P. Quirk. 1972. "Anion Adsorption by Geothite and Gibbsite. The Role of the Porton in Determining Adsorption Envelopes." J. Soil Sci. Vol. 23, pp. 177-192.

Ho, C. H., and N. H. Miller. 1986. "Formation of Uranium Oxide Sols in Bicarbonate Solutions." J. Colloid Interface Sci. 113:232-240.

Hobbie, J. E., R. J. Dalley, and S. Jasper. 1977. "Use of Nucleport Filters for Counting Bacteria by Fluorescence Microscopy." App. Environ. Microbiol. 33: 1225-1228.

Hollander, M., and D.A. Wolfe. 1973. Nonparametric Statistical Methods. Wiley, New York.

Hsi, C-K. D., and D. Langmuir. 1985. "Adsorption of Uranyl onto Ferric Oxyhydroxides: Application of the Surface Complexation Site-binding Model." Geochim. Cosmochim. Acta, 49:1931-1941.

Idiz, E. F., D. Carlisle, and I. R. Kaplan. 1986. "Interaction Between Organic Matter and Trace Metals in a Uranium Rich Bog, Kem County, California, U.S.A.” Appl. Geochem. 1:573-590.

James, R. V., and J. Rubin. 1986. "Transport of Chloride Ion in a Water-unsaturated Soil Exhibiting Anion Exclusion." Soil Sci. Soc. Am. J. 50:1142-1149.

John, M. K., W. M. N. Saunders, and J. H. Watkinson. 1976. "Selenium Adsorption by New Zealand Soils I. Relative Adsoprtion of Selenite by Representative Soils and Relationship to Soil Properties. New Zealand J. Agr. Res. Vol. 19, 143-151. 
Kaplan, D. I., D. B. Hunter, P. M. Bertsch, S. Bajt, and D. C. Adriano. 1994. "Application of Synchrotron X-Ray Fluorescence Spectroscopy and Energy Dispersive X-Ray Analysis to Identify Contaminant Metals on Groundwater Colloids." Environ. Sci. Technol. 28:1186-1189.

Kaplan, D. I., P. M. Bertsch, and D. C. Adriano. 1995a. "Enhanced Transport of Contaminant Metals Through an Acidic Aquifer. Ground Water.

Kaplan, D. I., M. E. Sumner, and P. M. Bertsch. 1995b. "Dispersion Properties Conducive to Subsurface Mobile Colloid Generation." J. Soil Sci. Soc. Am.

Keller, C. 1971. "The Chemistry of the Transuranium Elements. Vol. 3." Kernchemie in Einzeldarstellunge. Verlag Chemie GmbH. Munchen.

Kemper, W. D., and J. C. Van Schaik. 1966. "Diffusion of Salts in Clay-Water Systems." Soil Sci. Am. Proc. 30:534-540.

Kent, D. B., V. S. Tripathi, N. B. Ball, J. O. Leckie, and M. D. Siegel. 1988. Surface-Complexation Modeling of Radionuclide Adsorption in Subsurface Environments. Final report, NUREG/CR-4807, U.S. Nuclear Regulatory Commission, Washington, D.C.

Kim, J. J. 1986. "Chemical Behavior of Transuranic Elements in Aquatic Systems." In Handbook on the Physics and Chemistry of the Actinides. eds. A. J. Freeman and C. Keller, pp. 413-455. Elsevier Science Publ., Amsterdam.

Kincaid, C. T., J. W. Shade, G. A. Whyatt, M. G. Piepho, K. Rhoads, J. A. Voogd, J. H. Westsik, Jr, M. D. Freshley, K. A. Blanchard, and B. G. Lauzon. 1993. Performance Assessment of Grouted double Shell Tank Waste Disposal at Hanford. WHC-SD-EE-004, Rev. 0, Westinghouse Hanford Company, Richland, Washington.

Knoll, K. C. 1960. Adsorption of Strontium by Soils Under Saturated and Unsaturated.Flow Conditions. HW-67830, General Electric Company, Hanford Atomic Products Operation, Richland, Washington.

Knoll, K. C. 1966. Reaction of High-Salt Aqueous Plus Organic Waste with Soil. BNWL-CC-313, Pacific Northwest Laboratory, Richland, Washington.

Knoll, K. C. 1969. Reactions of Organic Wastes in Soils. BNWL-860, Pacific Northwest Laboratory, Richland, Washington.

Langmuir, D. 1978. "Uranium Solution-mineral Equilibria at Low Temperatures with Applications to Sedimentary Ore Deposits." Geochim. Cosmochim. Acta, 42:547-569.

Langmuir, D. 1979. "Techniques of Estimating Thermodynamic Properties for Some Aqueous Complexes of Geochemical Interest" In Chemical Modeling in Aqueous Systems. ed. E. A. Jenne, pp. 353-387. American Chemical Society, Washington, D.C.

Leckie, J. O, M. M. Benjamin, K. Hayes, G.. Kaufman and S. Altman. 1980. “Adsorption/Coprecipitation of Trace Elements from Water with Iron Oxhydroxide." EPRI-RP-910. Palo Alto, Califomia: Electric Power Research Institute. 
Liang, L., J. F. McCarthy, L W. Jolley, J. A. McNabb, and T. L. Mehlhorn. 1993. "Iron DynamicsObservations of Transformation During Injection of Natural Organic Matter in a Sandy Aquifer." Geochim. Cosmochim. Acta. 27:3075-3094.

Macalady, D. L., P. G. Tratnyek, and T. J. Grundl. 1986. “Abiotic Reduction Reactions of Anthropogenic Organic Chemicals in Anaerobic Systems: A Critical Review." J. Contam. Hydrol. $1: 1-28$.

Matsuzuru H., and A. Ito. 1978. "Effects of Dimension of Specimen on Amounts ${ }^{137} \mathrm{Cs},{ }^{90} \mathrm{Sr}$ and ${ }^{60}$ Co leach from Matrix of Hardened Cement Grout." J. Nucl. Sci. Technol. 15:296-301.

Matsuzuru, H., and N. Moriyama. 1982. "Leaching Radionuclides from a Cement Composite Incorporating Evaporator Concentrates Generated at a Pressurized Water Reactor Nuclear Power Plan." Nucl. Sci. Eng. 80:14-25.

McCarthy, J. F., and D. Degueldre. 1993. "Sampling and Characterization of Colloids and Particles in Groundwater for Studying their Role in Contaminant Transport." In Environmental Particles, eds. J. Buffle and J. P. van Leeuwen, pp. 247-315. Lewis Publishers, Boca Raton, Florida.

McKinley, J. P., J. M. Zachara, S. C. Smith, and G. D. Turner. (in press). "The Influence of Hydrolysis and Multiple Site Binding Reactions on Adsorption of U(VI) to Montmorillonite." Clays Clay Minerals.

McMahon, M. A., and J. W. Thomas. 1974. "Chloride and Tritiated Water Flow in Disturbed and Undisturbed Soils Cores." Soil Sci. Soc. Am. Proc. 38:727-732.

Mills, W. B., S. Liu, and F. K. Fong. 1991. "Literature Review and Model (COMET) for Colloid/ Metals Transport in Porous Media." Ground Water 29:199-208.

Morel, F. M. M., and J. G. Hering. 1993. "Principles and Applications of Aquatic Chemistry." John Wiley \& Sons, Inc., New York.

Mott, C. J. B. 1981. "Anion and Ligand Exchange." In The Chemistry of Soil Processes. eds. D. J. Greenland and M. H. B. Hayes, pp 179-219. John Wiley \& Sons.

Mucciardi, A. N., I. J. Booker, E. C. Orr, and D. Cleveland. 1979. "Statistical Investigation of the Mechanics Controlling Radionuclide Sorption, Part II." In Task 4, Second Contractor Information Meeting, ed. R. J. Serne, Vol. 2, pp 333-425. PNL-SA-7352, Pacific Northwest Laboratory, Richland, Washington.

Mucciardi, A. N., T. C. Johnson, and J. Saunier. 1980. Statistical Investigation of the Mechanics Controlling Radionuclide Sorption, Part III. In Task 4, Third Contractor Information Meeting, ed. J. F. Relyea, Vol. 1, pp. 1-75. PNL-SA-8571, Pacific Northwest Laboratory, Richland, Washington.

Muller, A. B., D. Mangmuir, and L.E. Duda. 1983. "The Formulation of an Integrated Physicochemical-Hydrologic Model for Predicting Waste Nuclide Retardation in Geologic Media." In Scientific Basis for Nuclear Waste Management VI, Proceedings of Materials Research Society Symposia, ed. D. G. Brookings, pp. 547-564. North Holland, New York. 
Muramatsu, R., S. Uchida, P. Sriyotha, and K. Sriyotha. 1990. "Some Considerations on the Sorption and Desorption Phenomena of Iodide and Iodate on Soil." Water Air Soil Pollution. 49:125-138.

Nakashima, S., J. R. Disnar, A. Perruchot, and J. Trichet. 1984. "Experimental Study of Mechanisms of Fixation and Reduction of Uranium by Sedimentary Organic Matter Under Diagenrtic or Hydrothermal Conditions." Geochim. Cosmochim. Acta, 48:2321-2329.

Nash, K., S. Fried, A. M. Freidman, and J. C. Sullivan. 1981. "Redox Behavior, Complexing, and Adsorption of Hexavalent Actinides by Humic Acid and Selected Clays." Environ. Sci. Technol. 15:834-837.

Nelson, J. L. 1959. Soil Column Studies with Radiostrontium E. Effects of Temperature and of Species of Accompanying lon. HW-62035, Hanford Works (General Electric), Richland, Washington.

Nielsen, D. R., and J. W. Biggar. 1961. "Miscible Displacement in Soils: I. Experimental Information." Soil Sci Soc. Amer. Proc. 25:1-5.

Nielsen, D. R. and J. W. Biggar. 1962. "Miscible Displacement in Soils: II. Behavior of Tracers." Soil Sci Soc. Amer. Proc. 26:125-128.

Olsen, W. R., and W. D. Kemper. 1968. "Movement of Nutrients to Plant Roots." Adv. Agron. 30:91-151.

Parsons, R. 1982. "Surface Properties of Oxides." J. Electroanal. Chem 118:2-18.

Penrose, W. R., W. L. Plozer, W. H. Essington, D. M. Nelson, and K. A. Orlandini. 1990. "Mobility of Pu and Am Through a Shallow Aquifer in a Semiarid Region." Environ. Sci. Technol. 24:228-234.

Piepho, M. G. 1994. Grout Performance Assessment Results of Benchmark, Base, Sensitivity and Degradation Cases. WHC-SD-WM-TI-561, Westinghouse Hanford Company, Richland, Washington.

Piepho, M. G., R. J. Serne, E. I. Kaplan, and D. W. Langord. 1994. Importance Ranking of Nearand Far-Field Transport Parameters for a $L L W$ Glass Performance Assessment. WHC-8H210MGP94-018, Westinghouse Hanford Company, Richland, Washington.

Pilkington, N. J. 1990. "The Solubility of Technetium in the Near-Field Environment of a Radioactive Waste Repository." J. Less-Common Metals 161:203-211.

Plackett, R. L., and J. P. Burman. 1946. "The Design of Optimum Multifactorial Experiments." Biometrika 33:305-325.

Pourbaix, M. 1966. Atlas of Electrochemical Equilibria in Aqueous Solutions. Pergamon Press, Oxford, England.

Rai, D., A. R. Felmy, and J. L. Ryan. 1990. "Uranium(IV) Hydrolysis Constants and Solubility Product of $\mathrm{UO}_{2} \cdot \mathrm{xH}_{2} \mathrm{O}(\mathrm{am})$." Inorg. Chem. 29:260-254.

Rai, D., and J. M. Zachara. 1984. Chemical Attentuation Rates, Coefficients, and Constants in Leachate Migration. EPRI EA-3356, Electric Power Research Institute, Palo Alto, Califomia. 
Rajan, S. S. 1979. "Adsorption of Selenite, Phosphate, and Sulfate on Hydrous Alumina. J. Soil Sci., Vol. 30, pp. 709-718.

Rancon, D. 1973. "The Behavior in Underground Environments of Uranium and Thorium Discharged by the Nuclear Industry." In Environmental Behavior of Radionuclides Released in the Nuclear Industry. IAEA-SM-172/55. pp. 333-346.

Relyea, J. F., and R. J. Serne. 1979. Controlled Sample Program Publication Number 2:

Interlaboratory Comparison of Batch Kd Values. PNL-2872, Pacific Northwest Laboratory, Richland, Washington.

Rhoads, K., B. N. Bjomstad, R. E. Lewis, S. S. Teel, K. J. Cantrell, R. J. Serne, L. H. Sawyer, J. L. Smoot, J. E. Smoot, J. E. Szecsody, M. S. Wigmosta, and S. K. Wurstner. 1994. Estimation of the Release and Migration of Nickel Through Soils and Groundwater at the Hanford Site 218-E-12B Burial Ground. PNL-9791, Pacific Northwest Laboratory, Richland, Washington.

Rhoads, K., B. N. Bjornstad, R. E. Lewis, S. S. Teel, K. J. Cantrell, R. J. Serne, L. H. Sawyer, J. L. Smoot, J. E. Smoot, J. E. Szecsody, M. S. Wigmosta, and S. K. Wurstner. 1992. Estimation of Release and Migration of Lead Through Soils and Groundwater at the Hanford Site 218-E-12B Burial Ground. PNL-8356, Pacific Northwest Laboratory, Richland, Washington.

Rhodes, D. W. 1957. "The Adsorption of Pu by Soil." Soil Sci. 84:465-471.

Rhodes, D. W. 1956. Adsorption by Soil of Strontium from 216-S-Crib Waste. HW-42699, Hanford Works (General Electric), Richland, Washington.

Robertson, D. E. 1974. Physicochemical Characterization of N-Reactor Effluent Radionuclides in Soil and Water Systems. BNWL-1950, Pacific Northwest Laboratories, Richland, Washington.

Rockhold, M. L., M. J. Fayer, and P. R. Heller. 1993. Physical and Hydraulic Properties of Sediments and Engineered Materials Associated with Grouted Double-Shell Tank Waste Disposal at Hanford. PNL-8813, Pacific Northwest Laboratory, Richland, Washington.

Routson, R. C., G. S. Barney, and R. O. Seuk, 1978. Measurement of Fission Product Sorption Parameters for Hanford 200-Area Sediment Types: Progress Report. RHO-LD-73, Rockwell Hanford Operations, Richland, Washington.

Routson, R. C., G. S. Barney, and R. M. Smith. 1980. Hanford Site Sorption Studies for the Control of Radioactive Wastes: A Review. RHO-SA-155, Rev. 1, Rockwell Hanford Operations, Richland, Washington.

Routson, R. C., G. S. Bamey, R. H. Smith, C. H. Delegard, and L. Jensen. 1981. Fission Product Sorption Parameters for Hanford 200-Area Sediment Types. RHO-ST-35, Rockwell Hanford Operations, Richland, Washington.

Routson, R. C., G. Jansen, and A. V. Robinson. $1976 .{ }^{4241} \mathrm{Am},{ }^{237} \mathrm{~Np}$, and ${ }^{99} \mathrm{Tc}$ Sorption on Two United States Subsoils from Differing Weathering Intensity Areas." Health Phys. 33:311-317. 
Routson, R. C. , G. S. Barney, R. O. Seil. 1978. "Measurement of Fission Product Sorption Parameters for Hanford 200 Area Sediment Types. Progress Report." RHO-LD-73. Rockwell Hanford Operations, Richland, Washington.

Routson, R. C., and R. J. Seme. 1972. One-Dimensional Model of the Movement of Trace Radioactive Solute Through Soil Columns: The PERCOL Model. BNWL-1718, Pacific Northwest Laboratory, Richland, Washington.

Sandino, A., and J. Bruno. 1992. "The Solubility of $\left(\mathrm{UO}_{2}\right)_{3}\left(\mathrm{PO}_{4}\right)_{2} \bullet 4 \mathrm{H}_{2} \mathrm{O}(\mathrm{s})$ and the Formation of U(VI) Phosphate Complexes: Their Influence in Uranium Speciation in Natural Waters." Geochim. Cosmochim. Acta 56:4135-4145.

Schalla, R., R. W. Wallace, R. L. Aaberg, S. P. Airhart, D. J. Bates, J. V. M. Carlile, C. S. Cline, D. I. Dennison, M. D. Freshley, P. R. Heller, E. J. Jensen, K. B. Olsen, R. G. Parkhurst, J. T. Rieger, and E. J. Westergard. 1988. Interim Characterization Report for the 300 Area Process Trenches. PNL-6716, Pacific Northwest Laboratory, Richland, Washington.

Scheidegger, A. E. 1961. "General Theory of Dispersion in Porous Media." J. Geophysical Research 66:3273-3278.

Schindler, P. W., and G. Sposito. 1991. "Surface Complexation at (Hydro)oxide Surfaces." pp. 115-145. In Interactions at the Soil Colloid-Soil Solution Interface. G. H. Bolt, M. F. DeBoodt, M. H. B. Hayes, and M. B. Mc Bride (eds.). Kluwer Academic P.

Schulte, E. H., and P. Scoppa. 1987. "Sources and Behavior of Technetium in the Environment." Sci. Total Environ. 64:163-168.

Scott, H. D., R. E. Phillips, and R. F. Paetzold. 1974. "Diffusion of Herbicides in One Adsorbed Phase." Soil Sci. Soc. Am. Proc. 38:558-562.

Seaborg, G. T. 1994. "Overview of the Actinide and Lanthanide (the f) Elements." Radiochimica Acta $61,115-122$.

Serne, R. J., J. L. Conca, V. L. LeGore, K. J. Cantrell, C. W. Lindenmeier, J. A. Campbell, J. E. Amonette, and M. I. Wood. 1993. Solid-Waste Leach Characteristics and ContaminantSediment Interactions. Volume 1: Batch Leach and Adsorption Tests and Sediment Characterization. PNL-8889, Vol 1, Pacific Northwest Laboratory, Richland, Washington.

Serne, R. J. , W. J. Martin, S. B. McLaurine, S. P. Airhart, V. L. LeGore, and R. L. Treat. 1987. Laboratory Leach Tests of Phosphate/Sulphate Waste Grout and Leachate Adsorption Tests Using Hanford Sediment. PNL-6019, Pacific Northwest Laboratory, Richland, Washington.

Serne, R. J., D. Rai, M. J. Mason, and M. A. Molecke. 1977. Batch $K_{d}$ Measurements of Nuclides to Estimate Migration Potential at the Proposed Waste Isolation Pilot Plant in New Mexico. PNL-2448, Pacific Northwest Laboratory, Richland, Washington.

Serne, R. J., and D. Rai. 1976. "Adsorption-Precipitation Behavior of Eu in Soils and Standard Clays." Agron Abstr. 68:132.

Serne, R. J., R. C. Routson, and D. A. Cochran. 1973. Experimental Methods for Obtaining PERCOL Model Input Verification Data. BNWL-1721, Pacific Northwest Laboratory, Richland, Washington. 
Serne, R.J., and J.F. Relyea. 1983. "The Status of Radionuclide Sorption-Desorption Studies Performed by the WRIT Program." In The Technology of High-Level Nuclear Waste Disposal, Vol. 1, pp. 203-254. DOE/TIC-621, Technical Information Center, U.S. Department of Energy, Oak Ridge, Tennessee.

Serne, R. J., and M. I. Wood. 1990. Hanford Waste-Form Release and Sediment Interaction. A Status Report with Rationale and Recommendations for Further Studies. PNL-7297, Pacific Northwest Laboratory, Richland, Washington.

Shanbhag, P. M., and G. R. Choppin. 1981. "Binding of Uranyl by Humic Acid." J. Inorg. Nucl. Chem. 43:3369-3372.

Sheppard, J. C., J. A. Kittrick, and T. L. Hart. 1976. Determination of Distribution Ratios and Diffusion Coefficients of Neptunium, Americium, and Curium in Soil-Aquatic Environments. RLO-221-T-12-2, Rockwell Hanford Operations, Richland, Washington.

Sheppard, S. C., M. I. Sheppard, and W. G. Evenden. 1990. "A Novel Method Used to Examine Variation in Tc Sorption Among 34 Soils, Aerated and Anoxic." J. Environ. Radioact. 11:215.

Singh, M., N. Singh, and P. S. Relan: 1981. "Adsorption and Desorption of Selenite and Selnate Selenium on Different Soils." Soil Science. Volume 132, pp. 134-141.

Smith, P. A., and C. Degueldre. 1993. "Colloid-Facilitated Transport of Radionuclides Through Fractured Media." J. Contaminant Hydrol. 13:143-166.

Snedecor, G. W., and W. G. Cochran. 1967. Statistical Methods. 6th ed. Iowa State University Press, Ames, Iowa.

Sposito, G. 1984. The Surface Chemistry of Soils. Oxford University Press, New York.

Stalmans, M., A. Maes, and A. Cremers. 1986. "Role of Organic Matter as a Geochemical Sink for Technetium in Soils and Sediments." In Technetium in the Environment. eds. G. Desmet and C. Myttenaere, pp. 91-113. Elsevier Applied Science Publishers, Amsterdam.

Strenge, D. L., and S. R. Peterson. 1989. Chemical Databases for the Multimedia Environmental Pollutant Assessment System. PNL-7145, Pacific Northwest Laboratory, Richland, Washington.

Stumm, W., and J. J. Morgan. 1981. Aquatic Chemistry. An Introduction Emphasizing Chemical Equilibria in Natural Waters. 2nd Edition, John Wiley \& Sons, New York.

Szalay, A. 1964. "Cation Exchange Properties of Humic Acids and their Importance in the Geochemical Enrichment of $\mathrm{UO}_{2}^{2+}$ and Other Cations." Geochim. Cosmochim. Acta, 28:1605-1614.

Ticknor, K. V., and Y. H. Cho. 1990. "Interaction of Iodide and Iodate with Granitic FractureFilling Minerals." J. Radioanal. Nuclear Chem. 140:75-90.

Tri-Party Agreement. Washington State Department of Ecology, U.S. Environmental Protection Agency (EPA), U.S. Department of Energy (DOE). 1994. "Hanford Federal Facility Agreement and Consent Order." Fourth Amendment, January, 1994. Available from any of the parties. 
Van Genuchten, M. The., and P. J. Wierenga. 1986. "Solute Dispersion Coefficients and Retardation Factors." In. A. L. Page, R. J. Miller, and D. R. Keeney (Eds.). Methods of Soil Analysis, Part 1. Physical and Mineralogical Methods. Edition 2. Soil Science Society of America, Madison, Wisconsin.

Van Loon, L., M. Stalmans, A. Maes, A. Cremers, and M. Cogneau. 1986. "Soil-Humic Acid Complexes of Technetium: Synthesis and Characterization." In Technetium in the Environment. eds. G. Desmet and C. Myttenaere, pp 143-153. Elsevier Applied Science Publishers.

Walters, L. J., and J. W. Winchester. 1971. "Neutron Activation Analysis of Sediments for Halogens Using Szilard-Chalmers Reactions." Anal. Chem. 43:1020-1033.

Westall, J. C. 1986. "Reactions at the Oxide-Solution Interface: Chemical and Electrostatic Models." ACS Symposium Series 323. American Chemical Society, Washington, D.C.

Westall, J. C., and H. Hohl. 1980. "A Comparison of Electrostatic Models for the Oxide Solution Interface." Adv. Colloid Interface Sci. 12:265-294.

Whitehead, D. C. 1973. "The Sorption of Iodide by Soils as Influenced by Equilibrium Conditions and Soil Properties." J. Sci. Food Agric. 24:547-556.

Whitehead, D. C. 1974. "The Sorption of Iodide by Soil Components." J. Sci. Food Agric. 25:73-79.

Whitehead, D. C. 1984. "The Distribution and Transformations of Iodine in the Environment." Environ. Intern. 10:321-339.

Wildung, R. E., T. R. Garland and D. A. Cataldo. 1977. "Accumulation of Technetium by Plants." Health Phys. 32:314-317.

Wildung, R. E., T. R. Garland, K. M. McFadden, and C. E. Cowen. 1986. "Technetium Sorption in Surface Soils." In Technetium in the Environment. eds. G. Desmet and C. Myttenaere, pp. 115-129. Elsevier Applied Science Publishers, Amsterdam.

Wolfsberg, K. 1978. Sorption-Desorption Studies of Nevada Test Site Alluvium and Leaching Studies of Nuclear Test Debris. LA-7216-MS, Los Alamos Scientific Laboratory, Los Alamos, New Mexico.

Wood, M. I., R. Khaleel, P. D. Rittmann, A. H. Lu, S. Finfrock, R. J. Serne, and K. J. Cantrell. 1994. Performance Assessment for the Disposal of Low-Level Waste in the 218-W-5 Burial Ground. WHC-EP-0645 Draft, Westinghouse Hanford Company, Richland, Washington.

Yeh, G., and V. S. Tripathi. 1991. "A Model for Simulating Transport of Reactive Multispecies Components: Model Development and Demonstration." Water Resour. Res. 27:3075-3094. 


\section{Distribution}

No. of

Copies

OFFSITE

12 DOE/Office of Scientific and Technical Information

\section{ONSITE}

\section{DOE Richland Operations Office}

N. R. Brown

S7-53

S. T. Burnum

L. A. Huffman

J. C. Peschong

ONSITE

Westinghouse Hanford Company

M. R. Adams

H. Babad

H6-30

K. C. Burgard

J. W. Cammann

L. B. Collard

J. D. Davis

C. R. Eiholzer

J. S. Garfield

R. L. Gibby

F. N. Hodges

R. Khaleel

V. G. Johnson

S. S. Lan

N. K. Lane

A. H. Lu

F. M. Mann

D. E. Mitchell
No. of

Copies

R. J. Murkowski

G6-13

R. W. Powell

G3-21

S. P. Reidel

H6-06

J. F. Relyea

L4-69

P. D. Rittmann

H6-30

F, A. Schmittroth

H0-35

J. W. Shade

J. C. Sonnichsen

H5-27

H6-06

J. A. Voogd

G. F. Williamson

G6-13

G6-13

R. D. Wojtasek

S7-84

D. E. Wood

H6-30

M. I. Wood

N3-13

\section{Pacific Northwest Laboratory}

C. C. Ainsworth

K3-61

M. P. Bergeron

K9-33

J. M. Creer

K9-80

M. L. Elliott

P7-41

C. Franks

K9-72

C. J. Freeman

P7-41

J. H. Holbrook

K9-81

P. R. Hrma

P8-37

B. M. Johnson

K9-70

D. I. Kaplan (10)

K6-81

D. A. Lamar

P7-41

K9-80

K2-38

P7-19

K9-81

K5-12

K3-75

K6-81

P7-33 
No: of

Copies

P. Sliva

B. D. Slonecker

P. A. Smith

D. M. Strachan

J. H. Westsik, Jr.

G. A. Whyatt

K. D. Wiemers

Publishing Coordination

Technical Report Files (5)
No. of

Copies

P8-44

K9-80

P7-14

K9-78

K9-80

P7-19

P7-14

\section{Routing}

R. W. Bryce

R. M. Ecker

M. J. Graham

S. A. Rawson

R. L. Skaggs

P. C. Hays (last)
K9-34

SEQUIM

K9-38

K9-34

K9-34

K9-41 